\title{
Klasik ve Orta Moğolca Söz Varlığında Türkçe Kökenli Kelimeler I (A-D)
}

\section{Words of Turkic Origin in the Vocabulary of Written and Middle Mongol I (A-D)}

\author{
Orçun ÜNAL \\ Göttingen University (Göttingen/Germany) \\ E-mail: orcununal@live.com
}

The purpose of this study is to present all Written Mongol words of certain or possible Turkic origin with their cognates in Middle Mongol, modern Mongolic languages and Manchu. The word list is structured to be beneficial both to researchers who study the language contact between Turkic and Mongolic and to scholars who carry out research on their possible genetic relationship. Due to its length, the study is divided into three parts, of which the first part gives the Written Mongol words of Turkic origin in alphabetical order from A to D.

Key Words: Written Mongol, Middle Mongol, Manchu, Turkic language, loanword, borrowing. 


\section{$J(\Theta)$}

\section{Giriş}

İki dilin -genetik olsun veya olmasın- yakın ilişkisi, kendini öncelikle ve en görünür şekilde söz varlığında belli eder. Moğolca ile Türkçenin söz varlıklarındaki ortak ve benzer kelimeler Johannes von STRAHLENBERG'in 1730 tarihli Das Nord- und Östliche Theil von Europa und Asia adlı eserinden beri bilinmektedir. Bu olgu, J. P. Abel-RÉmusat, P. S. PAllas, W. Schott, M. A. CAStrén, J. Grunzel, W. BAnGKAUP gibi araştırmacılar tarafından XIX. yüzyıl sonuna kadar farklı şekillerde defalarca ele alınmış, söz konusu benzerliklerin XX. yüzyılın ilk çeyreğinde G. J. RAmstedt, N. N. Poppe, P. Pelliot ve Z. Gombocz tarafindan bir araya getirilerek sistematik bir şekilde sunulmasıyla bilimsel bir sav niteliği kazanmıştır. Bu sav, temel olarak Türkçe, Moğolca ve Mançu-Tunguzcanın Ana Altayca adlandırılan ortak bir dilden türediğini iddia eden Altay Dilleri Teorisi'dir. Bu teori, W. KotwicZ,J.C. StREET, R. A. MilleR ve T. TeKin gibi önemli taraftarlar kazandığı gibi, kendine karşıtlar da edinmiştir. XX. yüzyılın ikinci yarısında, özellikle Sir G. CLAUSON, A. M. ŞÇERBAK ve G. DOERFER gibi araştırmacılar Altay Dilleri Teorisi aleyhinde görüşleriyle öne çıkmış, yazılarında teorinin temel dayanaklarını farklı şekillerde çürütmeye, hatta bu dillerin akraba olmadığını kanıtlamaya çalışmışlardır. Bu bilim insanlarının temel savı, Türkçe, Moğolca ve Tunguzca arasındaki benzerliklerin uzun süren etkileşimlere dayandığı ve söz varlıklarındaki benzerliklerin de Türkçeden Moğolcaya, Moğolcadan Tunguzcaya yapılan ödünçlemeler ile açıklanması gerektiğidir. 1990'lara kadar hararetle tartışılan teori bu yıllardan itibaren eski hızını yitirmiş, Türkoloji, Mongolistik ve diğer ilgili bilim alanlarının çalışma kapsamından değilse de odağından çıkmıştır. 2003 yılında S. A. StAROSTIN, A. V. DYBo ve O. A. MUdRAK tarafindan (Korece ve Japonca dâhil olmak üzere) Altay dillerinin iki ciltlik An Etymological Dictionary of Altaic Languages adlı etimolojik sözlüğünün ve 2005 yılında M. ROBBEETS tarafından Is Japanese related to Korean, Tungusic, Mongolic and Turkic? adlı eserinin yayımlanmasiyla Altay Dilleri Teorisi tekrar gündeme taşınmış, başta A. VovıN'inki olmak üzere ilk eser için yazılan sert eleștirel tanıtmalar ve sözlüğün yazarları tarafından bunlara verilen cevaplarla mesele iyice hareketlenmiştir. 2000'li yıllarda, Altay Dilleri Teorisi bağlamında olmasa bile, Türkçe-Moğolca dil ilişkilerine ve kelime etimolojilerine değinen küçüklü büyüklü birçok araştırma yayımlanmıştır. Altay dilleri araştırmalarının ayrıntılı tarihi için BENZING (1953: 1-15), POPPE (1965: 125-156), 


\section{J(৫)}

GEORG et al. (1999: 74-79), SCHÖNIG (2003: 403-404) ve RACHEWILTZ-RYBATZKI'ye (2010: 348-355) başvurulabilir.

Şu kadarı kesindir ki Türkçe bir sözcüğün etimolojisi üzerinde çalışırken Moğolcaya başvurmamak, sözcüğün Moğolcada bir karşılığının olup olmadığını araştırmamak çalışmayı eksik bırakmaktadır. Bu nedenle, ortak sözcükleri teorik anlamda mümkün olduğunca tarafsız, tek bir kaynakta toplamak hem Türk dili tarihi ve Türkçe etimoloji çalışmaları hem de Moğol dili tarihi ve Moğolca etimoloji çalışmaları için elzemdir.

\section{Kelime Listesinin Amacı ve Düzeni}

Türkçe ile Moğolcanın söz varlığındaki ortak ve benzer kelimeler bu çalışma kapsamında Türkçeden Moğolcaya alıntılar olarak değerlendirilmiş olsa da, bu kelime listesinin birincil amacı, söz konusu kelimeler üzerinde çalışacak araştırmacılara temel bir başvuru kaynağı sağlamaktır. Bu sebeple, kelime listesi Türkçe ve Moğolcanın muhtemel genetik akrabalığı üzerinde çalışan araştırmacılar tarafından da kullanılabilecek şekilde düzenlenmiştir.

Bu çalışmada sunulan malzemenin önemli bir kısmı, 2016 yılında Prof. Dr. Gülşen Seyhan ALışıK danışmanlığında Marmara Üniversitesi'nde tamamladığım Klasik Moğolca Söz Varlı̆̆ında Türkçe Kökenli Kelimeler ve Türkçe-Moğolca Ses Denklikleri adlı doktora tezimden alınmıştır.

Listenin kolay ve hızlı anlaşılabilir olmasını sağlamak amacıyla, madde başlarında yalnızca esas unsurlar verilmiş, ek bilgiler ve yorumlar dipnotlarda sunulmuştur. Bütün madde başları, Moğolca ve Türkçe olarak iki kısımdan oluşmaktadır. Moğolca ve Türkçe kısımlar birbirlerinden çift düz çizgiyle (||) ayrılmıştır.

Moğolca kısım aşağıdaki gibi düzenlenmiştir:

1. Klasik Moğolca sözcük,

2. Sözcüğün daha eski farazi biçimi,

3. Sözcüğün anlamı, 


\section{J(৫)}

4. Orta Moğolca, Çağdaş Moğolca (Halha, Kalmuk, Ordos vd.), Mançuca, Tunguz dilleri, Proto-Tunguzca ve diğer dillerden karşılaştırma unsurları.

Aksi belirtmedikçe, bütün Klasik Moğolca sözcükler Ferdinand D. LESSING'in Mongolian-English Dictionary (1995) adlı sözlüğünden alınmıştır. Başka kaynaklardan alıntılanan biçimlerle karışmaması için gerektiği yerlerde bu sözcükler '(Less.)' kısaltmasıyla verilmiştir. F. D. LEsSING'in eserinde bulunmadığı için J. É. KoWALEWSKI'nin Dictionnaire Mongol-Russe-Français (1844-1849), K. F. GoLSTUNSKIY'in Mongol'sko-Russkiy Slovar' (1893-1895) veya F. BOBERG'in MongolianEnglish Dictionary (1954-1955) eserlerinden alınan sözcükler sırasıyla '(Kow.)', ‘(Gol.)' ve '(Bo.)' kısaltmalarıyla belirtilmiştir. Klasik öncesi biçimler içinse büyük ölçüde D. TUMURToGoo'nun Mongolian Monuments in Uighur-Mongolian Script (XIIIXVI Centuries) (2006) adlı eserinin sözcük dizininden faydalanılmıştır. Orijinal metinlere danışılarak verilen klasik öncesi biçimler '(k.ö.)' kısaltmasıyla gösterilmiştir. Söz varlığı değerlendirilen en önemli klasik öncesi eserlerin kısaltmaları ve bu eserler için kullanılan kaynaklar aşağıdaki gibidir:

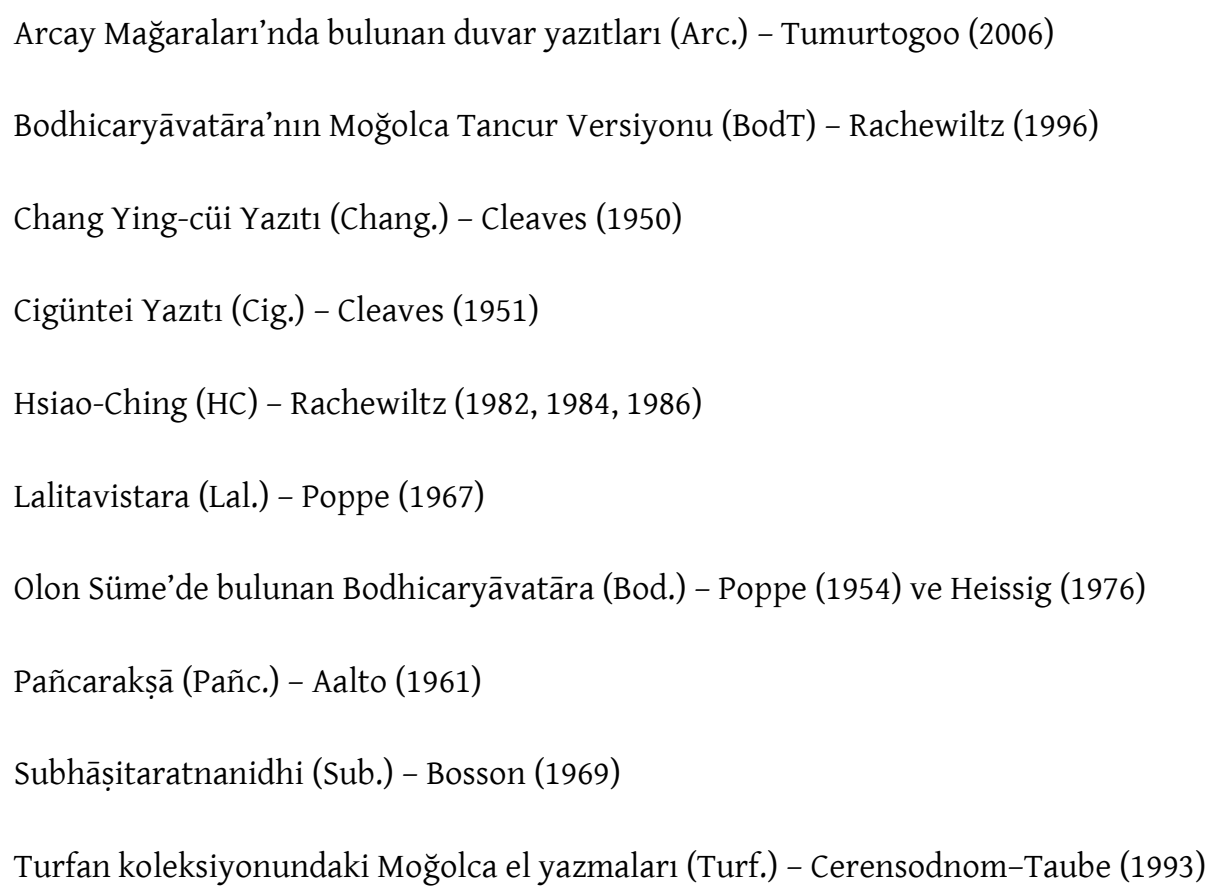

Budist terimler konusunda ise M. SHōGAITo'nun (1991 ve 2003) ilgili makalelerine danışılmış olup buradan alınan biçimler '(Shō.)' kısaltmasıyla verilmiş- 


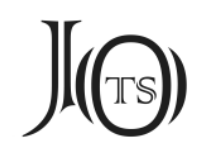

tir. Orta Moğolca, çağdaş Moğolca ve Mançu-Tunguz dillerinden verilen sözcüklerin anlamı Klasik Moğolca sözcüğün anlamıyla aynı ya da ona çok yakınsa ayrıca gösterilmemiştir. Aksi durumda, sözcüklerin anlamı verilmiştir.

Bir ve aynı Moğolca sözcüğün nöbetleşen şekilleri dalga ( ) işaretiyle, aynı kökten türemiş farklı sözcükler virgülle (,) ayrılmıştır.

Klasik Moğolca için kullanılan yazı çevrimi alfabesi şöyledir:

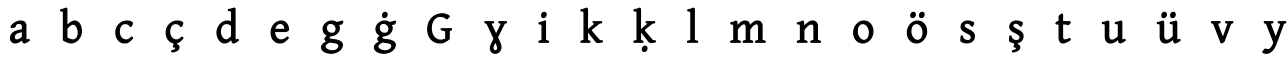

Görüldüğü üzere, bu yazı çevrimi F. LEssing'in Mongolian-English Dictionary adlı sözlüğünde kullanılan alfabeden biraz farklıdır ve büyük oranda Türk yazı çevrimi alfabesine uyarlanmıştır. Farklı olan harfler aşağıdaki tabloda verilmiştir:

\begin{tabular}{||c||c||}
\hline $\begin{array}{c}\text { Mongolian-English Dictionary'da } \\
\text { Kullanılan Yazı Çevrimi }\end{array}$ & $\begin{array}{c}\text { Bu Çalışmada Kullanılan } \\
\text { Yazı Çevrimi }\end{array}$ \\
\hline \hline $\mathrm{C}$ & $\mathrm{c}$ \\
\hline \hline $\mathrm{G}$ & $\mathrm{g} / \mathrm{g}$ \\
\hline \hline$\Gamma$ & $\dot{\mathrm{g}} / \mathrm{\gamma}$ \\
\hline \hline $\mathrm{X}$ & $\mathrm{k}$ \\
\hline \hline$\varnothing$ & $\ddot{\mathrm{o}}$ \\
\hline \hline $\mathrm{S}$ & $\mathrm{s}$ \\
\hline $\mathrm{Y}$ & $\ddot{\mathrm{u}}$ \\
\hline \hline $\mathrm{Z}$ & $\mathrm{c}$ \\
\hline \hline $\mathrm{Z}$ & $\mathrm{dz}$ \\
\hline \hline
\end{tabular}

Ayrıca, kelime içindeki $\Omega g$ ve $! \dot{g}$ harfleri, Klasik Moğolca sözcüğün Orta Moğolca ve çağdaş Moğol dillerindeki karşıllklarına göre, $g: \gamma$ ve $\dot{g}: \gamma$ olmak üzere iki farklı şekilde gösterilmiştir. Klasik Moğolca sözcüğün Orta Moğolca ve çağdaş Moğol dillerindeki karşlıklarında damaksıl bir sesin korunduğu durumlarda $g$ ve $\dot{g}$ harfleri, korunmadığı (diğer deyişle bir uzun ünlünün ya da bir kesintili ünsüzün bulunduğu) durumlarda § harfi kullanılmıştır. Bu yazım, yazıda ayrıştırılma- 


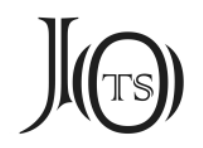

yan farklı sesbirimleri (fonemleri) gösterebilmek için tercih edilmiştir. Bu ayrımın yapılamadığ durumlarda, $g: \gamma / \dot{g}: \gamma$ belirsizliğini vurgulamak için $G$ harfi kullanılmıştır. Moğolca sözcüklerin sonunda bulunan ve LEssing tarafından parantez içinde gösterilen oynak $n$ (İng. unstable $n$ ) ünsüzü ise üst simge olarak $\left({ }^{n}\right.$ ) şeklinde verilmiştir.

Aksi belirtilmedikçe, Orta Moğolca kaynaklardan verilen tanıklar için aşağıdaki kaynaklar kullanılmıştır:

XIV. yüzyıl anonim Gürcüce tarih kitabındaki Moğolca hayvan yılı adları (AGT) - Vladimirtsov (1917)

Aknerli Grigor'un ‘Okçu Milletin Tarihi' adlı eserindeki Moğolca isim ve terimler (AG) - Cleaves (1949) ve Boyle (1975)

Altı dilli Resūlī Sözlüğü (RS) - Golden et al. (2000) ve Ligeti-Kara (2012)

Beilu Yiyu 北虜譯語 (BY) - Apatóczky (2009)

Bibliothèque Nationale Paris, Fonds Arabe No. 6040 (AS) - Franke (1988)

Genceli Kirakos (GK) - Boyle (1963) ve Ligeti (1965)

Hua Yi Yiyu 華夷譯語 (HY) - Lewicki (1959) ve Mostaert (1977)

İbni Mühenna Lügati (Moğolca bölümü) (iM) - Melioranskiy (1903), Poppe (1938) ve Gül (2016)

Kitāb-1 Mecmūc-1 Tercümān-ı Türkī ve ‘Acemī ve Muggalī (TA) - Poppe (1927-1928) ve Saitô (2006)

Moğolların Gizli Tarihi (MGT) - Haenisch (1939) ve Rachewiltz (2004)

Mukaddimetü'l-Edeb (ME) - Poppe (1938) ve Saitô (2008)

Nüzhetü'l-Kulūb (NK1) - Poppe (1925)

Nüzhetü'l-Ḳulūb (NK2) - Pelliot (1931)

'Phags-pa yazılı kaynaklar (PH) - Poppe (1957) ve Tumurtogoo (2010)

Roma El Yazması (RM) - Weiers (1972)

Şāmilü'l-Lug̉a (ŞL) - Ligeti (1962), Kaçalin (1997) ve Saitô (2013) 


\section{$J(\Theta)$}

Zhiyuan yiyu 至元譯語 (ZY) - Ligeti-Kara (1990) ve Rachewiltz (2006)

Aksi belirtilmedikçe, çağdaş Moğol dillerinden verilen tanıklar için aşağıdaki kaynaklar kullanılmıştır:

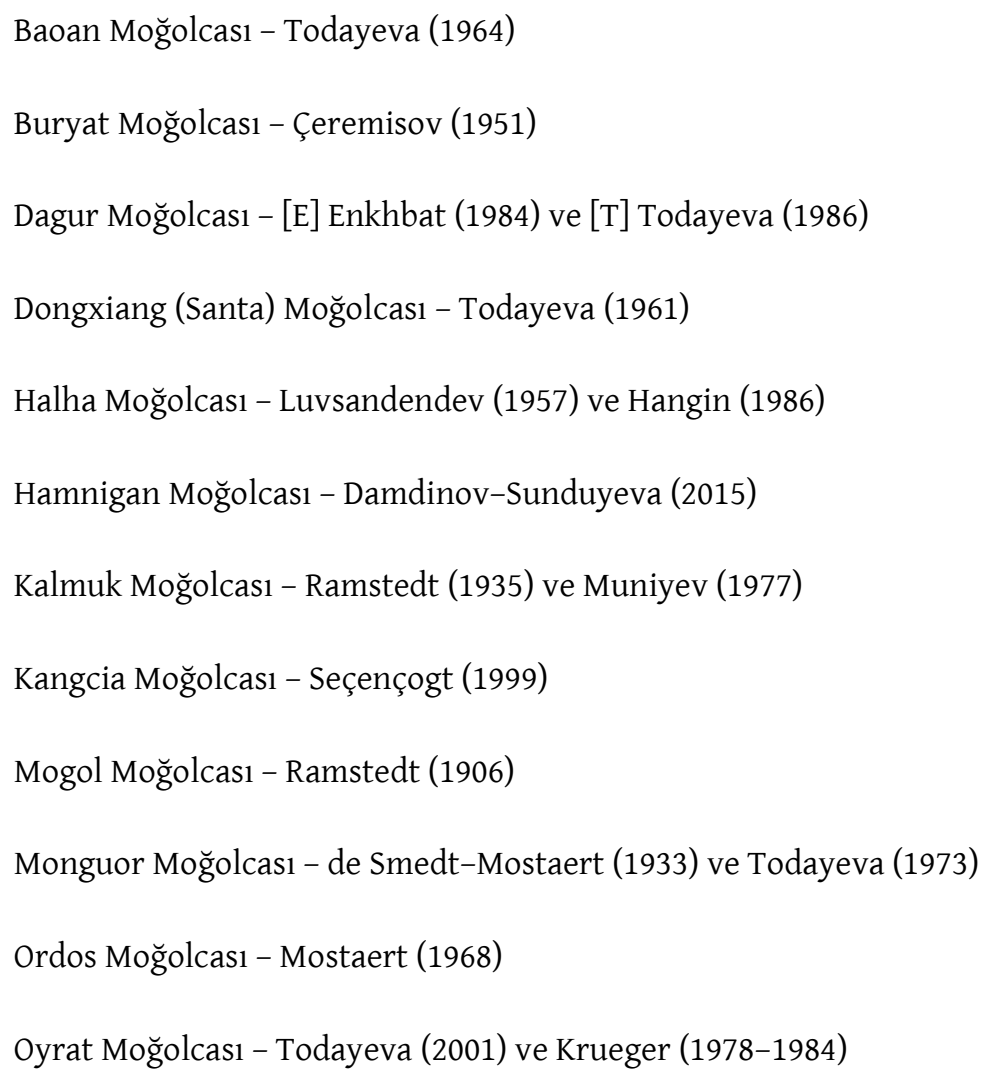

1. Genel Türkçe sözcük,

2. Genel Türkçe sözcüğün daha eski farazi biçimi,

3. Sözcüğün anlamı,

4. Bulgar Türkçesi sözcüğün farazi biçimi ve anlamı,

5. Bulgar Türkçesi farazi sözcük biçiminin dayandığı Volga Bulgarca ya da Çuvaşça sözcük, 6. Türkçe sözcük yabancı kökenli ise köken dildeki biçimi ve anlamı, 7. Macarca, Çeremisçe, Proto-Samoyedce, Proto-Yeniseyce ve diğer dillerden karşılaştırma unsurları. 


\section{$J(\Theta)$}

Bir ve aynı Türkçe sözcüğün nöbetleşen şekilleri dalga ( ) işaretiyle, aynı kökten türemiş farklı sözcükler virgülle (,) ayrılmıştır. Klasik Moğolca sözcük için önerilen birden fazla Türkçe sözcük varsa bunlar 'veya' ibaresiyle ayrılmıştır.

Halaç Türkçesinin ön seste $h$ - gösterdiği sözcükler Genel Türkçe biçime yansıtılmış, bu sözcükler $h$ - ile tasarlanmıştır. Söz başı $h$ - sesinin Halaç Türkçesine dayanmadığı örneklerde, bu sesin geçtiği lehçe ve o lehçedeki biçim ayrıca verilmiştir. Genel Türkçe sözcük tek örnek (hapax legomenon) ise tanıklandığı eser parantez içinde verilmiştir. Tarihî ya da çağdaş lehçelerde yaygın şekilde tanıklanmış Genel Türkçe sözcüklerin tanıkları verilmemiştir. Yayılım alanı dar sözcüklerin tanıkları ise dipnotlarda gösterilmiştir.

Az sayıdaki Türkçe sözcük, Moğolcada iki veya üç farklı şekilde görülmektedir. Diğer deyişle, bu sözcükler Moğolcaya farklı dönemlerde ve/veya farklı lehçelerden birden çok kez alıntılanmıştır. Bu tür ' çifte/çoklu alıntılar', madde başının altında eğik ok $(\triangleleft)$ işaretiyle diğer biçime gönderme yapılarak gösterilmiştir.

Aksi belirtilmedikçe, tarihî Türk lehçelerinde yazılmış eserlerden ya da Türkçe sözcükler içeren kelime listelerinden verilen tanıklar için aşağıdaki kaynaklar kullanılmıştır:

1283 numaralı Tibetçe Pelliot el yazması (P1283) - Moriyasu (1980) ve Venturi (2008)

Altun Yaruk (AY) - Kaya (1994)

Atebetül-Hakayık (AH) - Arat (1951)

Brāhmī yazılı Eski Uygurca metinler (Br.) - Gabain (1954), Maue (1996) ve Maue (2015)

Bulġatü'l-Muştak fī Luġati’t-Türk ve'l-Ḳifcāḳ (BM) - Zajączkowski (1954, 1958)

Codex Cumanicus (CC) - Grønbech (1942)

Çağatay Türkçesi (Çă̆.) - Courteille (1870) ve Kúnos (1902)

Daśakarmapathāvadānamālā (DKPAM) - Wilkens (2016)

Dīvānü Luġāti't-Türk (DLT) - Dankoff-Kelly (1982-1985)

Ed-Durretü'l-Mudiyye Fi'l-Luġati’t-Türkiyye (DM) - Zajączkowski (1965a, 1965b, 1968, 1969) 


\section{$J(\Theta)$}

El-İdrak Haşiyesi (IH) - İzbudak (1936)

El-Kavānīnü'l-Külliyye li-Żabți'l-Luġati't-Türkiyye (KK) - Toparlı et al. (1999)

Ermeni Kıpçak Türkçesi (Erm. Kıp.) - Garkavets (2010)

Et-Tuhfetü'z-Zekiyye Fi'l-Lūgati't-Türkiyye (TZ) - Atalay (1945)

Göktürk ve Uygur dönemi runik harfli metinler - Berta (2004)

Harezm Türkçesi satır arası Kur'an tercümesi (HKT) - Sağol (1995)

Hotanca-Türkçe Kelime Listesi (HTKL) - Emmerick-Róna-Tas (1992)

Irk Bitig (IB) - Tekin (1993b)

İbnü Mühenna Sözlüğü (Türkçe bölümü) - Battal (1934)

İrşādü'l-Mülūk ve's-Selātin (IMS) - Toparlı (1992)

Karahanlı Türkçesi Kur'an Tercümesi Rylands Nüshası (RKT) - Ata (2004)

Ḳıșaṣü'l-Enbiyā (KE) - Ata (1997)

Kitāb-1 Mecmūc-1 Tercümān-1 Türkī ve 'Acemī ve Mugaalī (TA) - Toparl1-Çögenli-Yanık (2000)

Kitābu'l-İdrāk li-Lisāni'l-Etrāk (Kì) - Caferoğlu (1931)

Kutadgu Bilig (KB) - Arat (1979) ve Tezcan (1981)

Ḳutb’un Ḥusrev u Şīiñ'i (HŞ) - Zajączkowski (1961)

Ming dönemi Uygur Türkçesi-Çince Sözlük (UÇS) - Ligeti $(1966,1969)$ ve Yunusoğlu (2012)

Mu'īnü'l-Mürīd (MM) - Toparl1-Argunşah (2008)

Mukaddimetü'l-Edeb (ME) - Yüce (1993)

Münyetü'l-Ġuzāt (MG) - Öztopçu (1989)

Nehcü'l-Ferādīs (NF) - Ata (1998)

Oğuz Kağan Destanı (OKD) - Bang-Rahmeti (1936) ve Danka (2016)

Orta Asya Anonim Tefsiri (Tefs.) - Borovkov (1963) 


\section{$J(\Theta)$}

Osmanlı Türkçesi (Osm.) - Tarama Sözlüğü (1996)

Türk ve İslam Eserleri Müzesi 73 numarada kayıtlı Türkçe Kur’an Tercümesi (TİEM 73) Ünlü (2012)

Volga Bulgar Türkçesi (VB) - Erdal (1993)

Aksi belirtilmedikçe, çağdaş Türk lehçelerinden verilen tanıklar için aşağıdaki kaynaklar kullanılmıştır:

Altay Türkçesi - Gürsoy-Naskali-Duranlı (1999) ve Baskakov-Toşçakov (1947)

Azerbaycan Türkçesi - Orucov (2006)

Başkurt Türkçesi - Uraksin (1996)

Çulım Türkçesi - Biryukoviç (1984)

Çuvaş Türkçesi - Skvortsov (1982) ve Fedotov (1996)

Dolgan Türkçesi - Stachowski (1993) ve Stachowski (1998)

Gagauz Türkçesi - Baskakov (1973) ve Baskakov (1991)

Hakas Türkçesi - Subrakova (2006)

Halaç Türkçesi - Doerfer-Tezcan (1980) ve Doerfer (1987)

Karaçay-Malkar Türkçesi - Tavkul (2000)

Karakalpak Türkçesi - Baskakov (1958)

Karay Türkçesi - Baskakov (1974)

Kazak Türkçesi - Shnitnikov (1966) ve Koç (2003)

Kırgız Türkçesi - Yudahin (1985)

Kırım Tatar Türkçesi - Asanov (1988)

Kırımçak Türkçesi - Rebi (2004)

Kumuk Türkçesi - Bammatov (1969)

Nogay Türkçesi - Baskakov (1963) 


\section{$J(\Theta)$}

Özbek Türkçesi - Karı-Niyazov-Borovkov (1941)

Salar Türkçesi - Tenişev (1976)

Sarı Uygur Türkçesi - Shimin-Clark (1992-1993) ve Roos (2000)

Sibirya Tatar Türkçesi - Tumaşeva (1992)

Şor Türkçesi - Kurpeşko-Tannagaşeva-Apon'kin (1993) ve Kurpeşko-Tannagaşeva-Akalın (1995)

Tatar Türkçesi - Dawletschin et al. (1989) ve Ganiyev (1997)

Teleüt Türkçesi - Ryumina-Sırkaşeva-Kuçigaşeva (1995)

Tofa Türkçesi - Rassadin (1971) ve Rassadin (2005)

Tuva Türkçesi - Arıkoğlu-Kuular (2003) ve ölmez (2007)

Türkiye Türkçesi ağızları - Derleme Sözlüğü (1993)

Türkmen Türkçesi - Baskakov et al. (1968) ve Tekin et al. (1995)

Yakut (Saha) Türkçesi - Böhtlingk (1851), Pekarskiy (1958-1959) ve Monastyrjew (2006)

Yeni Uygur Türkçesi - Schwarz (1992) ve Necip (1995)

Türkçe ve Moğolca dışında kalan dillerden verilen tanıklar için aşağıdaki kaynaklar kullanılmıştır:

Akatça - Black et al. (2000)

Arapça - Wehr (1985)

Cürçence - Kiyose (1977) ve Kane (1989)

Çeremisçe (Marice) - Moisio-Saarinen (2008)

Çince - Giles (1912)

Eski Farsça - Schmitt (2014)

Evence - Robbek-Robbek (2005)

Evenkice - Vasilyeviç (1958) 
Farsça - Steingass (1963)

Hotan Sakacas1 - Bailey (1979)

Kilise Slavcası - Granberg (2009)

Macarca - Gombocz (1912), Benkő (1993-1997) ve Róna-Tas-Berta (2011)

Mançuca - Rozycki (1994) ve Norman (2013)

Maniheist Partça - Durkin-Meisterernst (2004)

Maniheist Soğdca - Sims-Williams \& Durkin-Meisterernst (2012)

Orta Çince - Pulleyblank (1991) ve Schuessler $(2007,2009)$

Orta Farsça - MacKenzie (1986) ve Durkin-Meisterernst (2004)

Osetçe - Abayev (1958-1989)

Proto-Permce - Csúcs (2005)

Proto-Samoyedce - Janhunen (1977)

Proto-Tunguzca - Doerfer (2004)

Proto-Yeniseyce - [W] Werner (2002), [S] Starostin-Ruhlen (1994)

Proto-Yukagirce - Nikolaeva (2006)

Rusça - Vasmer (1986-1987) ve Anikin (2000)

Sanskrit - Monier-Williams (1899) ve Edgerton (1993)

Soğdca - Gharib (2004)

Solonca - Poppe (1931) ve Aalto (1976-1977)

Sonraki Han Çincesi - Schuessler $(2007,2009)$

Şibe (Çağdaş Mançu) - Stary (1990), Kim et al. (2008) ve Stary (2017)

Tibetçe - Jäschke (1881)

Toharca A, Toharca B ve Proto-Toharca - Windekens (1941), Poucha (1955), Thomas (1964) ve Adams (2013) 


\section{J(G)}

Udihece - Şneyder (1936)

Udmurtça (Votyakça) - Wichmann (1987)

Yunanca - Beekes (2010)

Türkçe-Moğolca sözcük karşılaştırmalarının altında Moğolca biçimle bağlantılı olduğu düşünülen Kitan/Kitay (契丹 Qidān), Tabgaç (拓跋 Tuòbá) ve 鮮卑 Xianbei (diğer adıyla Sienpi) dilinden biçimler " " işaretiyle verilmiş, ilgili kaynak veya kaynaklar da maddenin sonuna eklenmiştir.

Çalışmamız, uzunluğu dolayısıyla A-D, E-N ve O-Y olmak üzere üç bölüm hâlinde yayımlanacaktır. Kısaltmalar ve kaynaklar birinci bölümün sonunda verilmiştir. Ek kısaltmalar ve kaynaklar kullanılması durumunda bunlar ilgili bölümlerin sonuna eklenecektir. Son bölümde ayrıca 'Şüpheli Karşılaştırmalar' ve 'Sonuç' başlıkları yer alacaktır. 'Şüpheli Karşılaştırmalar' başlığı altında, esas listede yer almayan, ses ve anlam bağları zayıf ancak ilişkili olmaları muhtemel sözcüklere yer verilirken 'Sonuç' bölümünde kelime listesinden çıkarılabilecek dolaysız ve tarafsız bilgiler özetlenecektir.

\section{Alıntıların Belirlenme Ölçütleri}

Klasik Moğolca söz varlığındaki Türkçe alıntıların belirlenmesinde É. CSÁKI'nin (2006: 10-11) ve É. KINCSES-NAGY'in (2018: 32-33) verdiği ölçütler kullanılmıştır. Bu ölçütler, çalışmamız özelinde aşağıdaki gibi tanımlanabilir:

\section{a. Zaman Dizinsel (Kronolojik) Ölçüt}

Türkçe sözcüğün Moğolca sözcükten daha erken tanıklanmış olması.

\section{b. Ses Bilgisel (Fonetik) Ölçüt}

Türkçe sözcüğün Moğolcaya özgü ses özelliklerini taşımaması ve/veya Moğolcaya özgü ses değişimlerini geçirmemiş olması.

\section{c. Köken Bilgisel (Etimolojik) Ölçüt}

Türkçe sözcügün Türkçe bir kökünün olması veya Türkçe içinde etimolojisinin yapilabilmesi.

\section{d. Biçim Bilgisel (Morfolojik) Ölçüt}




\section{J(৫)}

Türkçe sözcük yapı bakımından bir gövde ise, üzerindeki eklerin Türkçe kökenli olması.

\section{e. Anlam Bilimsel (Semantik) ölçüt}

Türkçe sözcüğün anlamının Moğolcadaki alıntıya göre daha geniş olması.

\section{f. Anlamdaşlık (Eş Anlamlılık) Ölçütü}

Türkçede o anlamda tek bir sözcük bulunuyorken Moğolcada aynı anlamda birden fazla sözcüğün bulunması.

\section{g. Yaygınlık ölçütü}

Sözcüğün Türkçede daha geniş bir yayılım alanının olması.

\section{h. Kültür Tarihsel Ölçüt}

Kültür tarihi açısından değerlendirildiğinde, sözcüğün karşıladığı nesne, kişi, eylem veya kavramın Türk kültür dairesinde daha erken görülmesi veya daha ön planda olması.

Bu ölçütlerden ilk dördü öncelikli olup alıntıların belirlenmesinde hepsinin bir arada görülmesi şartı aranmamıştır. 


\section{$J(\Theta)$}

\section{Kelime Listesi}

A

KM aba 'av, sürek avı' (OM ${ }^{\mathrm{MGT}} a b a,{ }^{\mathrm{HY}} a b a c ̧ i$ 'avc1', ${ }^{\mathrm{ME}} a b a,{ }^{\mathrm{iM}}$ abala- 'avlamak', ${ }^{\mathrm{RS}} a-$ bala- 'avlamak', ${ }^{\mathrm{PH}}$ abala- 'avlamak', Hlh. aв, Dag. au, Ma. aba) || GT ( $h$ ? $) \bar{a} v^{1}$ 'av'

KM (k.ö.) abidarim (Less.) abidarma 'temel Budist metinlerin Budist öğretinin sistemleşmesini sağlayan üçüncü bölümünün adı' (OM -, Hlh. -, Ma. -) || GT (EUyg.) abidarim abidaram abid(a)rm 'Budizm'deki Tripițaka'nın üçüncü bölümünün adı, Skolastik felsefe' ( $\leftarrow$ Toh. A abhidharm 'yüce gerçek, metafizik', Toh. B abhidhārm abhidārm 'Budizm'in metafiziği' $\leftarrow$ sk. abhidharma 'Budist kutsal yazıların üçüncü bölümünün adı')

KM abisig abisig 'kutsama, takdis, papazlı̆̆a atanma töreni, kabul töreni' (OM -, Hlh. aвumuг, Ma. -) || GT (EUyg.) abişek abijek 'kutsama, takdis etme; taç giyme töreni' ( $\leftarrow$ Toh. A abhiṣek ‘taç giyme töreni', Toh. B abhīṣek '(başın üzerinden su dökülerek yapılan) kutsama töreni; papazlığa atanma töreni’ $\leftarrow$ Sk. abhișeka '(su serperek) mesh etmek, göreve getirmek veya kutsamak, kralın taç giyme töreni, krala yağ sürme; taç giyme töreninde kullanılan su veya sıvı; yıkanarak arınma, abdest')

KM abiyas 'tutku; eğilim, temayül, yatkınlık; yetenek, kabiliyet, marifet; yaradılış, izlenim' (OM - Hlh. aвъяac, Ma. -) || GT (EUyg.) abiyaz abyaz 'eski bir alışkanlık, eylem veya eğilimin kalıntısı, kötü alışkanlık' $(\leftarrow$ ? $\leftarrow$ Sk. abhyāsa 'tekrar eden veya kalıcı bir uygulama, disiplin, alışkanlık, huy, âdet; etüt, çalışma; askerî tatbikat')

KM absa 'tabut' (OM -, Hlh. aвc(aH), Ma. absa, PTg. *hapsa 'huş ağac1 kabuğundan yapılmış kap, sepet') || GT kapsa ² 'sandık; tabut' (krş. EUyg. kaptse 'kap, sandık', DLT hafsı 'hokka') (? $\leftarrow$ Çin. 盒子 hézi 'kutu; tabut; mahfaza')

KM abura- (< abu.ra- < *abu-) 'kurtarmak, yardım etmek, canlıları korumak; korumak' (OM ${ }^{\mathrm{MGT}}$ abura-, ${ }^{\mathrm{HY}}$ abura-, ${ }^{\mathrm{PH}}$ abura-, Hlh. aбpax, Ma. -) \|| GT (EUyg.) apt-

\footnotetext{
Kmk. hau 'av', Kmk. hauçu 'avc1' (Németh 1990: 25), Kmk. hau 'av' (Gürsoy-Naskali-Halén 1991: 81).

2 CC kapsa, TZ apsa (< kapsa). Et-Tuhfetü̈z-Zekiye'de k- düşmesi bilinen bir ses olayıdır: TZ ögärçin (< *kökärçgün) 'güvercin', TZ urutka (< kurtga) 'ihtiyar, yaşlı', TZ ösäk (<*kō̈zä-k) 'ateş küreği'.
} 


\section{$J(\Theta)$}

'korumak, savunmak', GT (EUyg.) apın- '(bir şeyden) uzak durmak, sakınmak, çekinmek', GT (EUyg.) apıt- 'saklanmak, gizlenmek, korumak, himayesi altına almak'

$\mathrm{KM}$ acirg- $a^{n}\left(<{ }^{*}\right.$ adırka) 'aygır' (OM ${ }^{\mathrm{MGT}}$ acirqa, ${ }^{\mathrm{HY}}$ acirqa $,{ }^{\mathrm{ZY}} \operatorname{acirka}(i),{ }^{\mathrm{BY}} \operatorname{acar}[g] a,{ }^{\mathrm{ME}-}$ acirga $a{ }^{\mathrm{i}}{ }^{\mathrm{M}}$ acirga $a,{ }^{\mathrm{TA}}$ acirǵa,${ }^{\mathrm{SL}}$ acirga $a,{ }^{\mathrm{RS}}$ acirǵa, Hlh. aspaza, Ma. acırgan acirhan, Cür. acir morin, acara muri, Sol. adirga adigga) || GT adgır adkır (?< *adırkă) 'aygır', BT *adgır 'aygır' (> Çuv. ăyăr tră)

KM açi 'iyilik, lütuf, yardım' (OM MGThaçi, 'HY haçi 'karşllık, teşekkür; intikam', ${ }^{\mathrm{PH}}$ haçi 'fazilet', Hlh. au, ŞYug. hacig 'iyilik, yarar' [MYYC 125], ŞYug. hacag 'lütuf, iyilik' [MYYC 346], Ma. -) || GT açıg (< *aç- veya *açı- $\left.{ }^{3}\right)$ 'hediye, armağan, ödül, bahşiş; ihsan, lütuf, bağış; merhamet, bağışlama'

- Kit. 拝洗 bài-xì * pais(i)-5 'iyilik görmek, hediye almak' (Franke 1976: 176177; Vovin 2003: 240; Shimunek 2007: 68)

KM açi 'torun; yeğen' (OM ${ }^{\mathrm{HY}}$ haçi açi, ${ }^{\mathrm{ZY}}$ açi, ${ }^{\mathrm{BY}}$ açi, Hlh. au, Ma. -) \| GT atı 'torun; yeğen'

KM açi- (<*artı-) '(yük) yüklemek' (OM ${ }^{\mathrm{MGT}}$ açi-, ${ }^{\mathrm{ME}}$ açi-, ${ }^{\mathrm{i}}$ açi-, Hlh. aчux, Dag. at'-, Mgr. arći- [Nugteren 2011: 264], Ma. açi-) || GT ārt- '(yük) yüklemek'

KM açimag (<*arçı.mak ? *artımak?) 'heybe, hurç; kişisel eşyaları taşımak için bir torba' (OM ${ }^{\mathrm{RS} *}$ açimak 'semer', Hlh. aчмaz, Ma. -) \|GT (OTi) $\operatorname{artmak}^{6}(<* \bar{a} r t+m a k)$ 'çıkın, heybe' veya GT $\operatorname{artçu~} \sim \operatorname{arçı}^{7}(<\operatorname{art}+c ̧ u)$ 'heybe'

3 Dankoff-Kelly (1982-1985: III/4), açıg ve açın- sözcüklerinin kökeni olarak *aç- 'iyilik etmek, onurlandırmak' fiilini gösterirken, OTWF $(181,584)$ açı- 'acı vermek; dertlenmek, kederlenmek' fiilinden farklı, ikinci bir açı- 'merhamet etmek' fiiline işaret eder. UW Nb. (I/1 3) ise 'merhamet etmek' anlamında ikinci bir fiilin varlığını kabul etmenin gereksiz olduğunu ifade eder. Ancak açıg 'hediye, ödül, lütuf, ihsan' isminin açl- 'acı vermek; dertlenmek' fiilinden türemiş açıg 'acı, dert, ızdırap' ile bir ve aynı olması pek muhtemel değildir. Bu ismin kökü olarak ayrı bir *açı- 'iyilik etmek/görmek' fiili tasarlanmalıdır.

4 GOÇ pa:j-siaj, EMand. paj-si (Pulleyblank 1991: 28, 331).

5 Kit. * pais(i)-fili, Kitan dilinde başka örnekleri de görülen $a>$ ai ve $c ̧>s$ değişimleriyle (Shimunek 2007: $45,51){ }^{*}$ paçı- $(\leftarrow$ Tü. *paçı-) şeklinden gelmektedir.

6 CC artmak, Kİ artmak, TZ arıtmak, DM aratma, Krç.-Blk. artmak.

7 EUyg. artçu, DLT arçı. 


\section{J(৫)}

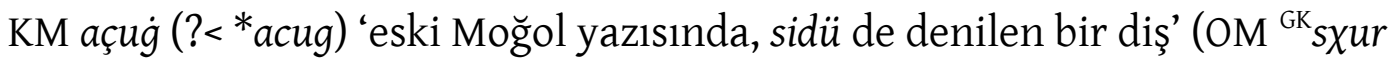
'diş', Hlh. au̧ar, Ma. -) \| GT azıg 'azı dişi, köpek dişi' (Çuv. asav 'azı dişi' $\leftarrow$ Tat. azau $<$ GT azıg)

$\searrow \mathrm{KM}$ aray- $a \sim$ ariy- $a$

KM ada 'kötü ruh; dert, engel' (OM ${ }^{\mathrm{HY}}$ ada, Hlh. ad, Ma. -) \| GT ada 'zarar; sıkıntı, güçlük, engel'

KM (k.ö.) adag 's 'ayak', (Less.) adag ‘son, bitiş; uç, sınır’ (OM -, Hlh. adaz, Ma. -) \|| GT hadak 'ayak; son, uç, bitim’

KM adali 'aynı, eş, benzer, eşit' (OM ${ }^{\mathrm{MGT}}$ adali, ${ }^{\mathrm{HY}}$ adali, ${ }^{\mathrm{ME}}$ adali, ${ }^{\mathrm{PH}}$ adali, Hlh. aduл, Ma. adali) \| GT adaş 'arkadaş, dost, eş'

KM adam ‘adım, yürüyüş; hızlı, çevik' (OM -, Hlh. adaм ‘paniğe kapılmış', Ma. -) || GT (OTi) *ātım (> adım) 'adım', BT *ātım ‘adım' (> Çuv. utăm)

KM (k.ö.) adisdid ${ }^{10} \sim$ (Less.) adis adistid 'kutsanmış, yetkilendirilmiş; lütuf, kutsama, takdis; bir tanının mucizevi güç bahşetmesi; her derde deva ilaç; çiçek hastalı̆̆ı' (OM ${ }^{\mathrm{PH}}$ adişdid 'lütuf, kutsama', Hlh. aducmum, Ma. adistit) || GT (EUyg.) adiştit 'büyü gücü' ( $\leftarrow$ Toh. B adhișțhit atișțhit (yām-) 'kontrolünü ele geçirmek, büyüyle kontrol etmek' $\leftarrow$ Sk. adhișthita 'yerleşilmiş, oturulan, denetlenen, kontrol edilen, düzenlenmiş, belirlenmiş')

KM adkag̀ 'maddi dünyaya bağlllık; yanılsama' (OM -, Hlh. amzaz, Ma. -) \|| GT adkak atkak (< *hadka-k) 'bilinç nesnesi; tutunma, bağll lık'

$8 \quad$ Lal. 32b. amdurin kölgen-eçeyen bayucu adaǵ-tur inu mörgübei.

9 Türkçe sözcük, köken bilgisi açısından karmaşıktır. Sözcüğün āt 'ad, isim' kökünden \{+dAş\} ekiyle türetilmiş olması, ses ve anlam bilgisi açısından ikna edici değildir. Benzer şekilde, *ada- (krş. Ma. ada'eşlik etmek, yakın durmak') farazî fiil kökünden $\left\{{ }^{*}\right.$-Xş\} ekiyle türetilmiş olması da pek olası görünmemektedir çünkü bu durumda türevin *adış biçiminde olması beklenir. Sözcük ancak *ada isminden nadir $\{+(\mathrm{X}) s ̧\}$ ile türetilmiş olabilir. Ancak bu farazî *ada isminin ET ada 'zarar, sıkıntı, güçlük' ile birleştirilmesi güçtür. Diğer bir ihtimal ise sözcüğün *ada+daş ‘sıkıntıları ortak olan' biçiminden hece düşmesiyle gelişmiş olmasıdır.

10 Turf. 40a3. 


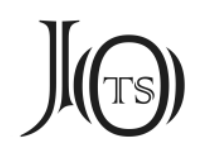

KM adku- 'elinde tutmak, eliyle sıkmak; sıkıca tutmak, kavramak; masaj yapmak' (OM ${ }^{\text {MGT }}$ hatqu- atqu-, Hlh. amzax, Ma. -), KM adku 'el ayasi; avuç, elde tutulan şey' (OM -, Hlh. amza, Ma. fatha 'toynak, kuş ayağı, pençe', Udh. pataxe 'perde ayaklıların ayağı') $\|$ GT *hadka- ${ }^{11}$ (< hadak+a-) '(kuş) tutmak, yakalamak, kapmak'

KM aduyun $\sim \operatorname{ada\gamma u}^{n}(<* a d V)$ 'at sürüsü, at' (OM ${ }^{\mathrm{MGT}} a d u$ 'u(n), ${ }^{\mathrm{BY}}$ adū-çi, ${ }^{\mathrm{ME}} a d u$ 'ūsun adūsun, ${ }^{\mathrm{iM}}$ adūn, ${ }^{\mathrm{SL}}$ adūnç̧i, ${ }^{\mathrm{RS}}$ adunçi, ${ }^{\mathrm{RS}}$ adūsun, ${ }^{\mathrm{PH}}$ adu'u:n, Hlh. adyy(H), Ma. adun, Evk. adugun), KM adask-a (<*ada) 'bitkin at' (OM ${ }^{\mathrm{ME}}$ adaska 'eski deri', Hlh. -, Ma. -) || GT hat 'at', BT *at 'at' (> Çuv. ut)

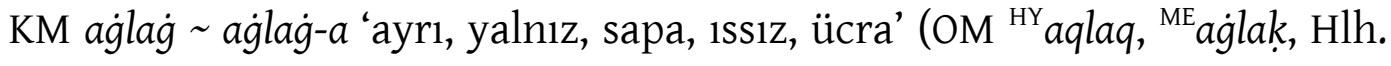
аглаг, Ma. -) || GT aglak '1ssiz, tenha, kuytu'

KM aǵsa- ${ }^{12}$ 'yükseltmek, kaldırmak, havaya kaldırmak; kemere takmak ya da asmak' (OM ${ }^{\mathrm{MGT}}$ agsa- 'üstünden sarkmak, üzerine almak, giymek, taşımak', ${ }^{\mathrm{RS}}$ aksau kurman 'sadak kemeri', Hlh. azcax 'yükseltmek, kaldırmak; yay veya kuburu kemere asmak', Bur. aha- 'tutunmak, takılmak; tırmanmak', Ma. asha- 'kemere takılı olarak taşımak, yakadaki bir düğmeye asılı olarak taşımak') || GT āg- 'tırmanmak, yükselmek' veya GT has- hās- ${ }^{13}$ 'asmak, takmak, bağlamak'

KM aǵsum 'azgınlık; şiddetli, azgın' (OM -, Hlh. azcaм, Ma. akşun 'karalayıcı, iftiralı') $\|$ GT ahsum ahsuy aksum 'kavga eden, sarhoş' $(\leftarrow$ ?)

KM azalcin $~$ ayalcan $^{n}$ (< haga.lcin) 'örümcek' (OM ${ }^{\mathrm{HY}}$ ha'alcin, ${ }^{\mathrm{NK} 2 *}$ ahhīn, Hlh. aалз, Ma. -) || GT (h’)ag 'ağ, örümcek ağı' (krş. Osm. ag (kurdu) 'ağ ören böcek, tırtıl') (krş. PY [W] ${ }^{*} p^{h} \partial^{2} \eta$, PY [S] * $\partial^{2} \eta$ 'balıkçı ağı')

KM (k.ö.) akas 14 'boşluk, boş yer' (OM -, Hlh. -, Ma. -) \| GT (EUyg.) akaş 'hava, gökyüzü' ( $\leftarrow$ Toh. A ākāss 'eter, atmosfer' $\leftarrow$ Sk. ākāśa 'boş alan, boşluk, eter, gözyüzü, atmosfer')

11 EUyg. adka- (Zieme 1998: 44-46; UW Nb. I/1 13), krş. CC ayagış- ( * ayakı-ş-) 'ayağını başka birinin ayaklarına dayamak'.

12 Moğolca fiil, bizce, ${ }^{*}$ agsa- (<*ag.sa-) 'yükseltmek, kaldırmak' ( $\leftarrow$ Tü. āg-) ve *aska- (<*as.ka-) '(kemere) asmak, takmak' ( $\leftarrow$ Tü. has-) biçimlerinin bir karışımıdır. Moğolca fiilden fiil yapan $\{-\mathrm{sA}-\}$ eki için krş. KM debse- 'ayağıyla sertçe vurmak, ayakla çiğnemek'.

13 DLT ās-, Tkm. as-, Hlç. has-.

14 Lal. 27b, 53a. 


\section{J(৫)}

KM al 'kırmızı, al' (OM ${ }^{\mathrm{MGT}} a l,{ }^{\mathrm{HY}} a l,{ }^{\mathrm{BY}} a l<a>,{ }^{\mathrm{PH}} a l$, Hlh. aл, Ma. - ) \| GT al 'al' (krş. Rus. алый 'kırmızi')

KM ala 'düz zirveli tepe' (OM -, Hlh. aл, Ma. ala, Şib. ala 'açık alan, açık tarla')

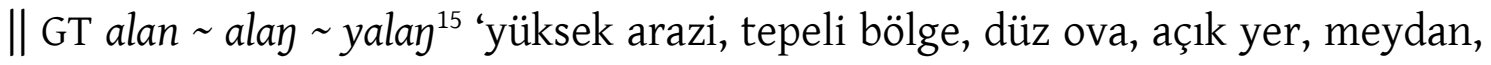
alan'

$\mathrm{KM}$ ala- 'öldürmek' (OM ${ }^{\mathrm{MGT}}$ ala-, ${ }^{\mathrm{HY}}$ ala-, ${ }^{\mathrm{ME}}$ ala-, ${ }^{\mathrm{TA}}$ ala-, ${ }^{\mathrm{M}}$ ala-, ${ }^{\mathrm{RS}}$ alaġda- 'öldürülmek', ${ }^{\mathrm{RM}} \bar{a}$ la- 'savaşmak', ${ }^{\mathrm{PH}}$ ala-, Hlh. aлax, Ma. -) \| GT (DKPAM) ala- (? lala-) 'kesmek, yırtmak, parçalamak' (?૯ Çin. 害 hài 'yaralamak')

- Kit. 万为 〈al.a〉 *ala- 'öldürmek' (Róna-Tas 2017: 145-146)

$\mathrm{KM}$ alag 'ala, alaca, benekli' (OM ${ }^{\mathrm{MGT}}$ alaq, ${ }^{\mathrm{HY}}$ alaq, ${ }^{\mathrm{ZY}}$ ala $[q],{ }^{\mathrm{ME}}$ ala, ${ }^{\mathrm{iM}}$ ala, ${ }^{\mathrm{RS}}$ ala, $\mathrm{Hlh}$. araz, Ma. alha alga) \|GT hāla 'ala, alaca, benekli', BT *(h)āla 'ala, alaca, rengârenk, çizgili' (> Çuv. ula) (krş. P1283 Ha-la yun-log *Hala Yuntlıg, Mac. alacs 'alaca')

KM (Kow.) alasira- 'kurnazca davranmak, hile yapmak' (OM -, Hlh. -, Ma. -) \| GT al 'araç, yol, hile' (krş. Mac. ál 'sahte, taklit')

KM (k.ö.) albaGud' 'yiğit, kahraman' (OM -, Hlh. -, Ma. -) \| GT (ET) alpagut 'savaşçı, yiğit, kahraman', BT *alpagut ‘bey, efendi, ağa' (> Çuv. ulput)

KM alca- (< *harı.ca-) 'acı çekmek, dayanamaz hâle gelmek' (OM ${ }^{\mathrm{MGT}}$ alca- 's1kıntıda olmak, zorda olmak', HYülü halcaqu 'engelsiz, zorluk olmadan', Hlh. aлзаx, ?Ma. alişa- 'ilgisiz olmak, sıkılmak, mutsuz olmak, endişelenmek'), KM alciya- (< harı.cı.ga-) 'yorulmak, bitmek, tükenmek; sıkıntıda olmak' (OM ${ }^{\mathrm{MGT}}$ alciya- 'ayrıl$\operatorname{mak}^{17}$, TA alcāş 'hata', Hlh. asxwaax, Ma. alca- 'ayrılmak; rengi solmak') \| GT hārt'yorulmak, bitkin düşmek, hâlsiz düşmek, bunalmak', BT *(h)ār(l)- 'yorulmak' (> Çuv. ır-)

15 Alt. calay.

16 Lal. 51a.

17 MGT alciya- 'ayrılmak' fiili, KM alciya- 'yorulmak' fiiliyle sesteş olsa da açıkça farklı bir köke dayanmaktadır. Söz konusu fiilin, GT hır- hıra- 'ayırmak; ayrılmak, uzaklaşmak' ile bağlantılı olması mümkündür. İlginç şekilde, GT hır- hıra- ve *hārl- fiilleri, Osm. ırl- 'ayrilmak; yorulmak' ve SUyg. har'ayrılmak; yorulmak' örneklerinde de kaynaşmaya uğramıştır. 


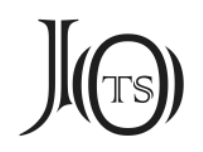

KM alçu ( alçungǵay) 'topuk kemiğinin yanındaki çöküklük' (OM -, Hlh. -, Ma. alçu) || GT aşuk (?<*alçuk) 'aşık kemiği' (krş. Rus. альчuк 'genç sığırların bacak eklemleri', Mac. os 'oyunda taş')

$\mathrm{KM}$ alda 'kulaç' (OM ${ }^{\mathrm{MGT}}$ alda, ${ }^{\mathrm{ME}}$ alda, ${ }^{\mathrm{SL}}$ alda, ${ }^{\mathrm{RS}}$ alda, Hlh. and, Ma. andan 'an, lahza', Cür. andando 'yolda', Evk. alda), KM alda aldadu 'yaklaşık, civarında, çevresinde' || BT *alta 'kucak; çevre' (> Çuv. ıtam), BT *altala- 'kucaklamak' (> Çuv. ttala-) (krş. Çer. öltö elte. 'kucak, kucak dolusu')

$\mathrm{KM}$ aldar ${ }^{18}$ (< *aldo.r < *aldo) 'ün, şöhret; isim, ad' (OM ${ }^{\mathrm{MGT}}$ aldar, ${ }^{\mathrm{PH}}$ aldar, Hlh. aлdap, PTg. *aldō ‘haber, havadis') || GT āt (<*altŏ) 'ad, unvan; ün, şöhret', BT *ätt > *yä̈t 'ad, isim; itibar' (> Çuv. yat)

$\mathrm{KM}$ alim-a 'elma' (OM ${ }^{\mathrm{HY}}$ alima, ${ }^{\mathrm{ZY}}$ alima, ${ }^{\mathrm{BY}}$ alima, ${ }^{\mathrm{ME}}$ alma, ${ }^{\mathrm{i}}$ alma, ${ }^{\mathrm{RS}}$ alima, Hlh. aлим, Ma. -) || GT alma almıla alımla 'elma', BT *alma 'elma' (> Çuv. ulma) (krş. Mac. alma)

KM (Kow., Gol.) aliusu (Bo.) alisun (<*alizu.sun ${ }^{19}$ ) 'bezelye samanı; arpanın yeniden canlanması' (OM -, Hlh. -, Kalm. älsn 'meyve kabuğu, tahıl kabuğu', Ma. alisun 'kayıp veya terk edilmiş tohumlardan yeşeren tahıl') || GT aş aş̧ 'yiyecek, yemek, besin; buğday, tahıl' veya GT aşllk 'tahıl, hububat, buğday, zahire' (Yak. Dolg. ahılık 'meyve, yemiş; ren geyiği yemi')

KM aliy-a (<*alıga) 'oyuncu, şakacı, haylaz' (OM -, Hlh. asua, Dag. əle: [MYYC 103], Ma. -) || GT allıg (< al+llg) 'hileli, aldatıc1' veya GT alıg 'kötü, aciz, aşağı'

$\mathrm{KM}$ altan 'altın' (OM ${ }^{\mathrm{MGT}}$ altan, ${ }^{\mathrm{HY}}$ altan, ${ }^{\mathrm{ZY}}$ altan, ${ }^{\mathrm{BY}}$ altan, ${ }^{\mathrm{ME}}$ altan, ${ }^{\mathrm{TA}}$ altan, ${ }^{\mathrm{S}}$ altat, ${ }^{\mathrm{iM}}$ altun, ${ }^{\mathrm{RS}}$ altan, ${ }^{\mathrm{PH}}$ altan, Hlh. asm(aH), Ma. aisin, Cür. ançun) $\|$ GT altun ${ }^{20}$ (Br. altun) 'altın', BT *altun 'altın' (> Çuv. vltăn llttăn lltăm vvtăn)

KM alus (<*alu-) 'mesafe, uzak yer; uzak gelecek, (zamanda veya mekânda) uzak; öte, ötede, öbür tarafta, karşıda' ( $\mathrm{OM}^{\mathrm{MGT}}$ alus, ${ }^{\mathrm{ME}}$ alus, Hlh. aлc, Ma. -, Evk. ala'(bir dağı) aşmak, geçmek') || GT āş- 'aşmak, geçmek'

18 Alıntı, Mo. *aldo $\leftarrow$ Tü. *altŏ şeklinde gerçekleşmiş olmalıdır.

19 Moğolca sözcük, GT *aşlk sözcüğüne karşılık gelen BT *allıg benzeri bir biçimden alınmış olabilir.

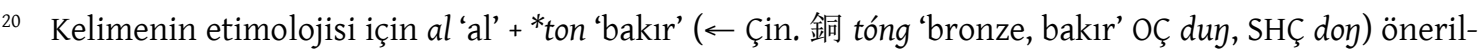
miştir. 


\section{$J(\Theta)$}

$\mathrm{KM} a m a^{n}$ 'ağız' (OM ${ }^{\mathrm{MGT}} a m a n,{ }^{\mathrm{HY}} a m a n,{ }^{\mathrm{ZY}}$ aman, ${ }^{\mathrm{BY}}$ aman, ${ }^{\mathrm{ME}} a m a n,{ }^{\mathrm{TA}} a m a n,{ }^{\mathrm{iM}}$ aman, \$Laman, ${ }^{\mathrm{RS}}$ aman, ${ }^{\mathrm{GK}}$ aman, Hlh. aм (ан), Ma. angga, ?Ma. femen 'dudak', Cür. amga) \|| GT hām 'kadınlık organı'

KM amara- amura- 'sevmek' (OM ${ }^{\mathrm{MGT}}$ amara-, Hlh. ampax, Ma. amuran 'düşkün, niyetli, iyi, özenli', Ma. amurangga 'bir şeye düşkün kimse') || GT amra- 'sevmek'

KM amu- 'dinlenmek, istirahat etmek, rahatlamak, sıkıntısından kurtulmak' (OM ${ }^{\mathrm{MGT}}$ amu-, ${ }^{\mathrm{HY}}$ amu-, ${ }^{\mathrm{ME}}$ amu-,${ }^{\mathrm{iM}}{ }^{\mathrm{M}} a m u-,{ }^{\mathrm{TA}}$ amu-, ${ }^{\mathrm{PH}}$ amu'u:l- 'huzur vermek', Hlh. amax, Ma. amha- 'uyumak'), KM amur 'barış, huzur, sessizlik' (OM ${ }^{\mathrm{ME}}$ amur, Hlh. aмap, Ma. -) || GT ( $h$ ?)amı ${ }^{21}$ 'huzur bulmak, rahatlamak', GT ( $h$ ?)amıl ${ }^{22}$ 'barış, uyum, ahenk' (?↔ Toh. B $\bar{a} m^{23}[\mathrm{am}]$ 'sessizlik; sessizce, ses çıkarmadan, sessiz’)

- Kit. 乃夾走 (am.l.ha〉 *amulġa- 'barıştırmak, yatıştırmak, uzlaştırmak' (Róna-Tas 2017: 146)

KM anar 'nar' (OM ${ }^{\mathrm{RS}}$ anār, Hlh. aнар, Ma. -) \| GT nara nār enār anar ${ }^{24}$ 'nar' ( $\leftarrow$ Far. نار nār انار anār 'nar' veya Soğd. n’r'kh nārāk 'nar')

KM ancira- angcira- (< ang.cira-) 'bilmek, anlamak, kavramak' (OM -, Hlh. -

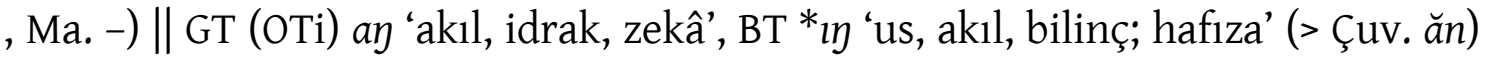
(krş. Çer. ôy uy ị̂ 'düşünme, akıl, hafıza, hatıra, anı'), GT a la- 'anlamak; araştırmak, incelemek', BT *ipla- 'anlamak, kavramak; dikkatle dinlemek' (> Çuv. ănla)

KM ancu 'para cezası, ceza' (OM -, Hlh. aн3, Ma. -) || GT anço 'ödül, mükâfat; (hükümdara verilen) hediye, sunu', ançola- (? ancola-) 'sunmak, takdim etmek, teslim etmek; hediye etmek, kurban etmek' (? $\leftarrow$ Çin. 暗償 àncháng (Kan'on anshō) 'telafi etmek, tazmin etmek')

21 Ünal'a göre (2015: 279), amı- fiili İhe Ashete Yazıtı'nda tanıklanmıştır: (A1v1) kül tud(u)n in(i)si (a)ltun t(a)mg(a)nt(a)rh(a)n yogin (a)m(l)dok üç(ü)n(a)d(l)r(l) tr(l)m(l)z "Kül Tudun'un kardeşi Altun Tamgan Tarkan'ın cenaze töreniyle huzur bulduğumuz için ayrıldık."

22 krş. Hlç. havul 'iyi'.

23 Adams (2013: 47), Toharca sözcüğün Hint-Avrupa kökenli bir etimolojisini vermemektedir.

24 EUyg. nara, TiEM 73 nār, KE nār, HKT nār, HŞ nār, TA enār nar, RS anar. 


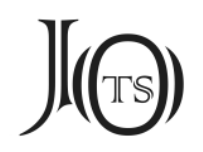

$\mathrm{KM}$ anda 'kan kardeşi' (OM ${ }^{\mathrm{MGT}}$ anda, ${ }^{\mathrm{HY}}$ Anda Naqaçu 'kişi ad1', ${ }^{\mathrm{BY}}$ anda, ${ }^{\mathrm{ME}}$ anda, Hlh. анд, Ma. anda) \|| GT and ant (? ānt $\left.{ }^{25}\right)$ 'ant, yemin' ${ }^{26}$

$\mathrm{KM}$ andag்ay andajar (< andag் $a^{-27}$ ) 'ant, yemin' ( $\mathrm{OM}{ }^{\mathrm{MGT}}$ andaqar, ${ }^{\mathrm{ME}}$ andajāar, ${ }^{\mathrm{RS}}$ andagjar, Hlh. андгaŭ, Ma. -) || GT antık- andık- 'ant içmek'

KM ang 'hayvan, yaban hayvanı avı' (OM -, Hlh. aн(2), Ma. -) || GT äg ‘büyük baş av hayvanı'

\Kit. 夹夾キ〈an.l〉*anla- 'avlamak' (Róna-Tas 2017: 147)

$\mathrm{KM}$ anggir 'bir tür sarı ördek' (OM ${ }^{\mathrm{MGT}}$ anggir, ${ }^{\mathrm{HY}}$ angir, ${ }^{\mathrm{ZY}}$ anggir, ${ }^{\mathrm{ME}}$ ankır, ${ }^{\text {NK1 }}$ anġır, Hlh. aнzup, Ma. anggir niyehe 'al kuşaklı ördek') \| GT hap $(g) \iota\left(r^{?}\right) t^{28}$ 'bir tür su kuşu'

KM angkar- 'dikkatini vermek, ilgilenmek' (OM -, Hlh. aнxaapax, ?Ma. anggala- 'rica etmek, talep etmek') || GT (ETŞ 142-143) aggar- ${ }^{29}$ (? agkar-) (< ay+gar-) 'anlamak, kavramak, idrak etmek', BT *ipkar- 'düşünmek, anlamak, kavramak' (> Çuv. ănkar-)

KM ar 'çizgi; kesik; çentik' (OM -, Hlh. ap 'desen, çizgiler', Ma. arun durun akū 'iz bırakmadan') || GT ( $h$ ? $) i z^{30}$ 'iz', BT *ir 'iz, çizgi' (> Çuv. yěr)

KM aray-a ariy-a (<*arıga) 'azı dişi; bir çarkın dişi' (OM ${ }^{\mathrm{MGT}}$ ara' $a,{ }^{\mathrm{HY}}$ ara-tai 'alageyik', ${ }^{\mathrm{B}}$ ara'a-tu 'erkek karaca, misk geyiğì', ${ }^{\mathrm{ME}}$ ari'a nari'a (?) hari'a, ${ }^{\mathrm{i}}$ arā, Hlh. apaa, Ma. argan 'filiz; hilal; uzun sivri diş, testere dişi') || GT azıg 'azı dişi, köpek dişi' (Çuv. asav 'azı dişi' $\leftarrow$ Tat. azau < GT azıg)

$\searrow \mathrm{KM}$ açug

25 Kzk. änt (R I 738), Hlç. a:nd.

26 Ünal 2013, kelimenin etimolojisi için *an-(U)t 'hatırlanan' < *an- 'hatırlanmak' > EUyg. anıt- 'hatırlamak, geçmişi düşünmek' (UW Nb. I/1 61) önermektedir.

27 Bu fiil, MGT'de andaqa- 'ant içmek', IM'de andag̀- 'yemin etmek, ant içmek' olarak tanıklanmıştır.

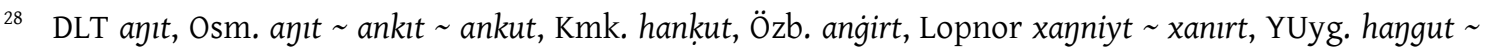
hangirt hangit hangirt, SUyg. ayıt $\sim$ anit $\sim$ anet, Hak. aat (Nugteren-Roos 2012: 125-126).

29 Sözcük tek örnek (hapax legomenon) olduğu için onar- olarak düzeltilmesi önerilmiştir (UWb 163; Zieme 2011: 110). Ancak UWb Nb. (I/1 63) sözcüğü angar- okumakta ve olduğu gibi kabul etmektedir.

30 Kmk. hiz. 


\section{$J(\Theta)$}

KM aray 'azıcık, biraz, biraz daha' (OM ${ }^{\mathrm{MGT}}$ aran, Hlh. apaŭ, Ma. arkan) \|| GT hāz 'az' (krş. Çer. ar, or 'küçük, az, genç' $\leftarrow$ BT *(h)ār 'az')

KM $\operatorname{araki}^{n} \sim \operatorname{ariki}^{n}$ 'alkollü içki' (OM ${ }^{\mathrm{BY}} \operatorname{araki}$, Hlh. apxu(H), Ma. arki) \| GT (h?) $\operatorname{arakl}^{31}$ 'alkollü içki' ( $\leftarrow$ Ar. عرق 'arak 'ter; sert alkollü içki')

$\mathrm{KM}$ aral 'dingil, araba oku; araba gövdesi' ( $\mathrm{OM}^{\mathrm{HY}}$ aral, ${ }^{\mathrm{ME}}$ aral, Hlh. apas, Ma. fara, PTg. *pāral [Benzing 1956: 966]) || GT (OTi) arış (< *hārış ${ }^{32}$ ) 'araba oku, mil, şaft' (krş. Ar. عريش 'arīş 'şaft, araba oku’33)

KM aran 'adam, erkek; kişi' (OM ${ }^{\mathrm{MGT}}$ haran, ${ }^{\mathrm{ME}}$ haran, ${ }^{\mathrm{IM}}$ haran, ${ }^{\text {SL }}$ haran, ${ }^{\mathrm{RS}}$ haran, ${ }^{\mathrm{GK}}$ haran heren, ${ }^{\mathrm{PH}}$ haran, Hlh. аран, Ma. -) || GT *härän *härän 'adamlar, erkekler', BT *(h)är 'erkek' (> Çuv. ar)

- Kit. 止キ〈p.ar〉 *par 'insanlar' (Wu-Janhunen 2010: 84-85; Janhunen 2012: 124; Shimunek 2017a: 361)

$\mathrm{KM}$ arasu ${ }^{n} \sim \operatorname{arisu}^{n}$ 'deri, gön; meyve kabuğu’ (OM ${ }^{\mathrm{MGT}}$ arasu, ${ }^{\mathrm{HY}}$ arasun, ${ }^{\mathrm{BY}}$ arasuçi, ${ }^{\mathrm{ME}}$ arasun, ${ }^{\mathrm{SL}}$ arāsun, ${ }^{\mathrm{iM}}$ arasu, ${ }^{\mathrm{RS}}$ arasun, ${ }^{\mathrm{PH}}$ aras, Hlh. apbc(aH), Ma. -) \| GT yarıg (< *yar) 'ince deri, ham deri'

$\mathrm{KM}$ arbay 'arpa' (OM ${ }^{\mathrm{HY}} a r b a i,{ }^{\mathrm{ZY}} a r[b a i],{ }^{\mathrm{BY}}$ arbai, ${ }^{\mathrm{ME}}$ arbai, ${ }^{\mathrm{SL}} a r p a,{ }^{\mathrm{RS}} a r p a,{ }^{\mathrm{PH}} \operatorname{arba}$, Hlh. арвай, Ma. arfa) || GT (h? arpa $^{34}$ 'arpa' (krş. Mac. árpa 'arpa')

KM arbiçi 'nahoş, can sıkıcı, sevimsiz, iğrenç, tiksindirici' (OM -, Hlh. арвич, Ma. -) || GT arvi 'şüphe, kuşku; kararsız'

KM arbis arvis 'bilgi, bilgelik' (OM -, Hlh. apвuc, Ma. -) \| GT arvış ‘büyü, sihir' (krş. Mac. orvos 'hekim')

$\mathrm{KM}$ arça 'ardıç (ağacl)' (OM ${ }^{\mathrm{MGT}}$ arça, ${ }^{\mathrm{HY}}$ arça, ${ }^{\mathrm{ME}}$ arçi, Hlh. apu, Ma. arça burga arşan burga 'büyük yapraklı söğüt') || GT artuç 'ardıç (ağacı)'

31 Kmk. harakl, Tar. haraki (VEWT 23).

32 Sözcük Türkmen Türkçesinde arış olarak kısa ünlülü görülse de GT hāra (Hlç. hāa ra) edatının farazî kökü *hār- 'aralamak, araya girmek' fiilinden $\{$-Xş\} türetme ekiyle türetilmiş olabilir.

33 Kelimenin kökeni hakkında tartışma için EDPT (239a) ve TMEN'e (II No. 454) bakılabilir.

34 SUyg. harwa hırwa biçimi, GT *harpa biçimine işaret etmektedir. 


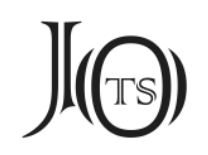

KM $\operatorname{arçi-~(<*arl.çı-~?~*arıtı-~?)~'kazımak,~silmek,~çıkarmak,~ayıklamak'~(OM~}$ ${ }^{\mathrm{MGT}} \operatorname{arçi-},{ }^{\mathrm{ME}} \operatorname{arçi-}{ }^{\mathrm{iM}} \operatorname{arçi-},{ }^{\mathrm{RS}} \operatorname{arçi-}{ }^{\mathrm{PH}}{ }^{\operatorname{arçi-}}$, Hlh. apuux, Ma. -) \| GT art- 'temiz olmak, temizlenmek' veya GT artt- 'temizlemek, silmek, ayıklamak'

KM arçila- (< *arıçıla-) 'bakmak, ilgilenmek' (OM ${ }^{\mathrm{MGT}}$ ariçi 'kurtarıcı', Hlh. арчлах, Ma. -) || GT arıçı ${ }^{35}$ 'şefaatçi, koruyucu', arıla ${ }^{36}$ 'müdahil olmak, şefaat etmek'

KM ardag 'deneyimsiz, beceriksiz, eğitilmemiş (at)’ (OM -, Hlh. apdaz, Ma. arda 'denenmemiş, yeni, acemi', Ma. ardashūn 'narin, kırılgan') || GT artak (< arta) 'harap, zayıf, güçsüz, kötü’

$\mathrm{KM}$ arg்-a 'araç, yol, vasıta; hile, düzen, oyun' (OM ${ }^{\mathrm{HY}}$ arqa calitan 'akıllı, aldatıcı, kurnaz', ME $\arg a,{ }^{\text {IM }}$ arǵa 'hile, çare', Hlh. apza, Ma. arga 'plan, yöntem, entrika') \| GT *arku 'araç' > GT arkula- ${ }^{37}$ 'aracıllk etmek', GT arkuçı ${ }^{38}$ 'aracı kişi'

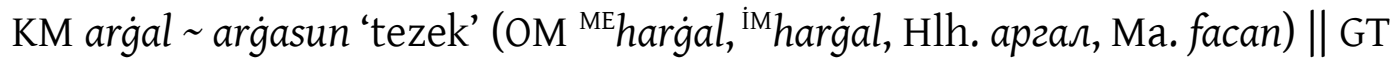
hark 'dışkı'

KM arǵali 'yaban koyunu, dağ koyunu' (OM ${ }^{\mathrm{RS}}$ arkar, Hlh. apzaль, Ma. argali) \| GT arkar 'dişi dağ keçisi, yaban koyunu'

KM arǵamag் (<*argu.mag $\left.{ }^{39}<* a r k u^{n}\right)$ 'saf kan at, soylu at' (OM -, Hlh. apzaмaz, Ma. -) || GT arkun 'yaban aygırı ile evcil kısraktan olan at, melez'

KM arǵul argaar 'yavaşça, sessizce' (OM ${ }^{\text {iM }}$ argil 'sakin', Hlh. -, Ma. -), KM alg̈ur alag̉ur 'yavaşça, sessizce, sakince' ( $\mathrm{OM}{ }^{\mathrm{HY}}$ alqur alu'ur, ${ }^{\mathrm{ME}}$ alg̀ü 'aheste', ${ }^{\mathrm{ME}}$ alg̀ūr 'ahestelik', ${ }^{\mathrm{RS}}$ algur, Hlh. aлzyyp, Ma. -) || GT akuru akru arkun 'yavaş, yavaşça'

$\searrow \mathrm{KM}$ arukan

KM arig 'arı, saf, temiz, berrak' (OM ${ }^{\mathrm{MGT}}$ Ariq Usun ‘yer adı', ${ }^{\mathrm{HY}}$ Ariq Bökö 'kişi adı', Hlh. apuz, Ma. -) \| GT arıg 'arı, saf, temiz, berrak'

\footnotetext{
35 EUyg. arıçı (UW 182).

36 EUyg. arıla- (UW Nb. I/1 70). Krş. Tel. Alt. Bar. Osm. Tat. arala- 'korumak, kurtarmak' (R I 254).

37 EUyg. arkula-, DLT argūla-.

38 DLT arkuçı.

39 Mo. *argumag $\rightarrow$ UÇS argumak 'bir tür at', YUyg. argumak 'soylu at'.
} 


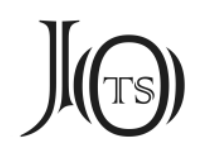

KM arizun ( $<*$ arı.gun < arı-) 'temizlik, saflık, arılık, iffet; temiz, arı, saf; iffetli, günahsız; kutsal' (OM ${ }^{\mathrm{HY}}$ ari'un, ${ }^{\mathrm{ME}}$ ari'ūn ariyūn, ${ }^{\mathrm{IM}}$ ari'ūn, ${ }^{\mathrm{SL}}$ arun, ${ }^{\mathrm{RS}}$ ariyun ${ }^{40},{ }^{\mathrm{PH}}$ ari'u:i, ${ }^{\mathrm{PH}}$ ari' 'u:l 'kutsal', Hlh. ариун, Ma. -) || GT art- 'temiz olmak, temizlenmek'

KM aril- 'temizlenmek, arınmak; yok olmak, kaybolmak; (hava) açmak' (OM ${ }^{\mathrm{MGT}}$ aril-, ${ }^{\mathrm{BY}}$ aril-, Hlh. apuлax, Ma. -) \| GT arl- 'arınmak'

KM (k.ö.) arḳand (Less.) arḳad 'dünya zevklerinden vazgeçmiş bir kişi' (OM -, Hlh. apxad, Ma. arhat) || GT (EUyg.) arhant 'saygıdeğer, kutsal (kişi), aziz, rahip, peygamber' $\left(\leftarrow\right.$ Soğd. 'r' $\gamma^{\prime}$ 'n arhan 'arhat, Buda'nın unvanı' $\leftarrow$ sk. arhat 'değerli, muhterem, saygıdeğer; övülen, hayranlık duyulan; hâlâ Nirvāṇa'ya aday olan bir Buda')

$\mathrm{KM}$ arsalan arslan 'aslan' (OM ${ }^{\mathrm{MGT}}$ arslan, ${ }^{\mathrm{HY}}$ arslan, ${ }^{\mathrm{ZY}} a[r]$ slan, ${ }^{\mathrm{BY}} \operatorname{ar}(a)$ salan, ${ }^{\mathrm{ME}-}$ arslan, ${ }^{\mathrm{iM}}$ arslan, ${ }^{\mathrm{TA}}$ arslan, ${ }^{\mathrm{RS}}$ arslan, ${ }^{\mathrm{NK} 1}$ arslan, ${ }^{\mathrm{NK} 2}$ arslān, ${ }^{\mathrm{PH}}$ arslan, Hlh. арслан, Ma. arsalan, Ma. erselen) || GT arslan ‘aslan' (krş. Mac. oroszlán ‘aslan')

KM arsi risi 'bilge, keşiş' (OM -, Hlh. apu, Ma. -) \| GT (EUyg.) arji erşi erji rşi riji 'kâhin, doğaüstü varlık, keşiş, ölümsüz kişi' ( $\leftarrow$ Soğd. rz’y rš’k 'kâhin' [Bailey 1950: 405-406] $\leftarrow$ Prakrit *rijaya- < Sk. rși 'kâhin, bilge')

KM arug 'ark' (OM -, Hlh. -, Ma. -) \| GT ārık 'irmak, ark, su yolu, kanal' (krş. Mac. árok ‘su yolu, ark, hendek')

KM arukan 'yavaş; ağırca, yavaşça' (OM -, Hlh. -, Ma. -) || GT arkun 'yavaşça, sessizce'

$\searrow \mathrm{KM}$ arg்ul arǵar, KM alg̈ur alag்ur

KM arur- $a$ 'dericilikte ve boya işlerinde kullanılan helile ağacının meyvesi' (OM -, Hlh. apyp, Ma. -) \|| GT (EUyg.) arire arure āririy 'bir ilaç adı' $(\leftarrow$ Soğd. 'rwr(h) arwar, arurā 'tıbbi bir bitki', Toh. B arirāk 'kara halile (Terminalia chebula Retz.)' $\leftarrow$ Sk. haritakī 'sarı halile ağacı, Terminalia chebula')

40 Sözcük, ariwun olarak da okunabilir. 


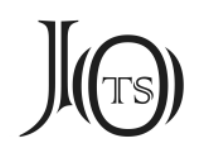

KM asa- '(bir şeye) asılmak, yapışmak' (OM ${ }^{\mathrm{MGT}}$ asa- 'bacaklarını açarak durmak', Hlh. acax, Ma. fasi- '(kendini) asmak; (bir şeye) asılmak, yapışmak, tırmanmak') || GT has- hās-41 'asmak, takmak, bağlamak'

KM asaman 'monorşid, tek testisi olan; büyüdükten sonra iğdiş edilen hayvan; asi, azıll, serkeş' (OM -, Hlh. aсмaн, Ma. -), KM asamag̀ (<asama.g்) 'iğdiş yaban domuzu' (OM -, Hlh. acmaz, Ma. -) \|| GT azma azman āzmān 'iğdiş, kısırlaştırılmış; büyük, iri yarı, güçlü, kuvvetli; iğdiş koç veya aygır; dört yaşındaki koyun'

KM asanki asangki asanggi 'sayısız' (OM -, Hlh. -, Ma. asanggi 'yüz katrilyon, sayısız, sonsuz') || GT (EUyg.) asanke 'Asaṃkhyeya çağı, sayılamayacak kadar uzun bir devir; sayısız, çok sayıda, pek çok' ( $\leftarrow$ Toh. A asaṃkhe asaṃkhye 'hesaplanamaz bir süre, muazzam uzun bir dönem' veya Soğd. "s" ${ }^{\prime k} \bar{a} s \bar{a} k \sim$ "s'nk āsānk 'sayısız' $\leftarrow$ Sk. asaṃkhyeya 'sayısız, hesaplanamaz, çok büyük bir sayı')

KM asar 'büyük çadır, otağ; kule, çan kulesi, burç, köşk, süslü hafif yapı' (OM -, Hlh. acap, Ma. asari 'kule, taht odası, arşiv') || GT (EUyg.) isırka 'saray, kule' (krş. CC astr 'düğün')

KM asig̈ 'yarar, kazanç, kâr, çıkar' (OM ${ }^{\mathrm{ME}}$ asik, ${ }^{\mathrm{i} M}$ asig, ${ }^{\mathrm{i} M}$ asġan 'kazanç, mutluluk', Hlh. auuz, Ma. aisi) || GT asıg (<as-) ‘yarar, kazanç, kâr, çıkar’

KM (k.ö.) asuri' 'As 'Asura, dev' (OM -, Hlh. acyypь, Ma. asuri) \| GT (EUyg.) asure 'iblis, dev, bir şeytan sınıfının adı' ( $\leftarrow$ Toh. B asūre 'iblis, şeytan' $\leftarrow$ Sk. asura 'kötü ruh, iblis, hayalet, tanrıların düşmanı')

KM asuru 'pek, çok, pek çok' (OM -, Hlh. acap, Ma. asuru) || GT aşru 'pek çok, aşırı derecede'

KM ata" 'iğdiş deve' (OM -, Hlh. am(aн), Ma. -) || GT atan 'iğdiş deve'

KM atar 'bakir toprak, işlenmemiş veya nadasa bırakılmış tarla' (OM -, Hlh. amap, Bur. amap, Ma. -) || GT atız 'sulama çukuru; suyun iki yanı arasındaki dar toprak parçası' (krş. PP * Jdas 'tarh, iki evlek arasındaki toprak parçası' $\leftarrow$ BT *adas $\leftarrow \mathrm{GT}^{*}$ adaz < GT atız)

${ }^{41}$ DLT ās-, Tkm. as-, Hlç. has-.

${ }_{42}$ Lal. 6b, 24a, Bod. 19a. 


\section{J(৫)}

KM (k.ö.) ay-a $a^{43}$ 'aya, avuç içi' (OM -, Hlh. -, Mgr. aya $\dot{g} \sim$ xaya $\dot{g} \sim$ xaya [Nugteren 2011:351], Dong. xziya [Nugteren 2011: 351], Kgc. xaya, Ma. -) || GT hāya $a^{44}$ 'aya, avuç içi'

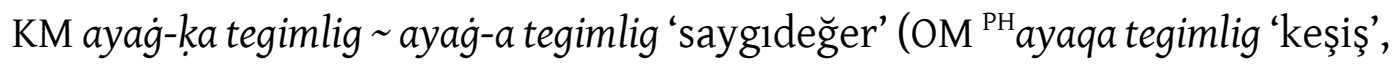
Hlh. -, Ma. -) || GT ayagka tägimlig 'saygıdeğer'

KM ayag்- $a^{n}$ 'kâse, tas, çanak' (OM ${ }^{\mathrm{MGT}}$ ayaqa, HY ayaqa, ${ }^{\mathrm{ZY}} a<y>y a q a,{ }^{\mathrm{ME}}$ ayag்a, ${ }^{\mathrm{im}}$ ayaġa, ${ }^{\mathrm{TA}}$ ayaka ${ }^{\mathrm{RS}}$ ayaǵa, ${ }^{\mathrm{PH}}$ ayiqa, Hlh. asza(H), Ma. -) \| GT ańak (<ańa $\left.{ }^{45}\right)$ 'kap, kupa, kadeh, kâse'

- Kit. 阿札割只 $\bar{a}$-zhá-gē-zȟ̌ *acagaçi 'bir unvan'46 (Wittfogel-Fêng 1949: 432, 442, 476; Menges 1953: 73) (krş. KM ayaġaçin 'hizmetçi', OM \$̊ ayaḳaçi 'hizmetçi', ${ }^{\mathrm{RS}}$ ayakaç̧i 'saki', Hlh. aszau 'hizmetçi')

KM ayiburçi 'konuşkan kişi' (OM ${ }^{\mathrm{ME}}$ ailbura ${ }^{-47}$, Hlh. aŭвapu, Ma. -), KM ayiburla- 'çok konuşmak' (OM -, Hlh. айварлах, Ma. -) || GT hāyl- 'söylemek, demek' (krş. ET ayl-k'söz’)

KM (k.ö.) ayig̈uçi48 '(dinî) danışman' (OM -, Hlh. -, Ma. -) \|| GT ayguçı 'hakan adına emir veren, sözcü; bakan, vekil, din temsilcisi’

KM ayil (<*ayl <*agl) 'aile, ev halkı, yerleşke, köy' (OM ${ }^{\mathrm{MGT}}$ ayil, ${ }^{\mathrm{ZY}}$ ai $[1],{ }^{\mathrm{BY}}$ ayil, Hlh. aŭл, Ma. -) || GT agıl āglt 'agıl' (krş. Mac. ól 'domuz ahırı, köpek kulübesi, kümes', Far. غَāǵil 'ağıl')

- Tabg. 屋引 wū-y̌ñ ${ }^{50}$ *agyIl / *agil 'ev' (Shimunek 2017a: 326), Kit. 瓦里 wălǐ *hwal 'kabile birimi' (Wittfogel-Fêng 1949: 226, 430, 432)

43 Lal. 49b.

44 Tkm. àya, SUyg. xaya xayan.

45 krş. Dolg. ańa 'ağız'.

46 Wittfogel-Fêng (1949: 432) ve Menges (1953: 73), bu unvanı GT açkuçı (< açku+çı) 'hazinedar' olarak yorumlamaktadır.

47 Bu fiil, ME'de ailburaksan kelen = Çă̆. til olarak geçmektedir.

48 Turf. 69a1.

49 DLT agll, Tkm. ägll, Hlç. ayll $(\leftarrow$ Az.).

50 EKBÇ *?ok-in (Coblin 1994: 361-362, 453). 


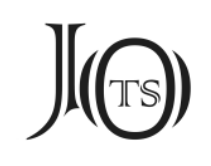

$\mathrm{KM}$ ayirag் 'kımız' ( $\mathrm{OM}{ }^{\mathrm{HY}}$ ayiraq, ${ }^{\mathrm{BY}}$ aira[q], Hlh. aŭpaz, Ma. ayara 'ekşi süt, ayran', Şib. ayaran 'ekşi süt, yoğurt') || GT ayran 'ayran', BT *ayran 'ayran' (> Çuv. uyran) (Çer. yôra 'ayran' $\leftarrow$ Çuv. *yıra < BT *irag) (krş. Mac. író 'ayran' $\leftarrow$ BT *irag) (krş. Çin. 酪 lào EÇ *râk ‘mayalı koyu sıvı, yoğurt, ekşi süt, kımız' [Schuessler 2007: 345])

KM ayu- ayi- 'korkmak, ürkmek' (OM ${ }^{\mathrm{MGT}}$ ayu-, ${ }^{\mathrm{HY}}$ ayu-, ${ }^{\mathrm{ME}}$ ai-, ${ }^{\mathrm{TA}}$ ayu-,${ }^{\mathrm{i}}{ }^{\mathrm{M}}$ aya-, ${ }^{\mathrm{im}}$ ayūla- 'tehdit etmek', ${ }^{\mathrm{RM}}$ ai-, ${ }^{\mathrm{PH}}$ ayi- $\sim$ ayu-, Hlh. aюyx $\sim$ aŭx, Ma. -$)$, KM ayidasu ${ }^{n}$ 'korku, üzüntü, dehşet' || GT ayın- ( < *ań-ın-) 'korkmak', GT ańıt- ${ }^{51}$ 'korkutmak, tedhiş etmek' (Çer. oyem oya 'korkmak, ürkmek' $\leftarrow$ Çuv. *oyă- < BT *ayl-) (krş. Mac. ijeszt 'korkutmak', Mac. ijed 'korkmak, ürkmek')

- Kit. * 〈ai〉 *ayi- 'korkmak' (Róna-Tas 2017: 143).

\footnotetext{
${ }^{51}$ BK D 41 ańtt-, ŞU D 8 aylt- (Şirin 2008).
} 


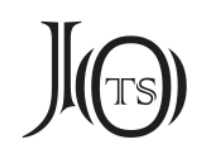

\section{B}

KM bacu- 'bastırmak, ezmek, sıkmak' (OM -, Hlh. бaзax, Ma. -) \| GT *baz- > GT bazgan 'büyük çekiç’, GT baz(g)u ${ }^{52}$ 'oklava' (krş. Mac. buzogány 'sopa, topuz, gürz, su kamışı')

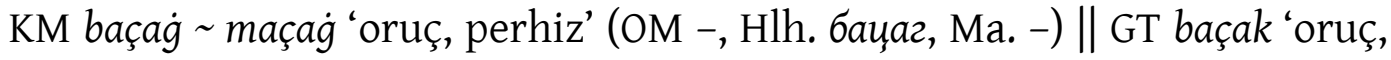
perhiz' $(? \leftarrow$ Soğd. p’ş pāş 'oruç')

KM baçim (<*batı.m) 'acele, tez, çabuk' (OM -, Hlh. бaчuм, Ma. -) || GT bat (? $\left.b \bar{a} t^{53}\right)$ 'çabuk, derhal, hemen'

KM badag 'dörtlük, kıta, bent; cümle, paragraf' (OM -, Hlh. бadaz, Ma. -) || GT (EUyg.) padak 'mısra, dize, şiir; söz, deyiş' $\left(\leftarrow\right.$ Soğd. p’ ${ }^{\prime} \mathrm{k}$ 'yasa, kanun' $\leftarrow$ sk. pādaka 'herhangi bir şeyin çeyreği')

KM badar badir badr-a 'sadaka kâsesi' (OM -, Hlh. бadap, Ma. badar badiri) \| GT (EUyg.) patır 'kâse, tas, dilenci kâsesi' ( $\leftarrow$ Soğd. p’tr 'sadaka kâsesi' [Reck 2016: 424] veya Toh. A pātär 'sadaka kâsesi' $\leftarrow$ sk. pātra 'kâse')

KM badm-a 'lotus, nilüfer' (OM -, Hlh. бadмa, Ma. batman 'lotus çiçeği desenli süsleme') || GT (EUyg.) padma padm-a 'nilüfer' ( $\leftarrow$ Sk. padma 'lotus, lotus deseni')

KM (k.ö.) badman 'ağırlık birimi’ (OM IM batma[n] 'yaklaşık bir kilogramlık

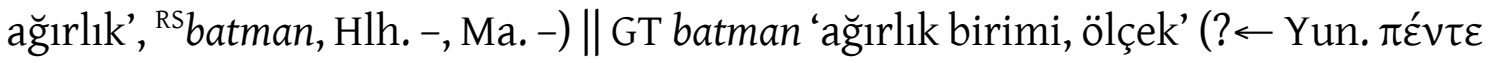
$\mu \nu \tilde{\alpha}$ 'beş mina (ağırlık birimi)', Far. هن man 'ağırlık birimi')

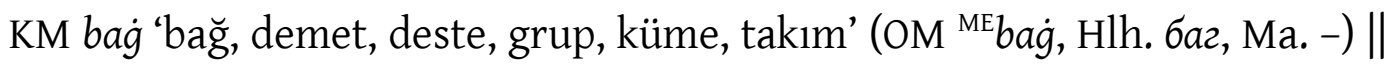
GT bāg 'bă̆, demet; birleşik boylar'

KM baġsi ‘hoca, öğretmen' (OM ${ }^{\mathrm{HY}}$ baqşi, ${ }^{\mathrm{BY}} b a[q] s ̧ i,{ }^{\mathrm{PH}}$ baqşi, Hlh. бazu, Ma. baksi) || GT bagşı 'hoca, öğretmen' ( $\leftarrow$ Çin. 博士 bó-shi ‘saray hocası')

KM baġta- 'sı̆ğmak' (OM MGT bagta'alda-, ${ }^{\text {ME} b a k t a-, ~ H l h . ~ б a z m a x, ~ M a . ~ b a k t a-~ ' i c ̧ e r-~}$ mek, kapsamak', Evk. bat- bati-, Sol. bakta- batta-, Neg. bat- bati-) $\|$ GT bat- (?<

\footnotetext{
52 Kİ bazu 'oklava'.

${ }^{3}$ Tkm. bādına ve Tkm. bāda-bat biçimleri uzun ünlüye işaret ederken, Osm. batun sözcüğü aksini göstermektedir.
} 


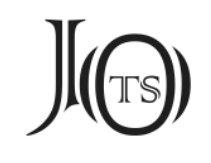

*bakta-) 'batmak, içine girmek, sığmak', BT *bat- 'batmak, gömülmek' (> Çuv. put, pıtan-, pıtar-) (krş. PS *pôt- 'dalmak, batmak')

KM baya - $^{54}$ (< *baga- < *boka-) 'dışkılamak, (bağırsak) hareketlenmek' (OM

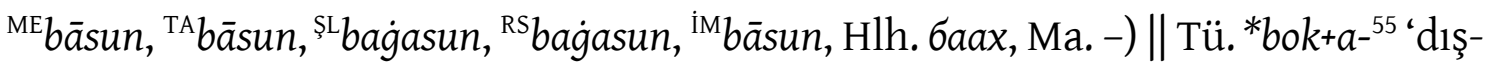
kılamak'< GT bok ( bōk $\left.{ }^{56}\right)$ ‘bok, dışk1; küf', BT *bok 'dışk1, gübre; cüruf, metal küfü; kulak pisliği' (> Çuv. păh)

$\searrow \mathrm{KM}$ bog், KM boki

KM bayala- bala- '(yara) kabuk bağlamak; iltihaplanmak' (OM -, Hlh.

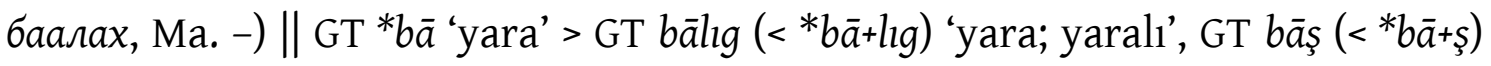
'yara', GT balık- (?<*baş+ık-) 'yaralanmak'

KM bayatur 'kahraman, cesur' (OM ${ }^{\mathrm{MGT}} b a$ 'atur, ${ }^{\mathrm{HY}} b a$ 'atur bātur, ${ }^{\mathrm{ME}} b \bar{a} d u r,{ }^{\mathrm{TA}} b a-$

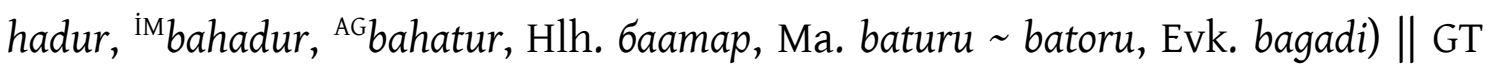
bagatur $^{57}$ batur 'bahadır, yiğit, kahraman' (Çuv. pattăr 'kahraman; kuvvetli, güçlü' $\leftarrow$ Tat. batır 'bahadır') (krş. Mac. bátor 'cesur', Far. بهادر bahādur 'kahraman, yiğit') (? * twir [Beckwith-Kiyose 2018: 154])

KM bak-a 'kurbağa' (OM NK1 baka, ${ }^{\text {NK2} b a ̄ k a, ~ H l h . ~ б a x, ~ M a . ~-) ~|| ~ G T ~ b a ̄ k a ~ ' k u r b a g ̆ a, ~}$ kaplumbağa' (krş. Mac. béka 'kurbağa')

KM bakayu bakau bakuu (< *bakagu) 'guatr' (OM -, Hlh. бaxyy, Ma. -) || GT bokok(l) $)^{58}$ 'guatr, boğaz, damağın altı, (kuşta) kursak; ağaçlı dallı budaklı büyüme; gonca'

54 ŞL baǵasun 'dışkı' ve RS (199B2) baġasun 'insan dışkısı' sözcükleri bag̉a- şekline işaret etmektedir. Ayrıca, SUyg. $p^{h} a q a-\sim p a q a-$ 'dışkılamak' fiili de kaynağı belirsiz bir alıntı olarak Mo. *baka- biçimine işaret etmektedir. Tü. /k/: Mo. /y/ ve Tü. /o/: Mo. /a/ ses denkliklerinin -nadir de olsa- örnekleri mevcut-

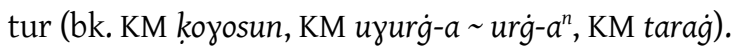

55 DLT'de bu anlamda bokla- sözcüğü kullanılmaktadır.

56 Ünlü uzunluğu sadece DLT'de tanıklanmıştır.

57 /g/'li biçim, yalnızca Or. 8212/77 numaralı yazma parçasında özel isim olarak görülmektedir: b(a)gatur çigşi (Yıldırım et al. 2013: 471-472).

58 EUyg. bokok, DLT bokak bokuk, Çăg. bukak bugak (R IV 1802, 1806), Kİ bogag, BM bogagı, KK bogak, Kzk. bugak (R IV 1805), Kırg. bokok bogok, Alt. bogok, Hak. poğo, Tel. pogok. 


\section{J(৫)}

KM bal 'bal' (OM ${ }^{\mathrm{BY}} b a l,{ }^{\mathrm{ME}} b a l,{ }^{\mathrm{iM}} b a l$, Sू $b a l,{ }^{\mathrm{RS}} b a l$, Hlh. 6aл, Ma. -) \| GT bāl bal 'bal', BT *bal veya *bāl 'bal' (> Çuv. pll)

KM balçig ‘balçık, batak, çamur’ (OM MEbalçik, Hlh. бaлчuz, Ma. -) || GT balçık 'çamur, balçık, bataklık' (krş. Mac. balkány 'çamurlu yer, bataklık')

KM balçir (<*baltır) 'bebek, çocuk, genç’ (OM -, Hlh. бaлчup, Ma. -) \| GT (DLT) baldır 'ilgili dönemin en başında gerçekleşen' (krş. Alt. baldar 'çocuklar')

KM balçirǵan-a baldargan-a 'baldıran otu' (OM -, Hlh. балчиргана, Ма. -) II GT baldırgan baltırgan 'baldıran otu', BT baltırgan 'tavşancıl otu' (> Çuv. pultăran pultran) (krş. Mac. bojtorján 'dulavrat otu, Arctium')

KM balġasun (< *balaka) 'şehir, kasaba' (OM ${ }^{\mathrm{MGT}}$ balaqasu(n), ${ }^{\mathrm{HY}}$ balaqasun, ${ }^{\mathrm{ZY}}$ balaqasun, ${ }^{\mathrm{BY}}$ bal[g]asun, ${ }^{\mathrm{ME}}$ balgasun balkasun, ${ }^{\mathrm{TA}}$ balkasun, ${ }^{\mathrm{S} L}$ balakasun, ${ }^{\mathrm{i} M}$ balgasun, ${ }^{\mathrm{RS}}$ balaġasun, ${ }^{\text {PH} b a l a q a s u n, ~(c ̧ o g ̆ .) ~ b a l a q a d, ~ H l h . ~ б a л z a c, ~ M a . ~-) ~ \| ~ G T ~ b a l ı k ~ ~ ~ b a ̄ l l k ~ ' s ̧ e h i r ' ~}$

KM balg̀ ‘'lgın ağacı' (OM -, Hlh. балгана, Ma. -) || GT balgun '59 ‘'lgın ağacına benzeyen bir çalı'

KM baling (< *bali.y) 'tanrılara sunulan yiyecek' (OM -, Hlh. бaлuн, Ma. -) \| GT (EUyg.) bali 'kurban, haraç, bağış’ ( $\leftarrow$ Sk. bali ‘adak, kurban, bağış; yemek sunusu')

KM balta 'balta' (OM -, Hlh. бasm, Ma. -) \| GT baltu (? balto) baldu (? baldo)

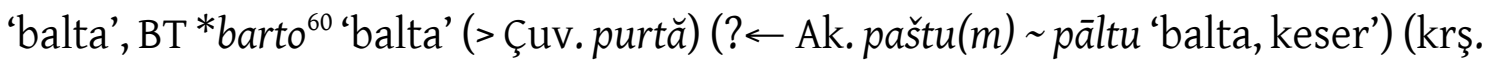
Mac. balta 'balta')

KM (k.ö.) bançaki' (I) ‘beş kişiden oluşan’ (OM -, Hlh. -, Ma. -) \| GT (EUyg.) pançike 'beşten oluşan' $(\leftarrow$ ? $\leftarrow$ Sk. pañcaka 'beşten oluşan, beşten yapılmış, beşlik bir grup')

59 DLT bolguna malguna, Kirg. balgun, YUyg. malgun (Shaw 1878: 226).

60 BT *barto (> Çuv. purtă) biçimi, GT balto sözcüğüne -r- : -l- denkliği yüzünden bire bir uymamaktadır ve bu nedenle soydaşlıkları şüphelidir. Poppe (1953), Genel Türkçe sözcükten ayrı tuttuğu Bulgar Türkçesi sözcügü EFar. *paraӨu- 'balta' biçiminden bir alıntı olarak değerlendirmektedir.

61 Lal. 34a, 41a, 42b. 


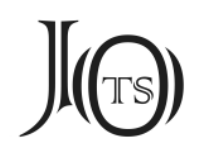

KM (k.ö.) bançaki ${ }^{62}$ (II) ‘bir Yakșa'nın adı' (OM -, Hlh. -, Ma. -) \|| GT (EUyg.) pançike 'bir Yakșa'nın adı' $(\leftarrow$ ? $\leftarrow$ Sk. Pãñcika 'bir Yakșa'nın adı')

KM bandida 'bilgin, âlim, hoca' (OM -, Hlh. бандид, Ma. bandi) || GT (EUyg.) pandit pandida 'bilgin, âlim, çok bilgili' ( $\leftarrow$ Sk. paṇdita 'bilgin, âlim, eğitimli kişi, hoca, filozof')

KM baramanu 'en küçük toz zerreciği; atom, molekül' (OM -, Hlh. -, Ma. -) || GT (EUyg.) paramanu 'atom, zerre, parçacık' ( $\leftarrow$ Toh. A/B paramāṇu paramānu 'atom' $\leftarrow$ Sk. paramāṇu ‘sonsuz küçük bir parçacık veya atom')

KM barinirvan 'tam nirvana veya tamamen yok olma' (OM -, Hlh. -, Ma. -) $\|$ GT (EUyg.) parinirvan 'tam nirvana, eksiksiz nirvana' ( $\leftarrow$ Soğd. prnnyr $\beta^{3} n$ parnirvān 'kurtuluş' $\leftarrow$ Sk. parinirvāna 'tam nirvana, eksiksiz nirvana')

KM barkira- 'bağırmak, böğürmek' (OM -, Hlh. бapxupax, Ma. -) || GT bākırbakra- 'bağırmak, haykırmak'

KM (k.ö.) barman ${ }^{63} \sim$ (Less.) biraman 'Brahman' (OM -, Hlh. бярман, Ma. -) \| GT (EUyg.) braman ‘Brahman' ( $\leftarrow$ Toh. A brāmaṃ brāhmaṃ prāmaṃ prāhmaṃ

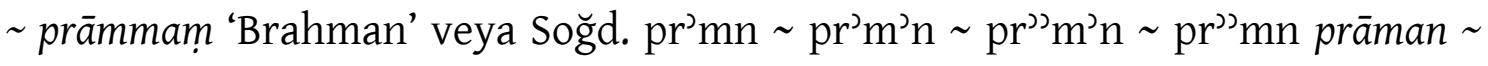
brāman b/prăman 'Brahman' $\leftarrow$ Sk. Brāhmaṇa 'tanrısal bilgiye sahip olan, Brahman')

KM bars bers 'kaplan, pars' (OM ${ }^{\mathrm{MGT}}$ bars barus, ${ }^{\mathrm{HY}}$ bars, ${ }^{\mathrm{BY}} \mathrm{ba}[r] \mathrm{s} /$ bar, ${ }^{\mathrm{ZY}}$ bars, ${ }^{\mathrm{ME}}$ bars, ${ }^{\mathrm{IM}}$ bars, ${ }^{\mathrm{TA}}$ bars, ${ }^{\mathrm{SL}}$ pars, ${ }^{\mathrm{RS}}$ bars, ${ }^{\mathrm{NK} 1}$ arslan, ${ }^{\mathrm{AGT}}$ pars, ${ }^{\mathrm{PH}}$ bars, Hlh. бap бapc, Ma. -) || GT bars 'pars, leopar'

KM basa 'sonra, yine, tekrar, daha' (OM ${ }^{\mathrm{MGT}}$ basa, ${ }^{\mathrm{HY}}$ basa, ${ }^{\mathrm{ME}}$ basa, ${ }^{\mathrm{iM}}$ basa, ${ }^{\mathrm{S}}{ }^{\mathrm{L}} \mathrm{b}$ basa,

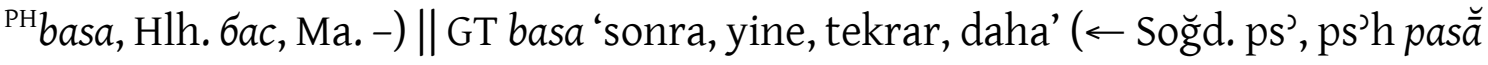
'sonra, sonradan, diğer taraftan')

- Kit. 丹冬〈b.as〉 *bas 'tekrar, sonra, ondan sonra' (Kane 2009: 82; Shimunek 2017a: 327; Ōtake 2017: 202; Wu-Róna-Tas 2019: 55)

\footnotetext{
62 Lal. 15a.

63 Bod. OS I/8b 12.
} 


\section{J(G)}

KM basal-a 'hâlâ, yine, tekrar, sonra da' (OM -, Hlh. -, Ma. -) \| GT (KB 484) basala 'sonra'

KM (k.ö.) basar ${ }^{64}$ '(basar balgasun ikilemesinde) saray; pazar' (OM MEbazar, Hlh. -, Ma. -) || GT bāzār ${ }^{65}$ 'çarşıı, pazar' ( $\leftarrow$ Far. باز bāzār 'pazar, market')

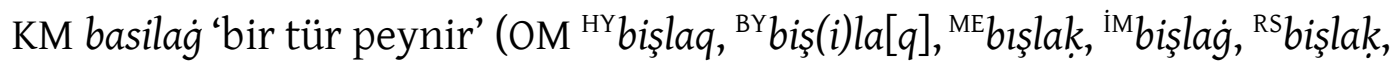
Hlh. бяшлаг бяслаг, Ma. -) || GT (OTi) bışlak 'bir tür peynir'

KM basu- 'aşağılamak, hor görmek, önemsememek' (OM -, Hlh. бacax, Ma. basu- 'alay etmek') || GT bas- 'basmak, bastırmak, baskın yapmak, alt etmek, yenmek, aşağılamak' (krş. Mac. baszik 'sikmek')

KM bayan 'zenginlik, bolluk; zengin, varlıkl1' (OM ${ }^{\mathrm{MGT}}$ baiyan, ${ }^{\mathrm{HY}}$ bayan, ${ }^{\mathrm{ME}} b a-$

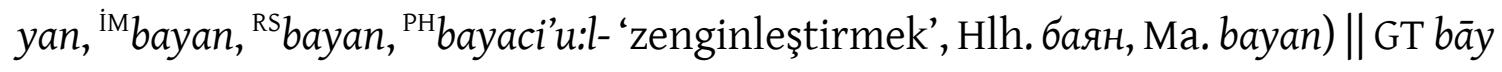
'zengin, varlıklı', BT *bāyl- 'zengin olmak' (> Çuv. puy-) (krş. PY [W] *bajay 'çok')

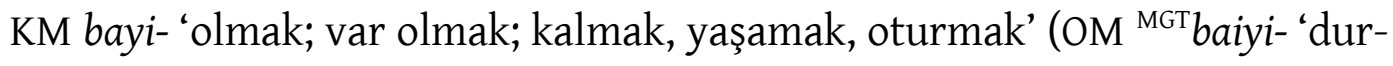

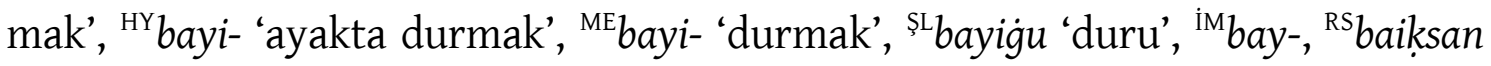
'ayakta', ${ }^{\mathrm{PH}}$ bayi-, Hlh. бaŭx, Ma. -) \| GT bār ( $\left.<^{*} b \bar{a}-\right)$ 'var, mevcut', BT *bār 'var, mevcut' (> Çuv. pur)

- Kit. 可 〈bai〉 (?) 寸 〈bai $\left.{ }_{2}\right\rangle$ (?) ‘hareketsiz kalmak, durmak' (Kane 2009: 4142, 8766; Wu-Róna-Tas 2019: 57-58)

KM bayidasu ${ }^{n} \sim$ bayitasu $^{n}$ (< *bayttal.sun) 'henüz yavrulamamış üç-dört yaş arası hayvan, kısır' (OM -, Hlh. бaŭdac, Ma. -) || GT (OTi) baytal 'kısrak'

KM bayiġal ‘Baykal gölü’ (OM -, Hlh. бaŭzaл, Hmg. Baigul [Janhunen 1996], Ma. -) || GT *bāy+kȫl' 'zengin göl'

$\mathrm{KM}$ beçi ${ }^{n} \sim$ biçi $i^{n} \sim$ meçi $i^{n}$ 'maymun' (OM ${ }^{\mathrm{HY}}$ beçin, ${ }^{\mathrm{BY}}$ beçin/böçin meçin/möçin, ${ }^{\mathrm{ME}}$ beçin, ${ }^{\mathrm{SL}}$ piçin, ${ }^{\mathrm{RS}}$ biçin, ${ }^{\mathrm{NK}} 1$ becin, ${ }^{\mathrm{PH}}$ beçin biçin, Hlh. мэч(uн) бич(uн), Ма. -) \| GT

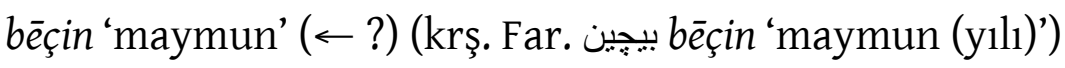

\footnotetext{
64 Lal. 15b13, 32b3.

65 Sözcük, Türkçede ilk olarak Karahanlı Türkçesinde tanıklanmıştır: TíEM 73 bāzār, Tefs. bazar.

66 Kane 2009, ilgili karakterleri 〈kẻ` olarak okumaktadır.

67 krş. Yak. bayzal 'deniz, okyanus', Dolg. baygal 'deniz; nehir, akarsu'.
} 


\section{J(৫)}

KM beder bider 'hayvanların derisindeki çizgiler, lekeler, benekler; süs, süsleme; metal, taş ya da ahşap üzerine kazınmış desen' (OM -, Hlh. бudəp, Ma. bederi, Şib. biter '(derideki) lekeler') || GT bädiz 'süs, süsleme, bezek'

KM (k.ö.) bedüyün büdüyün (Less.) büdüyün bidüyün (<*bedü.gün) 'geniş,

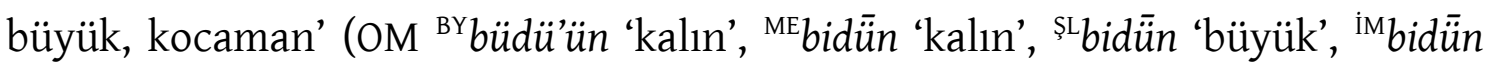

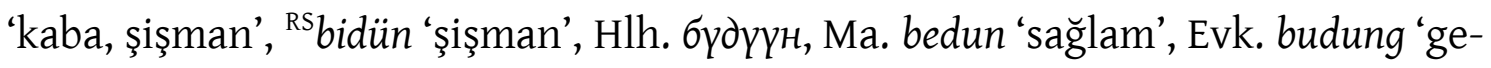
niş’) || GT bädü- 'büyümek; artmak, çoğalmak'

KM beke 'mürekkep' (OM ${ }^{\mathrm{HY}}$ beke, ${ }^{\mathrm{ZY}}$ beke, ${ }^{\mathrm{ME}}$ beke, Hlh. бэx, Ma. behe) \| GT mäkä mäkkä 'siyah mürekkep' ( $\leftarrow$ Çin. 墨 mò 'mürekkep')

$\mathrm{KM}$ beki 'güçlü, sıkı, sağlam' (OM ${ }^{\mathrm{MGT}}$ bekile- 'müdafaa etmek', ${ }^{\mathrm{HY}}$ bekile- 'savunmada durmak', MEbekit- 'berkitmek', Hlh. бэx, Ma. beki) || GT bäk ‘sert, sağlam, sık1, pek'

KM bel 'bel' (OM ${ }^{\mathrm{ME}} b e l$, Hlh. бэл, Ma. -) \| GT bēl 'bel'

KM belçir 'çatal, kesişme noktası, kavşak' (OM ${ }^{\mathrm{MGT}}$ belçir 'koyak, nehir (ağzl)', MEbelçil 'otlak', Hlh. бәлчир билчир, Ma. -) || GT bältir bäldir 'iki veya daha fazla yolun veya nehrin kesiştiği nokta, kavşak'

KM (k.ö.) belder ${ }^{68} \sim$ bildar (?< *belte.r) ‘dış görünüş, fiziksel görünüş’ (OM -, Hlh. бялдар, Bur. beye belder, Kalm. bildr, bildrl - 'kendine has olmak, özel olmak', Ma. -) || GT bät ( * *bält ?) 'yüz, çehre, suret', BT *bät 'ön, yan, huzur' (> Çuv. pat) (Çuv. pit 'yüz, çehre' $\leftarrow$ Tat. bit 'yüz') (krş. Toh. A arämpāt 'görünüş, figür, güzellik', Toh. B erepate ‘şekil, biçim' < (aräm/ere+) PToh. *pāte ? $\leftarrow$ Sk. bhấti- 'ihtişam, 1 1̧ı')

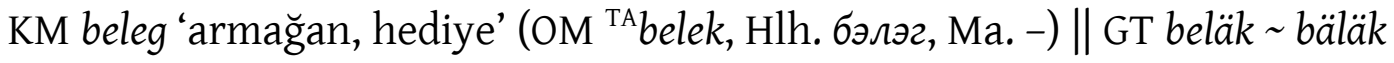
'armağan, hediye' (krş. KS в'kn'tr' 'hediye; işaret, simge')

KM beleng 'mühtehcen veya uygunsuz sözler; sıçrayan Fransız sendromu, Latah' (OM -, Hlh. билэн бәлэн, Ma. -) || GT bälig 'korku, endişe, panik'

68 HC 2a5 bey-e belder ‘boy pos, endam, fiziksel görünüş’. 


\section{$J(\Theta)$}

$\mathrm{KM}$ belge 'işaret, alamet, belirti; kehanet' (OM ${ }^{\mathrm{MGT}}$ belge, ${ }^{\mathrm{HY}}$ belge, ${ }^{\mathrm{ME}}$ belge, ${ }^{\mathrm{Rs}} b e l g e,{ }^{\mathrm{PH}}$ belge, Hlh. бәлэг, Ma. -) \|| GT bälgü (?<*bäl-69) 'işaret, alamet, belirti', BT *bälgü > *bälü 'işaret, alamet, belirti; mezar taşı' (> VB belü, Çuv. pală pallă $\left.{ }^{70}\right)(\mathrm{krşs}$.

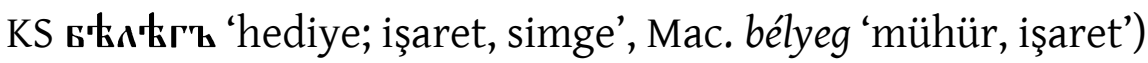

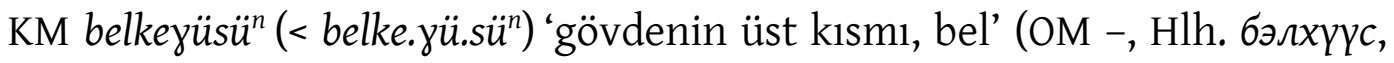
Ma. -) || GT bēl 'bel', BT *bēlik (<*bēl+ik) 'bel' (> Çuv. pilěk)

KM berbeyi- (<*berpe.yi-) 'ürpermek, üşümek, soğuktan uyuşmak; korkmak, ürkmek' (OM -, Hlh. бэрвийх, Ma. bere- 'korkudan veya öfkeden dili tutulmak, topal olmak') || GT bäz- 'titremek, sallanmak, korkmak, ürkmek, ürpermek'

KM ber-e 'bir uzunluk ölçüsü (yaklaşık iki kilometre)' (OM -, Hlh. бээp, Ma. ) || GT berä bärä 'uzunluk ölçüsü, mil' (?૯ Toh. A pär 'ok', Toh. B prere 'ok', Toh. A pärra-krase 'bir ok atımı mesafe')

$\mathrm{KM}$ beri 'gelin' (OM ${ }^{\mathrm{HY}}$ beri, ${ }^{\mathrm{ME}}$ beri, ${ }^{\mathrm{BY}}$ beri, ${ }^{\mathrm{zY}}$ beri, ${ }^{\mathrm{TA}}$ beri, ${ }^{\mathrm{RS}}$ beri, ${ }^{\mathrm{RM}}$ bari, Hlh. бəp, Ma. -) || BT *bēri (< bēr-) *'verilen bir şey’ (krş. Mac. bér 'yevmiye, ödeme, kira')

KM beriy- $e^{n}(<$ *berizen < berigen) 'destek, sopa, asa, baston; kamçının sapı' (OM ${ }^{\mathrm{MGT}}$ beri'e, ${ }^{\mathrm{IM}}$ beriye, ${ }^{\mathrm{SL}}$ bérie, ${ }^{\mathrm{RS}}$ berie, Hlh. бэрээ(н), Ma. berge) \| GT bärgä 'değnek, sopa, kamçı' (? $\leftarrow$ Tib. ber-ka 'sopa, değnek, baston')

$\mathrm{KM}$ berke 'güç, çetin, zor' (OM ${ }^{\mathrm{MGT}}$ berke, ${ }^{\mathrm{HY}}$ berke, ${ }^{\mathrm{ME}}$ berke, ${ }^{\mathrm{IM}}{ }^{\mathrm{B}}$ berke, ${ }^{\mathrm{RS}}$ berke 'zor; değerli', ${ }^{\mathrm{RM}}$ barkā 'pahalılık, maliyet', ${ }^{\mathrm{AG}}$ Berk'ēe, Hlh. бэрx, Ma. -) \| GT bärk 'sert, kat1, sağlam, kuvvetli’ (? $\leftarrow$ Toh. A prākär ‘sert, sıkı, güçlü, şiddetli’, Toh. B prākre 'sabit, sık1, sert, katı')

KM berseyüü (< *berse.ðü) 'sertlik, nasır, şişlik, tümör, yumru' (OM -, Hlh. бәрсүү, Ma. -) \|| GT bēz" ‘1 'bez, beze, gudde, yumru', BT *bä̈r 'bez, şişlik, ur' (> Çuv. par) veya GT bärç̧2 ‘bez, şiş, şişkinlik' (krş. Kzk. berişäk 'tümördeki yoğun irin’ [Budagov 1869: I/252]) veya GT (DLT) bars (? bärs) 'vücuttaki kabartı'

\footnotetext{
69 krş. Ma. bele- 'masum birine yanlış suçlamayla zarar vermek' (? * 'göstermek').

70 Çuv. palăk palkă 'işaret, alamet, belirti, eser, anıt' sözcüğ̈̈ ise Tatar Türkçesinden eski bir alıntıdır.

71 EUyg. bäz, DLT bēz, Tkm. mäz, Tuv. bes.

72 Tkm. berç, Alt. berç.
} 


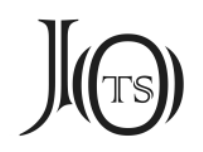

KM berte- 'yaralanmak, incinmek' (OM ${ }^{\mathrm{MGT}}$ berte- 'yaralamak', ${ }^{\mathrm{MGT}}$ mer 'yara', Hlh. бэртэх, Ma. berte- 'kirletmek') || GT bärt- (< *bär-t-) 'yaralamak, incitmek' veya GT bärt (<*bär-t) 'yara, yaralama' (krş. Mac. börtön 'hapis, hapishane')

KM bertegçin 'aptallık, cahillik; dar kafalı veya aydınlanmamış kişi; aptal, cahil' (OM -, Hlh. -, Ma. -) \| GT (EUyg.) pardagçan partagçan prtagçan 'basit insan, sıradan insan' $(\leftarrow$ ? $\leftarrow$ Sk. prthagjana '(Budizme inanmış) sıradan insan')

KM biba 'dört veya altı telli bir çalgı, lavta, gitar' (OM -, Hlh. -, Ma. -), KM (Bo.) bibalig 'bir tür gitar' (OM -, Hlh. -, Ma. -) \| GT (EUyg.) biba 'lavta, gitar' $(\leftarrow$ Çin. 琵琶 pípá ‘Çin lavtası')

KM biçi- (< *biti-) 'yazmak' (OM ${ }^{\mathrm{MGT}}$ biçi-, ${ }^{\mathrm{HY}}$ biçi-, ${ }^{\mathrm{ME}}$ biçi-, ${ }^{\mathrm{IM}}$ biçi-, ${ }^{\mathrm{RM}}{ }^{\mathrm{b}}$ biti--, ${ }^{\mathrm{PH}}$ biçi-,

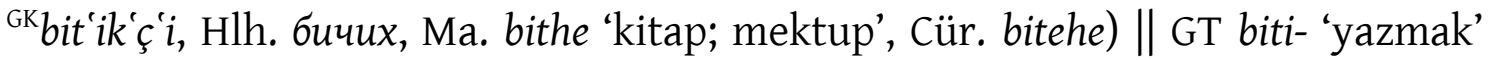
(krş. Mac. betü 'harf')

- Tabg. 比德眞 bì-dé-zhēn *bitigçin 'kâtip, yazman' (Boodberg 1936: 170, Bazin 1950: 300-301, Ligeti 1970: 298-302, Tekin 1993a: 25-26; Vovin 2007: 196, Shimunek 2017a: 156-157), Tabg. 拂竹眞 fú-zhú-zhēn *bitigüçin ${ }^{73}$ 'posta görevlisi' (Bazin 1950: 303)

KM biçil bisil 'küçük, kısa boylu' (OM -, Hlh. -, Ma. -) \| GT bäçäl ( beçäl) 'kötürüm, sakat, topal'

KM bila- (< *bıla-) 'sürerek kaplamak, sürmek, yaymak; kirletmek' (OM -, Hlh. бялах, Ma. -), KM bilça- (< *blla-ça-) 'her yere sürmek, bulaştırmak; çamura düşmek' (OM -, Hlh. бялu̧ax, Ma. bilça-), KM bilda- (< *bıla-da-) ‘sürmek, bulaştırmak, yaymak' (OM -, Hlh. бялдаx, Ma. -) || GT bış-75 'sürmek; kirletmek'

KM bilçuu (< *bịalça.gu) 'şişlik, kabarcık, çıban' (OM -, Hlh. бялuyy, ?Ma. bulcan 'derideki şişlik') || GT bāş (< *b(i)ālçă) 'yara, apse, çıban'

${ }^{73}$ Kelimenin Çince transkripsiyonu, *bitigüçin şeklinden ziyade *putugçin veya *pütügçin şekline işaret etmektedir.

74 EUyg. bäçäl, CC bäçäl, Kİ biçäl bäçäl, Krç-Blk. beçel, Trk. ağ. beçal beçll.

75 Yak. bis-, Dolg. bis-. DLT bis (bıs ?) 'tortu, katran gibi bir şey’ sözcüğü de *biş veya *bış olarak düzeltilip bu fiille ilişkilendirilebilir. Diğer yandan, Trk. pis 'kirli' sıfatı DLT'de geçen sözcükle soydaşsa /s/ ünsüzünü teyit eder niteliktedir. 


\section{$J(\Theta)$}

KM bileçüg bileçüg biliçeg bilüçeg büleçeg bülüçüg bilisüg 'yüzük' (OM мEbilezük, Hlh. бялжиг, Ma. -) || GT bilä(r)zök 'bilezik' (krş. KS в'Łл'ъчоугъ 'yüzük', Mac. bilincs 'pranga, köstek')

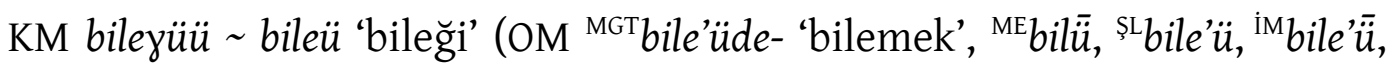
${ }^{\mathrm{RS}}$ bileü, Hlh. билүү, Ma. -) || GT bilägü 'bileği'

KM (k.ö.) bilge ${ }^{76}$ 'bilgelik' (OM ${ }^{\mathrm{MGT}}$ Bilge 'kişi adı', ME bilge 'bilgelik', Hlh. -, Ma. -) || GT bilgä 'âlim, bilge, bilgili kişi; bilgelik, hikmet'

KM (Shō.) bilge bilig belge bilig '(en yüce) bilgelik, içgörü, irfan' (OM -, Hlh. бэлэг билиг, Ma. -) || GT (EUyg.) bilgä bilig 'bilgelik, bilgi, manevi yetenek'

KM bilig 'akıl, zekâ, idrak; bilgi, bilim; Cengiz Kağan'ın özdeyişleri' (OM ${ }^{\mathrm{ME}} b i-$ lik, ${ }^{\text {PH }}$ bilig, Hlh. билиг билэг 'yetenek, kabiliyet', Ma. -) || GT bilig 'akıl, zekâ, idrak; bilgi, bilgelik, bilim; bilinç’

KM (k.ö.) bilirr7 'üflemeli bir çalgı' (OM -, Hlh. -, Ma. bileri 'sekiz delikli ve metal ağızlıklı üflemeli bir çalgı, sona') || GT (EUyg.) bilir 'flüt'

KM (k.ö.) bimba 78 'bir tür meyve' (OM -, Hlh. -, Ma. -) \| GT (EUyg.) bimba 'kırmızı meyve, yemiş' ( $\leftarrow$ Sk. bimba 'parlak kırmızı sukabakları veren bir bitki, Momordica Monadelpha')

KM binvad 'sadaka' (OM -, Hlh. -, Ma. -) || GT (EUyg.) pinvat ( pinpat pinput) 'sadaka' ( $\leftarrow$ Toh. A pinwāt (pintwāt, pimnnwāt) ‘sadaka' $\leftarrow$ Sk. pinḍapāta ‘sadaka olarak verilen yiyecek')

KM bir bigir 79 'yazı veya boya fırçası' (OM -, Hlh. бuŭp, Ma. fi, Cür. fi) \|| GT bir (? biri) 'yazı veya boya fırçası' ( $\leftarrow$ Çin. 筆 bǐ 'yazı firçası')

76 Turf. 81a11 ele küci eyin bilge surtaku aran elçi yabulbasu [...], Arc. III: 8-1 möngdel ügei ünen bilge-iyer tegüs nayirayulugssan burkan-u ulus-aça [...], Bod. OS I/8a 11-12 ker be dayunu bilge möngke ele bügesü.

77 Lal. 2b, 10b, 11a.

78 Lal. 28b, 61b.

79 Mo. bizir > biyir $\rightarrow$ Tuv. biyir 'firça'. 


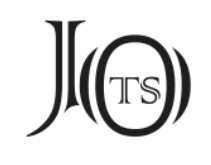

KM biraqu ' 'iki yaşındaki buzağı' (OM ${ }^{\mathrm{MGT}} b u r a^{\prime} u,{ }^{\mathrm{ME}} b u r a ' u \sim b u r \bar{u}$, Hlh. бяруy, Ma. -, Şib. boro 'buzağı') || GT bızagu ${ }^{80} \sim$ buzagu 'buzağı', BT *bıragu veya *buragu 'buzağı' (> Çuv. păru) (krş. Mac. borjú, Buruşaski biráġo [Rybatzki 2010: 154-155])

KM birid biriti ${ }^{81}$ 'aç ruh, açlık iblisi' (OM -, Hlh. бupd, Ma. birit 'canavar') || GT (EUyg.) pret 'aç ruh' ( $\leftarrow$ Toh. A pret ‘hayalet, kötü ruh, iblis, şeytan' veya Soğd. pr'yt pret 'aç ruh' $\leftarrow$ Sk. preta 'ölü, müteveffa; ölü bir kişinin ruhu; hayalet, kötü varlik')

KM (k.ö) bisaçi ${ }^{82} \sim$ (Less.) bişaçi 'kötü ruh, insan yiyen iblis' (OM -, Hlh. -, Ma. -) || GT (EUyg.) pişaçe ‘bir şeytan sınıfının adı' ( $\leftarrow$ Sk. piśáca 'et yemeyi seven bir şeytan sinıfının adı')

KM (k.ö.) bisizun (Less.) bisizu busizu 'zeki, akıllı, hızlı düşünen; uyanık; hızlı, çabuk' (OM ${ }^{\mathrm{HY}}$ bişi'un, ${ }^{\mathrm{ME}}$ bişūn, ${ }^{\mathrm{R}}{ }^{\mathrm{B}}$ biş̧ūn, Hlh. бywyy, ?Ma. bişun 'pürüzsüz, düz; yemek konusunda ölçülü (kişi)') || GT bışıg 'pişmiş; olgun; kuru; (metal için) işlenmiş; gayretli; olgun, tecrübeli (kişi)'

KM bisil- bisilga $a-\left({ }^{*}\right.$ bisll- $\left.{ }^{83}\right)$ 'düşünmek, meditasyon yapmak, tasavvur etmek; kendini bir şeye hevesle vermek, azmetmek, alıştırma yapmak’ (OM -, Hlh. бясалгах, Ma. -) || GT (EUyg.) bışrun- (< bış-ur-un-) 'meditasyon yapmak, alıştırma yapmak, alıştırma yaparak ustalaşmak, uygulamak'

KM bisire- $\left(<^{*}\right.$ biti.re- $\left.{ }^{84}\right)$ 'inanmak, tapmak, tapınmak; çok sevmek, hayran olmak; saygı duymak, hürmet etmek, takdir etmek' (OM ${ }^{\mathrm{MGT}}$ büşire-, ${ }^{\mathrm{H}}$ büşire-, ${ }^{\mathrm{HY}}$ bişire'ül 'iyi niyet', ${ }^{\mathrm{PH}}$ büşire-, Hlh. бumpэx, Ma. -) || GT bit- büt- 'inanmak, tapmak, bağlanmak, iman etmek; güvenmek'

80 Sözcük *bız+a-gu olarak tahlil edilebilir. 'Bız *buz kökü, Trk. ağ. bızla-, buza-, buzla- 'inek doğurmak' fiillerinde korunmuş olabilir.

81 Pañc. 24b.

82 Pañc. $4 \mathrm{~b}$.

83 Moğolca sözcüğğn Türkçe bışrun- fiilinin doğrudan karşılığı olmadığı açıktır. Alıntılanma sırasında benzeşme rol oynamış olmalıdır.

${ }^{84}$ Mo. $t>s$ değişimine diğer bir örnek olarak KM silta- 'sebep olmak, bahane bulmak' $(\leftarrow$ GT tılta- ‘sebep olmak, bahane aramak') fiili gösterilebilir. 


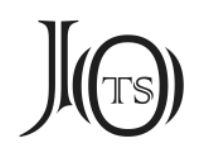

KM (k.ö.) biy tas buy tas 'yazıt taşı' (OM ${ }^{\mathrm{MGT}}$ (Torbi) Taş 'kişi adı' [Rachewiltz 1972: 319], Hlh. -, ŞYug. taş [Nugteren 2011: 235], Mgr. tas tašl [Nugteren 2011: 235], Bao. tass(i) [Nugteren 2011: 235], Kgc. txaşi [Nugteren 2011: 235], Dong. taşı [Nugteren 2011: 235], Ma. -) || GT (EUyg.) pi taş 'yazıt taşı' ( $\leftarrow$ Çin. 碑 bēi 'anıt, yazıt, taş levha' + GT tāşs 'taş')

KM boco 'tortu, posa, kesilmiş sütün suyu' (OM -, Hlh. 603, Ma. bacu 'arki'nin tortusu', Cür. 勃蘇 bó-sū 'şarap' [Franke 1999: 57]) || GT boza 'boza' (Çer. pura 'bira' $\leftarrow$ BT *bora veya *bura 'bira') (krş. Mac. boza 'bir tür bira, alkollü içki', Far. بوزه būza 'farklı tahıllardan yapılan bir tür bira')

KM boda (I) 'madde, cisim; vücut, vücut yapısi; nesne' (OM ${ }^{\mathrm{MGT}}$ bodo, ${ }^{\mathrm{PH}}{ }^{6}$ bodo, Hlh. бод, Ma. -) || GT bōd 'vücut, beden, gövde, boy' (Çuv. pěv 'boy' $\leftarrow$ Tat. buy 'boy')

KM boda (II) '(at, inek, deve gibi) büyükbaş hayvan; bir inek, bir öküz, bir at, yarım deve, yedi koyun ya da on dört keçiye denk çiftlik birimi; satranç taşları' (OM ${ }^{\mathrm{MGT}}$ bodo 'bir büyükbaş hayvan', Hlh. бod, Ma. -) \| GT bod ( bōd) 'boy, kabile'

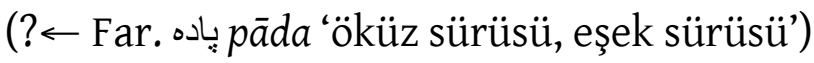

KM bodgali ‘birey, kişi, ruh' (OM -, Hlh. бodzaль 'bireysel', Ma. -) \| GT (EUyg.) pudgıl pudgala pudgale 'insan, kişi, birey' ( $\leftarrow$ Sk. pudgala 'beden, vücut; ruh, kişisel varlık, benlik, birey')

KM bodi 'aydınlanma, dinî aydınlanma' (OM -, Hlh. бodъ, Ma. bodi) \| GT

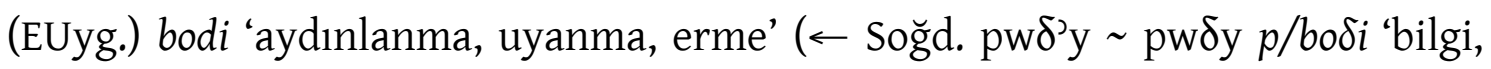
aydınlanma' $\leftarrow$ Sk. bodhi 'mükemmel bilgi veya bilgelik, aydınlanmış akıl')

KM bodiçid 'aydınlanma düşüncesi' (OM -, Hlh. -, Ma. -) || GT (EUyg.) bodiçit 'aydınlanma düşüncesi' ( $\leftarrow$ Sk. bodhicitta 'aydınlanma düşüncesi, Budalığı veya Bodhisattvalığı arzulayan zihinsel tutum')

KM (k.ö.) bodistv (Less.) bodisadu-a bodisadv bodisung 'Bodhisattva, mükemmel aydınlanmaya ve böylece Buda olmayan yaklaşan kutsal kişi' ( $\mathrm{OM}^{\mathrm{PH}}$ bodhisivid bodisi'u:d, Hlh. бodbcad, Ma. bodisatu) \| GT (EUyg.) bodisatav 'gelecekteki Buda' $(\leftarrow$ soğd. pwdyst $\beta \sim$ pwtyst $\beta$ botisat $\beta \sim$ putisat $\beta$ 'Boddhisattva' $\leftarrow$ sk. bodhisattva 'özü mükemmel bilgi olan') 


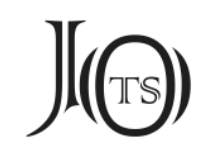

KM bog 'pislik, kir, çöp, süprüntü, suyun üstündeki kalın köpük' (OM -, Hlh. бor, Ma. -) || GT bok bōk 'bok, dışkı; küf', BT *bok ‘dışkı, gübre; cüruf, metal küfü; kulak pisliği' (> Çuv. păh) (krş. PY [S] *po? q 'dışkı')

$\searrow \mathrm{KM}$ baya-, KM boki

KM boğça boǵço (< bog்.ça $\left.a^{85}\right)$ 'seyahat çantası, bavul; heybe; çanta; paket' (OM -, Hlh. бozu, Ma. -) || GT bōg(u) 'es 'eşya konan heybe, bohça, bir mal yığını veya çıkını' (krş. Far. غُ نōg 'çıkın, bohça')

KM boġoni 'alçak, dip, taban' (OM ${ }^{\mathrm{MGT}}$ boqonitqa- 'alçaltmak', ${ }^{\mathrm{HY}}$ boqoni, ${ }^{\mathrm{BY}}{ }^{\mathrm{O}}$ o-

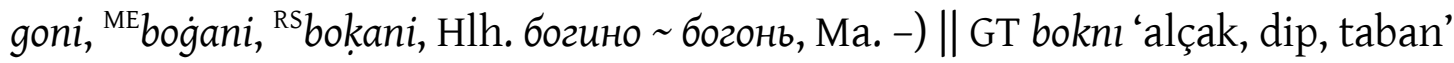

KM boyo- 'bağlamak, bohçalamak, dolamak; durdurmak, önünü kesmek'

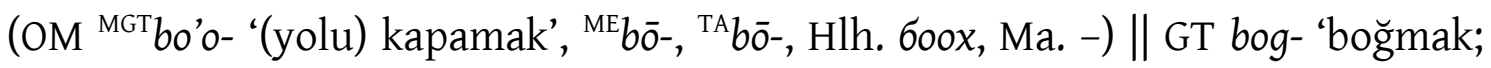
sıkmak, bağlamak; önlemek, durdurmak, bent çekmek' (krş. Mac. bog 'düğüm, boğum', Mac. boly 'karınca yuvası' $\leftarrow$ BT *bog-ul)

KM boyom- $a$ boom-a 'apse, çıban, şirpençe' (OM -, Hlh. бoom, Ma. -) \| GT (T II Y 27: 21) bwgan ${ }^{87}$ 'tümör, şişlik'

KM boyorsog boyorçog 'ekmek, pasta' (OM -, Hlh. бoopu̧oz 6oopcoz, Ma. -) || GT (OTi) bogursag் 'hamurdan yapılan bir yemek türü'

KM boyos 'embriyo; hamile (hayvan)' (OM ${ }^{\mathrm{ME}}$ bogar 'hamile', ${ }^{\mathrm{RS}} b o g$ gz ‘hamile (kısrak)', Hlh. 6ooc, Ma. -) || GT bogaz 'hamile, gebe'

KM boki $i^{89}$ 'pipoların içinde kalan artık; ağaç reçinesi' (OM -, Hlh. бoxb, Bur. mohi(n), Kalm. mokn, Dag. bok [bok ${ }^{y}$, Ma. -) \| GT bok ( bōk $\left.k^{90}\right)$ 'bok, dışk1; küf', BT

$85 \mathrm{KM}\{+c ̧ \mathrm{~A}\}$ eki için krş. KM çamça.

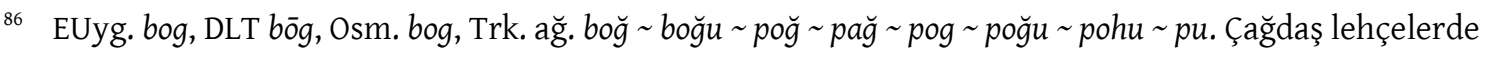
taniklanan bogça $\sim$ bohça $\sim$ bokça pokço vb. şekilller Moğolcadan geri ödünçlemedir.

87 Bk. Rachmati (1932: 420) ve Károly (2005: 57).

88 Sözcük, tespit ettiğimiz kadarıyla ilk olarak Oğuz Kağan Destanı'nda (64-65) geçmektedir: döl bogaz boldı 'k1z gebe kaldı' (Bang-Rahmeti 1936: 14-15, 37), töl boǵus boldı (Danka 2016: 317, 351). Bunun d1şında sözcük, birçok çağdaş lehçede tanıklanmıştır: Tkm. bogaz, Tat. buaz, Kırg. booz, Alt. boos, Tuv. boos, Yak. buos.

89 Doerfer (1985: 125) de Moğolca sözcüğü “Tü. boq” ile karşılaştırmaktadır.

90 Ünlü uzunluğu sadece DLT'de tanıklanmıştır. 


\section{$J(\Theta)$}

*bok 'dışk1, gübre; cüruf, metal küfü; kulak pisliği' (> Çuv. păh) (krş. PY [S] *po?q 'dışk1')

$\searrow \mathrm{KM}$ baya-, KM bog

KM bokir- (< *bokl-r- $\left.{ }^{91}\right)$ 'bükülmek, kivrılmak' (OM -, Hlh. бoxupox, Ma. bohi'ayakları sarmak'), KM bokiski- (< bokl-s ki-) 'bükülmek, kıvrılmak, bağdaş kurmak' (OM -, Hlh. бохисхиŭx, Ma. bohi- 'ayakları sarmak') || GT bok- 'ayağını bükmek, diz bükmek, toplamak, bacak bacak üstüne atmak, bağdaş kurmak' (Yak. bokuy-)

KM bol- 'olmak, gerçekleşmek' (OM ${ }^{\mathrm{MGT}}$ bol-, ${ }^{\mathrm{HY}}$ bol-, ${ }^{\mathrm{ZY}}$ bol-, ${ }^{\mathrm{BY}}$ bol-, ${ }^{\mathrm{ME}}$ bol-, ${ }^{\mathrm{iM}}$ bol-, SLbolgakssan 'pişmiş', ${ }^{\mathrm{TA}}$ bol-, ${ }^{\mathrm{RS}}$ bolai '-dır/-dir', ${ }^{\mathrm{PH}}$ bol-, Hlh. болох, Ma. -) \|| GT bōl- (< *bō-l-) ‘olmak, gerçekleşmek', BT bōl- 'olmak' (> Çuv. pul-) (?־Soğd. $\beta w-, \beta-, w \beta-$ 'olmak, gerçekleşmek' ${ }^{92}<$ İr. bauH 'olmak' [Cheung 2007: 16-18])

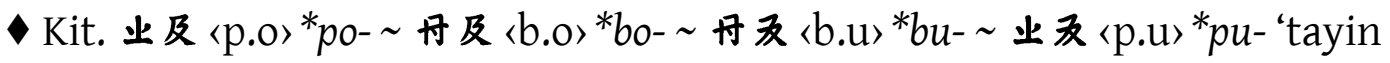
etmek, terfi ettirmek, olmak, var olmak' (Kane 2009: 84, 156; Wu-Janhunen 2010: 67, 110; Shimunek 2014: 107-108, 115; Shimunek 2017a: 330; Wu-Róna-Tas 2019: 56-57)，丹及子 (eb.oo.ol-> *bool- 'olmak' (Ōtake 2017: 202, 203)

KM bolca- bolco- (<*boliga-) '(bir konuda) anlaşmak, fikir birliğine varmak; randevulaşmak; önceden belirlemek, önceden düzenlemek; öngörmek, tahmin etmek, önceden bilmek' (OM ${ }^{\mathrm{MGT}}$ bolca- 'randevuleşmek, bir tarih kararlaştırmak', Hlh. болзох, Ma. bolco- 'anlaşmak, söz vermek, bir tarih belirlemek, (bir şeye) karar vermek') || GT *boşgu- > GT boşgun- 'öğrenmek, talimat almak', GT boşgur- 'öğretmek, akıl vermek, talim etmek; yapmak, düzene sokmak', GT boşgut 'talimat, öğreti, ders, nasihat'

KM bolor 'kristal, kaya kristali' (OM ${ }^{\mathrm{HY}}$ bolor, ${ }^{\mathrm{PH}}$ bolor, Hlh. болоp, Ma. bolosu 'cam') || GT bolor bolur bulur 'kristal' ( $\leftarrow$ Far. بلور ballūr billaur bulūr 'kristal',

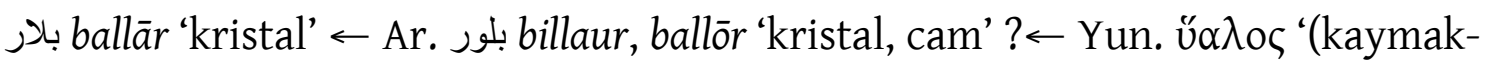
taşı, kristal, kehribar gibi) şeffaf taş; cam')

91 Fiilden fiil yapan $\{-$ r- $\}$ eki için, krş. KM caki-r- 'yönetmek, hükmetmek, idare etmek' < caki- 'talimatlar vermek; emanet etmek'.

92 Türkçe kelimenin kökeni olarak Proto-Soğdca *bō- şeklinden de yola çıkılabilir. Ayrıca krş. OFar. Part. bw-/baw-/ 'olmak', Bakt. ßo- 'olmak'. 
$\searrow \mathrm{KM}$ molor

KM (k.ö.) bor ${ }^{93}$ 'şarap üzümü, şarap' (OM ${ }^{\mathrm{MGT}}$ bor, ${ }^{\mathrm{ME}}$ bor, ${ }^{\mathrm{RS}}$ bor, Hlh. -, Ma. -) \| GT bōr 'şarap, alkol' (? $\leftarrow$ Far. بور bor 'kırmızı; antep fistığ1 rengi; bal rengi; doru

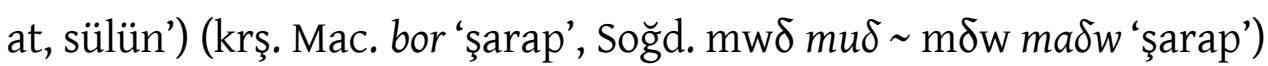

KM boroy-a $a^{n}$ <*boragan) 'yağmur' (OM ${ }^{\mathrm{MGT}}$ boro'an boro'on boroqan 'kar firtınası', By buruqan 'yağmur', Rs bora'un 'kasırga, kar firtınası', Hlh. бороo(н), Ma. -) ॥ GT (EUyg.) bwran' ${ }^{94}$ 'bir tür doğal felaket' veya GT buzkun' 'fırtına, kasırga, kar fırtınası' (krş. Yak. buor '(soğuk için) güçlü, şiddetli, sert', PS * pur 'duman; tipi, kar firtınasi')

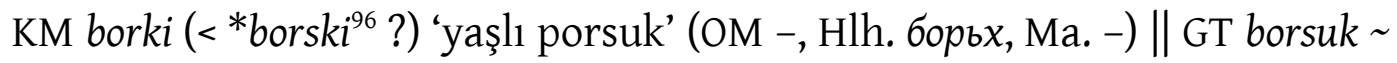
borsmuk 'porsuk', BT *borsı 'porsuk' (> Çuv. purăş) (krş. Mac. borz 'porsuk')

KM (k.ö.) borlug 'üzüm bağı' (OM -, Hlh. -, Ma. -) || GT bōrluk 'üzüm bağı, bă̆, bahçe'

KM boro 'boz, gri' (OM ${ }^{\mathrm{MGT}}$ boro, ${ }^{\mathrm{HY}}$ boro, ${ }^{\mathrm{ZY}}$ buro, ${ }^{\mathrm{ME}}$ bora, ${ }^{\mathrm{RS}}$ bora, ${ }^{\mathrm{RM}}$ būz, ${ }^{\mathrm{AG}}$ Bawra, Hlh. бop, Ma. boro, Evk. boro) || GT bōz ‘boz, gri’ (krş. PS *puro 'gri’ [Róna-Tas 1988: 744])

KM bosuga (< *basurga) 'kapı eşiği, eşik' (OM MGTbosoqa, ${ }^{\mathrm{HY}}$ bosoqa, ${ }^{\mathrm{ME}}$ bosaǵa bosaka, ${ }^{\mathrm{RS}}$ bosaka, Hlh. бoczo, Dag. [E] basrzy, Dag. [T] basarga basarag, Ma. bokson, Evk. basurga, Sol. basarga basagga) || GT basurok ${ }^{97}$ (< basur-ok) 'herhangi bir şeyi baskı altında tutan şey'

KM boşug 'kader, alın yazısı; emir, talimat; izin, müsaade’ (OM -, Hlh. бouuz, Ma. -) || GT boşug (< boş+u-g) 'izin, müsaade; af, bağışlama, serbest birakma' (krş. Mac. búcsú 'veda, endüljans')

93 Turf. 72a, 74a, 76a.

94 Bk. Tezcan-Zieme (1994: 262, 264-265).

95 Ongin $9\left\langle b_{1} w^{w}{ }^{w} k w n_{1}>b w z k u n\right.$ 'firtına, kasırga', Alt. buskan 'kar firtınası'.

96 Moğolcadaki *-Csk- >-Ck- ses değişiminin diğer muhtemel örnekleri için KM engke ve cirke sözcüklerine bakilabilir.

97 EUyg. basrok basurok 'zırh, koruma, destek; stabilizatör', DLT basruk, YUyg. bosuruk (Shaw 1880: 49). 


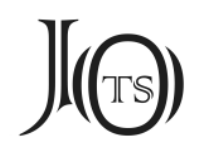

$\mathrm{KM}$ botog ${ }^{n} \sim$ botog்-a 'deve yavrusu' (OM ${ }^{\mathrm{MGT}}$ botoqan, ${ }^{\mathrm{ME}}$ botaġan $\sim$ botag் $a,{ }^{\mathrm{RS}} b o-$ tagiān, Hlh. 6omzo, Ma. -) \| GT boto bota botu 'deve yavrusu'

KM (Kow.) boyidog (oku: boyitog ?) 'büyümeye başladığında geyik boynuzu' (OM -, Hlh. boŭmoz 'bir geyik boynuzunu döktüğünde geride kalan yumuşak ç1kıntı', Ma. -) || GT bodtak *bodtag ${ }^{98}$ (> boytak boydak) 'genç erkek koyun; kısırlaştırılmış koç; kabile üyesi, bekâr erkek; ergen, genç; yalnız, tek'

KM bögle- (< bög99) 'tıkamak, tıpalamak, mantarlamak' (OM ${ }^{\mathrm{MGT}}$ bökle-, Hlh. бөглөх, Ma. -) || GT bög ${ }^{100}$ 'mantar, tıpa, tıkaç, engel', BT *bök(ü) 'tıkaç, mantar, tıpa' (> Çuv. păkă)

KM bögse " 'arka taraf, kıç; but, kalça' (OM ${ }^{\mathrm{MGT}}$ bökse, ${ }^{\mathrm{ME}}$ bökse, Hlh. бөгc, Ma. buksu) || GT bögsäk ${ }^{101}$ 'göğsün yukarı kısmı, belden yukarısı, göğüs, gövde, karın', BT *büsgäk 'guatr; göğüs' (> * pěse > Çuv. pěsehe) (krş. HTKL «būhä:sakä> bügsäk)

KM bögsi- 'pusuda beklemek' (OM -, Hlh. бүгшux 'gülmekten veya öksürmekten nefessiz kalmak; pusuya yatmak', Ma. buksi-) || GT (DLT) bös- 'vurmak, darp etmek', (DLT) bösüg bös- 'pusuya yatmak' (krş. YUyg. bös- 'patlamak, çatlamak; toprağ1 elle boylu boyunca kürümek' [Shaw 1880: 49], YUyg. bös- 'bir şeyi yerde sürüklemek' [Jarring 1964: 59])

KM böye 'şaman, kam' (OM ${ }^{\mathrm{MGT}} b o ̈ e, e,{ }^{\mathrm{HY}} b o ̈{ }^{\prime} e,{ }^{\mathrm{ZY}} b \bar{o},{ }^{\mathrm{BY}} b \bar{o}, \mathrm{Hlh} .6 \theta \theta$, Ma. - ) \| GT bügü

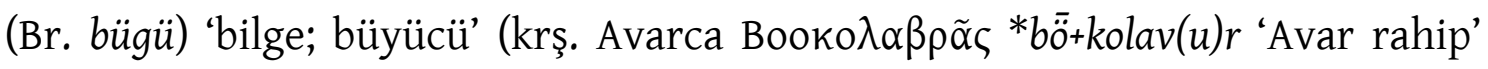

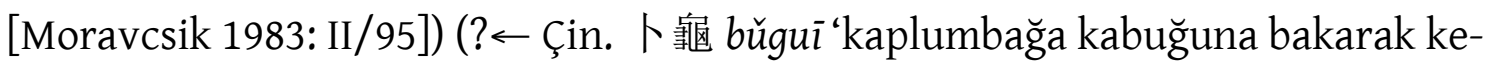
hanette bulunmak')

KM böyeçi 'şaman, kam' (OM -, Hlh. бөөч, Ma. -) || GT bügüçi ‘büyücü’ (krş. Mac. bölcs 'bilge')

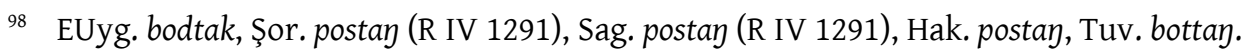

99 Ord. bög, Mog. bug 'tıpa, mantar'.

100 TZ bö 'ipin ve benzerlerinin düğümü’ (?), Alt. bök, Yak. büö, Dolg. büö.

${ }^{101}$ EUyg. bögsäk, DLT «BUK·SAK〉, Tuv. böskek 'kuş göğsü', Tof. böksek 'kuş göğsü’.
} 


\section{J(৫)}

KM böyelcirgene bülcirgene (< *böldirgene) 'ahududu' (OM -, Hlh. бөөрөлзгөнө, Kalm. bōldžrg g’ne, Ma. -) || GT (çTi) böldirgen büldirgen ${ }^{102}$ 'böğürtlen'

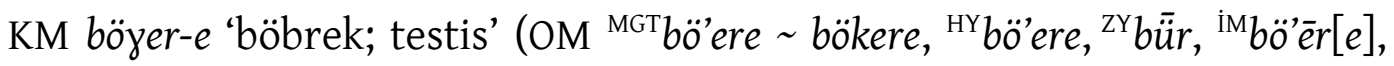

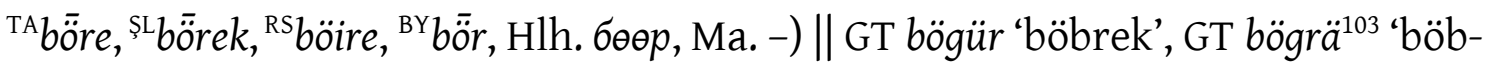
rek', BT *bögrä veya *bögräk ‘böbrek' (> Çuv. püre) (krş. HTKL «bau'hū':rä〉 bögür)

KM böyerelgen-e 'böğürtlen' (OM MEbürlügen 'kartopu (bitkisi)', Hlh. бөөрөлгөнө, Ма. -) || GT *bögürülgän ${ }^{104}$ (> *bögürlän) ‘böğürtlen'

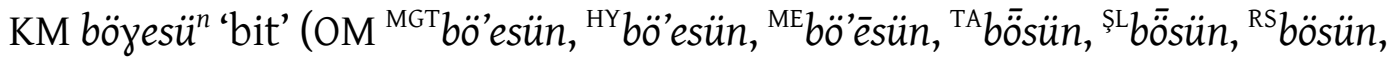
${ }^{\mathrm{NK} 1}$ bösün, ${ }^{\mathrm{NK}}$ bösün, ${ }^{\mathrm{RM}}$ bușun, Hlh. бөөc(өн), Ma. -) || GT bö bö̀y bög 'zehirli bir örümcek'

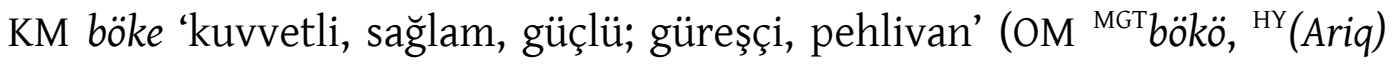
Bökö 'kişi adı', MEböke, Hlh. бөx, Ma. buku, Evk. buku) || GT bökä 'yiğit, savaşçı, pehlivan; ejderha'

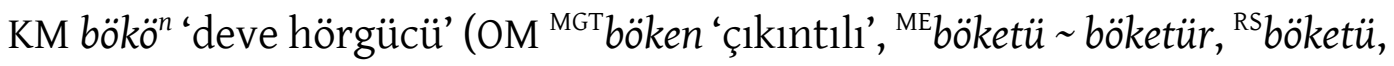
Hlh. бөx(өн), Kalm. bökn 'kambur, hörgüç, (ağaçlarda) yumru', Ma. bohoto 'deve hörgücü', Ma. bokto 'kambur', Ma. buktu 'kambur, çarpık'), KM bögtüyi- bökötüyi'öne doğru eğilmek, başını eğmek, eğilerek selam vermek, meyletmek' (OM -, Hlh. бөгтuйx, Ma. -), KM bögtür bögetür (< bög(e)tü(yi)-r) 'eğri, kıvrık, kambur' (OM MGT bögötür bökötür 'kambur', Hlh. бөгmөp, Ma. -) || GT bükün ${ }^{105}$ (< bük-ün) 'kıvrım, büküm, büküm yeri, kat', BT *bükün (?) > *büküm 'kıvrım' (> Çuv. pükĕm)

KM bökön-e bököyene 'at sineği' (OM ${ }^{\mathrm{HY}}$ bökö’üne, ${ }^{\mathrm{ZY}}$ bögeüne, Hlh. бөхне, Ма. ) || GT bügäläk 'at sineği', BT *bügän 'at sineği' (> Çuv. păvan) (krş. Mac. bögöly 'at sineği')

\footnotetext{
102 Trk. ă̆. büldürgen, Bşk. ağ. böldörgen, Nog. böldirgen büldirgen, Kırg. büldürkön, Kzk. büldirgen, YUyg. bölcürgen ( $\leftarrow$ Mo.).

${ }^{103}$ Mait. 75v2, 75v25 pwykr' (Tekin 1980: 86).

${ }^{104}$ Çă̆. bögürtkän, Trk. böğürtlen, Az. böyürtkän, Tkm. bövürslen.

${ }^{105}$ DLT 〈BUKN〉 bökün (?) ‘iktidarsız; körbağırsak', Osm. bükün, IMS bükün.
} 


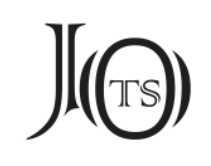

KM bököyi- bökeyi- '(öne doğru) eğilmek, başını eğmek' (OM ${ }^{\mathrm{MGT}}$ bük- 'eğil-

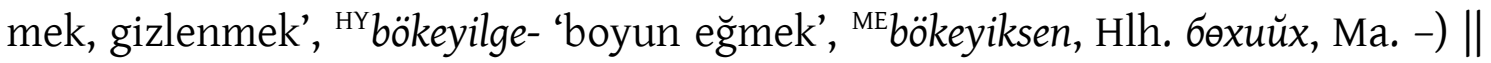
GT bük- 'bükmek, eğmek', BT *bök- 'kıvırmak, katlamak' (> Çuv. pük-)

KM (k.ö.) bölög (Less.) bülüg ‘bölüm, grup, topluluk; kısım, bölüm' (OM

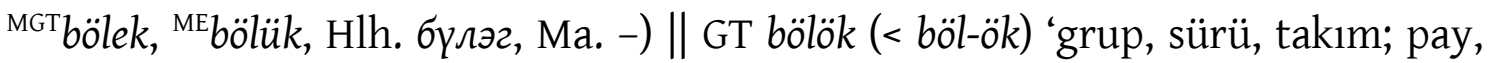
hisse; parça, kısım'

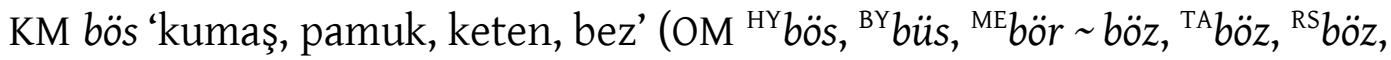
Hlh. бөc, Ma. boso) || GT bözz 'bez, kumaş, keten bezi', BT *bēr 'keten bezi' (> Çuv. pir)

$\searrow \mathrm{KM}$ büse

KM (k.ö.) bramid baramid 'en yüce bilgelik; erdem, mükemmellik, dinî fazilet' (OM -, Hlh. -, Ma. baramit) || GT (EUyg.) paramit '(temel erdem olarak) mükemmellik' ( $\leftarrow$ Toh. A/B pāramit 'yücelik, üstünlük, aşkınlık' veya Soğd. p’rmyt 'pāramitā' [Reck 2016: 434] $\leftarrow$ Sk. pāramitā 'bir şeye tam olarak ulaşma, bir şeyde mükemmellik, aşkın erdem')

KM (k.ö.) bratikabud ${ }^{106} \sim$ (Less.) bradikabud 'tek başına aydınlanmış (Buda)' (OM -, Hlh. -, Ma. -) \| GT (EUyg.) pratikabut piratikabut piradakabut 'tek başına aydınlanmış (Buda)' ( $\leftarrow$ Soğd. prt'ykpwt prt'ykpwtt 'Pratyekabuddha' [MacKenzie 1976: 214b] $\leftarrow$ Sk. pratyekabuddha 'aydınlanmaya ulaşmış olmasına rağmen tek başına yaşayarak bilgisini dünyayla paylaşmayan bir Buda')

KM buçal- (?< *bılça-) 'kaynamak' (OM ${ }^{\mathrm{MGT}}$ buçalqa- 'kaynatmak', ME buçal- 'kaynamak', Hlh. буu̧лах, Ma. -) || GT bış- 'pişmek, olgunlaşmak' (krş. Br. püş-är-, Br. büş(ü)r-, Yak. bus-), BT *bı(l)ç- 'pişmek, olgunlaşmak' (> Çuv. piś-)

KM bud 'Merkür (gezegeni); Çarşamba (günü)' (OM -, Hlh. бyd, Ma. -) || GT (EUyg.) but 'Merkür (gezegeni); Çarşamba (günü)' $(\leftarrow$ ? $\leftarrow$ Sk. budha 'uyanış; zeki, bilge; bir tanrı; bir köpek; Merkür (gezegeni); Çarşamba (günü)')

KM buday-an (**butagan) 'tahıl, darı; lapa, un çorbası, yulaf ezmesi; ayıklanmış ve dövülmüş buğday; yemek, öğün' (OM ${ }^{\mathrm{MGT}} b u d a^{\prime} a n,{ }^{\mathrm{HY}} b u d a{ }^{\prime} a n,{ }^{\mathrm{ZY}} b u d \bar{o},{ }^{\mathrm{BY}} b u d \bar{a}$,

106 BodT. 3650. 


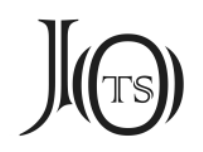

${ }^{\mathrm{ME}}$ budān, ${ }^{\mathrm{TA}}$ budaan, ${ }^{\mathrm{IM}}$ budān, ${ }^{\mathrm{RS}}$ budān, Hlh. бydaa, Ma. buda 'pişmiş tahıl, pişmiş pirinç, gıda', Cür. budga(i) 'yemek, öğün', Cür. buda ‘[çiğ] pirinç') || GT (OTi) botga butga ${ }^{107}\left(<^{*}\right.$ but- $\left.{ }^{108}\right)$ 'bir çeşit yem, sütlaç, çorba, lapa; karışıklık, kargaşa', BT *botık (?) *botgu (?) 'çorba, lapa' (> Çuv. pătă)

KM budang (<*buda.y < *buta) 'sis, pus, ince duman' (OM ${ }^{\mathrm{MGT}}$ budan, ${ }^{\mathrm{ME}}$ budan, Hlh. будан(2), Ma. -) || GT būs 'sis, pus', BT *būs ‘buhar, buğu' (> Çuv. păs) (krş. Mac. ağ. búsz 'bunaltan sıcak, yapış yapış hava; buhar')

KM budu- 'boyamak' (OM MEbudu-, ${ }^{\mathrm{ZY}}$ budu[q]ji ‘boyac1', ${ }^{\mathrm{BY}}$ buda[g] 'boya', Hlh. бydax, Ma. -, Evk. budu-) || GT bodo- 'boyamak' (Çuv. pěve- 'boyamak' $\leftarrow$ Tat. buya'boyamak')

KM (k.ö.) buduli-109 '(pislik içinde) yuvarlanmak veya yatmak', (Less.) buduli'bir şeyi karışıklık içinde yapmak; karışıklık çıkarmak; kafası karışmak' (OM -, Hlh. будлих, ?Ma. buduli- bulduri- '(atlar ve inekler) sendelemek, tökezlemek') || GT (EUyg.) bodul- (< bodu- 'çivilemek, sabitlemek') 'yapışmak, yapışıp kalmak, bağlanmak'

KM buġsa- 'kızgın veya somurtkan olmak; üzgün olmak' (OM ${ }^{\text {MGT }}$ bugsa- 'engellemek, dizginlemek', Hlh. бyzcax, Ma. -), KM buǵsi- 'kızgın olmak' (OM -, Hlh. , Ma. -) || GT buş- (?< *bugşă-) 'öfkelenmek, hiddetlenmek, kızmak'

KM bugssi- 'gizlenmek, saklanmak, saklı olmak' (OM -, Hlh. бyzuux, Ma. buksi'pusuya yatmak ${ }^{\prime 110}$ ) || GT bus- (< *bugš̌-) 'pusuya yatmak, gizlenmek, saklanmak'

KM buğu- 'siçramak, (at gibi) şahlanmak' (OM -, Hlh. бyzax, Ma. -) \| GT (DLT) bukra- 'şaha kalkmak, sıçramak'

107 Çağ. botka (botaka), TZ butka, Tat. butka botka, Bşk. butka, Kırg. botko, Kzk. botka, Alt. botko, Hak. pothı, Yak. butugas (<*butkaç).

${ }^{108}$ Tat. buta- 'karıştırmak', Yak. butuy- 'karıştırmak', Çağ. botra- (butra-) 'dağıtmak, yaymak', Çuv. pătran'bulanmak', Çuv. pătrat- 'bulandırmak'.

109 Lal. 8b.

110 Rozycki (1994: 37), Mançuca sözcüğü Mo. bögsi- ‘pusuda beklemek’ sözcüğ̈uyle karşılaştırmaktadır. 


\section{J(৫)}

KM buyuday buuday 'buğday' (OM ${ }^{\mathrm{HY}} b u$ 'udai, ${ }^{\mathrm{ZY}}$ būdai, ${ }^{\mathrm{BY}} b u$ 'uda[i], ${ }^{\mathrm{ME}}$ buġdai,

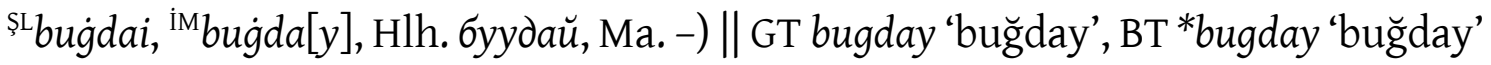
(> Çuv. pări) (krş. Mac. búza 'buğday')

KM bufur-a 'erkek deve' (OM ${ }^{\text {MGT }}$ bu'ura, Hlh. бyyp, Ma. -) \|| GT bugra bugur 'erkek deve'

KM buyural buyurul 'gri, kır, kır saçl1' (OM ${ }^{\mathrm{BY}}$ būrul bowurul, ${ }^{\mathrm{ME}} b \bar{u} r u l,{ }^{\mathrm{RS}} b \bar{r} r u l$, Hlh. буурал, Ma. burulu 'kırmızı ve beyaz donlu at', Evk. burul, Sol. bōral) || GT bogrul ${ }^{111}$ (? bogrll) 'boğazı ak olan hayvan'

KM buk-a 'boğa' (OM ${ }^{\mathrm{MGT}}$ buqa, ${ }^{\mathrm{HY}}$ buqa, ${ }^{\mathrm{BY}}$ buqa, Hlh. бyx, Ma. buha 'vahşi bizon', Ma. buka 'koç') || GT būka (?< *bikka) 'boğa' (krş. Mac. bika 'boğa', Mac. ağ. buga 'öküz, keçi, koç')

KM bukar 'tapinak, manastır' (OM -, Hlh. бyxaap, Ma. -) || GT (EUyg.) virhar 'manastır, Stūpa' ( $\leftarrow$ Soğd. ßry’r 'Stūpa' $\leftarrow$ sk. vihāra 'manasır, tapınak')

KM (k.ö.) bukug (? buǵug) $)^{112 ~ ‘ b o y u n d u r u k ’ ~(O M ~-, ~ H l h . ~-, ~ M a . ~-) ~|| ~ G T ~ b o k u r s ı ~}$ bukursi bokursa bukursa 'boyunduruk'

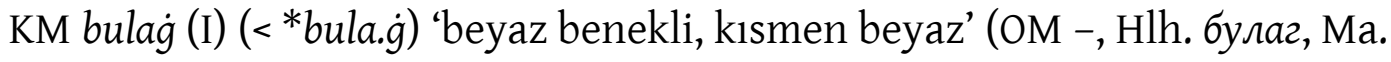
-) || GT bula 'alaca, bulaca, çok renkli'

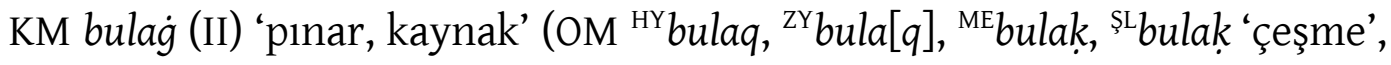
${ }^{\mathrm{RS}}$ bulak, ${ }^{\mathrm{PH}}$ bulaq, Hlh. булаг, Ma. -) \| GT bulak 'pınar, kaynak'

KM bulanggir bulunggir 'çamurlu, bulanık' ( $\mathrm{OM}^{\mathrm{HY}}$ bulungir 'bela', ${ }^{\mathrm{BY}}$ bulinggir, ${ }^{\mathrm{ME}}$ bulankir, ${ }^{\mathrm{RS}}$ bulangir, Hlh. булингар, Ma. -) || GT bulga- 'bulandırmak, karıştırmak', BT bulka- 'bulandırmak, karıştırmak' (> Çuv. pălhav, pălhan- pulhan-, pălhat-)

KM bulçing (< *bultı.y ? *bulçıg?) 'baldır; bacak veya kol adalesi' (OM -, Hlh. булчин(2), Ma. bulça yali 'kol ve bacaklardaki et'), KM bulçirkay 'beze, gudde' (OM ${ }^{\mathrm{ME}}$ bilçirkai, ${ }^{\mathrm{RS}}$ bulçirgá, Hlh. булчирхай, ?Ma. bulcan 'derideki ur') \| GT būt (?< *bult)

111 Sözcüğün etimolojisi, boguz 'boğaz' ve +ul eki olarak gösterilebilir. Türevde bir rotasizm söz konusudur. GT boyun 'boyun' isminden türetilen GT boymul ‘boynunda beyaz bir leke olan hayvan' sözcüğü de muhtemelen aynı eki içermektedir.

${ }^{112}$ Turf. 80a2. 


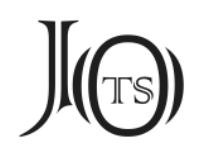

'but, uyluk, kalça' veya GT buçgak (? * *ulçgak < *bulçıg+ak) 'hayvanların baldır veya ayak derisi' (krş. PY [S] *bul 'ayak')

KM bulgar buligar 'yuft' (OM -, Hlh. булигаap, Ma. -) || GT (OTi) bulgar bulgarl 'deri, yuft, sahtiyan'

KM bulung 'köşe, açı' (OM -, Hlh. булан(2), Ma. -) || GT bulug 'köşe, açı, yön'

KM (k.ö.) bundarig ${ }^{113}$ 'beyaz lotus' (OM -, Hlh. -, Ma. -) || GT (EUyg.) pundarik 'bir ağaç türü (Artemisia indica)' ( $\leftarrow$ Sk. pund darika 'lotus çiçeği, beyaz lotus')

KM bur 'bulanık; loş, karanlık, gölgeli' (OM -, Hlh. бyp, Bur. бyp 'çamur; kil', Ma. buraki 'toz') || GT bōrr14 'toz, kum, toprak', BT bōr(V) 'tebeşir' (> Çuv. pur pură) (krş. PS *pur 'duman, toz')

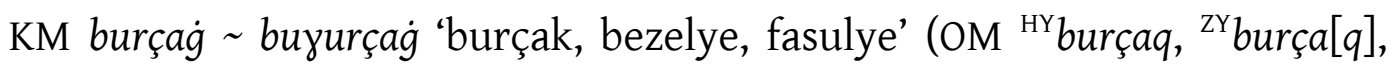
${ }^{\mathrm{BY}}$ borço[q], MEburçak, ${ }^{\mathrm{RS}}$ burçak, Hlh. бyypuaz, Ma. -) || GT burçak 'burçak, bezelye, fasulye', BT *burçak ‘bezelye' (> Çuv. părśa) (krş. Mac. borsó [borşō] ‘bezelye’)

KM burçi- (< *bur.çi-) 'yıkmak, tahrip etmek' (OM -, Hlh. -, Ma. -) \| GT buz'yıkmak, tahrip etmek' (krş. EUyg. burçıntur- 'incitmek, sıkıntı vermek, düzenini bozmak')

KM burgi- 'bulut şeklinde yükselmek, (toz, su, duman vb.) dönmek' (OM -, Hlh. бургих, Ma. burgi- 'dağınık olmak', Şib. burgaşa-, buruşa- 'süzülmek, daire çizmek, başıboş dolaşmak'), KM burciyi- 'kıvrılmak' (OM -, Hlh. бypжcuŭx, Ma. -) || GT būr- 'kokmak, (buhar) yükselmek' (Yak. burzay- '(toz) dönerek yükselmek'), BT *būr- 'burmak, çevirmek, döndürmek' (> Çuv. păr-) (krş. Mac borít 'örtmek, üzerine yaymak, devirmek', borul 'devirmek, düşmek, üzerine kaplamak', borogat 'üzerine koymak', borong 'üzerinde dolaşmak, (bulutla) kapanmak', ború 'bulutluluk, kasvet', burok 'kabuk, kapak', burkol 'kaplamak')

113 Lal. 53a, Pañc. 6b.

114 KT D 37 otça bwrça 'ateş ve toz gibi’ (?), Kİ bor 'kireç; beyaza mail yumuşak taş’, Osm. bor 'sürülmemiş, otsuz, pek toprak', Tkm. bōr (ağ.) 'tebeşir', Yak. buor 'toprak; balçık, kil; toz; memleket; mezar', Dolg. buor ‘toprak, balçık, kil, kum'. Diğer tanıklar için ESTYa’ya (II 192-193) bakılabilir. 


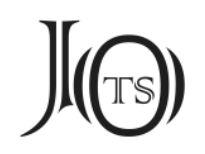

KM burg̉uy 'pipo temizlemek için kullanılan tel parçası' (OM ${ }^{\mathrm{ZY}}$ bur[qui] 'delgi', RS*burgu(i) 'delgi', Hlh. бypzyŭ, Ma. -) || GT borgu borguy 'boru', BT *borku > *boruk (?) 'boru' (> Çuv. părăh)

KM buri ( buriba) 'küf' (OM -, Hlh. -, Ma. -) || GT (DLT) buzı 'yanmış ekmeğin üzerindeki siyahlık'

KM burḳan 'Buda' (OM MGT burqan 'kişi ve dağ adı', ${ }^{\mathrm{HY}}$ burqan, ${ }^{\mathrm{PH}}$ burqan, Hlh. бурхан, Ma. -) || GT burhan 'Buda' ( $\leftarrow$ Çin. 佛 fó 'Buda', Tü. +kan)

KM bursang 'Budist rahip veya ruhban sinifi' (OM -, Hlh. -, Ma. bursan hubarak) || GT (EUyg.) bursay bursin bursoy 'rahipler topluluğu' ( $\leftarrow$ Çin. 佛僧(伽) fósēng(jiā) 'Budist tapınağı' $\leftarrow$ Sk. buddhasangha 'Budist rahip topluluğu' veya Soğd. pwrsnk ${ }^{(2)}$ pursang 'keşiş topluluğu' = Sk. bhikșu-samgha)

KM burtag (<*bur.ta.g) 'leke, pislik, kir’ (OM ${ }^{\mathrm{ME}}$ burtak, ${ }^{\text {PH }}$ burtaq, Hlh. бypmaz, Ma. borton '(özellikle yüz için) pis, kirli’) || GT (EUyg.) bırıg (<*bır-) 'kirli, temiz olmayan; dışkı, pislik'

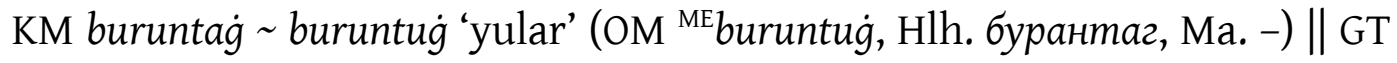
buruntuk burunduk burunduruk 'yular'

KM (k.ö.) bus ${ }^{115}$ ‘bir yildız kümesi’ (OM -, Hlh. -, Ma. -) || GT (EUyg.) puş 'Ay’ın Dünya'nın çevresinde dolaşırken geçtiği sekizinci istasyonun adı’ $(\leftarrow$ Sk. Puşya 'Ay'ın Dünya'nın çevresinde dolaşırken geçtiği altıncı veya sekizinci istasyonun adı')

KM busaki 'kötü, günahkâr, ahlaksız' (OM -, Hlh. бycxu, Ma. -) || GT (DLT) buşak (< buş-) 'sıkıntılı, hiddetli’ (krş. EUyg. buşı, KB buşı 'heyecanlı, hiddetli, sinirli, çabuk kızan')

KM busani- 'dağılmak, yıkılmak, harap olmak' (OM ${ }^{\mathrm{HY}}$ busaniqda- 'düzensiz şekilde dağılmak', Hlh. бусних, Ma. -) || GT busan- 'kederli olmak' (krş. Mac. bosszant 'kızdırmak, sinirlendirmek')

KM buta 'parça parça, paramparça; tamamen' (OM -, Hlh. бym, Ma. -), KM butara- 'parçalanmak; dağılmak' (OM MGT butara- 'dağılmak', MEbutara- 'dağılmak',

${ }^{115}$ Lal. 21b. 


\section{J(৫)}

Hlh. бympax, Ma. -) || GT (EUyg.) butarla- 'yırtarak parçalamak, paramparça etmek'

KM butani ${ }^{116}$ 'bir şeytan sınıfi' (OM -, Hlh. -, Ma. -) || GT (EUyg.) putane 'bir şeytan sınıfi' $(\leftarrow$ Toh. B pūtane 'bir tür iblis' $\leftarrow$ Sk. pūtana 'bir iblis veya ruh sınıfi')

KM buyan 'erdemli davranış, erdem, fazilet' (OM ${ }^{\mathrm{ME}}$ buyan, ${ }^{\mathrm{PH}}$ buyan, Hlh. буян, Ma. -) || GT buyan muyan 'iyi davranış, iyilik, sevap, erdem' ( $\leftarrow$ Sk. punya 'iyi, erdemli, doğru, değerli; erdem; iyi iş’)

KM buyila 'devenin burnuna geçirilen tahta çivi' (OM -, Hlh. бyŭл, Ma. -) \| GT (IB) budla (DLT) butlu (? buylu) 'devenin burnuna takılan halka, burunsalık'

KM büci- (< *büdi-) 'oynamak, dans etmek' (OM ${ }^{\mathrm{HY}} b$ öci-, ${ }^{\mathrm{BY}} b u[y ̌ i k] c ̧ i$ 'dansç1',

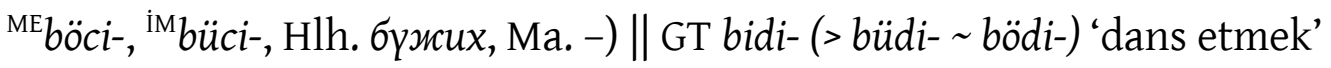

KM büdeg, büdeki (< *bide-) 'karanlık, bulanık, belirsiz, muğlak' (OM -, Hlh. бүдэг, бүдэx, Ma. -) || GT (DLT) bēd- 'görme yeteneği zayıflamak'

KM büle- büli- (< *bile-) 'saplamak, batırmak, delmek; kımız çalkalamak, çırpmak' (OM MGT büle-, Hlh. бүлэx, Ma. -) || GT bış- biş-117 '(süt) çalkalamak, çırpmak; tereyağı yapmak; dürtmek, firlatmak, saplamak' (krş. Toh. B peșke 'arıtılmış tereyağı, saf yağ, Ghee')

KM bürgüd 'kartal' (OM ${ }^{\mathrm{HY}}$ bürgüt, ${ }^{\mathrm{ZY}}$ bürküt, ${ }^{\mathrm{ME}} b u ̈ r k u ̈ t,{ }^{\mathrm{RS}} b \ddot{r} r k u ̈ t,{ }^{\mathrm{NK}} b \ddot{r}$ küt, Gк burk'u[t'], Hlh. бүргəд, Ma. -) || GT bürküt 'bir tür kartal'

KM büri- 'bürümek, örtmek, kaplamak' (OM ${ }^{\mathrm{MGT}}$ büri-, ${ }^{\mathrm{ME}}$ büri- 'süt kesilmek', ME bürkü- 'örtmek, örtülmek', Hlh. бүрэx, Ma. buri-) || GT büri- bürü- 'bürümek, sarmak, örtmek'

KM bürkü 'yaz şapkası' (OM -, Hlh. бүpx, Ma. -) || GT börk 'başlık, kalpak'

KM büse 'kuşak, kemer' (OM ${ }^{\mathrm{MGT}}$ büse, ${ }^{\mathrm{HY}}$ büse, ${ }^{\mathrm{BY}}$ büs, ${ }^{\mathrm{ZY}}$ büsi, ${ }^{\mathrm{ME}}$ büse, ${ }^{\mathrm{SL}}$ büse, ${ }^{\mathrm{IM}}{ }^{\mathrm{M}}$ büse, ${ }^{\mathrm{RS}}$ büse, Hlh. бүс(эн), Ma. -) || GT bō̈z 'bez, kumaş, keten bezi', BT *ber 'keten bezi' (> Çuv. pir)

\footnotetext{
116 Pañc. 30b.

117 Tkm. piş-ek, Bşk. besş̌̆-, Kzk. pis-, Kırg. bış-, Sib. Tat. pěş- (I, II), Tuv. bış-.
} 


\section{J(৫)}

$\searrow \mathrm{KM}$ bös

KM büta 'kötü ruh, şeytan' (OM -, Hlh. -, Ma. -) || GT (EUyg.) bute 'bir şeytan sinıfı' ( $\leftarrow$ Sk. bhūta 'tekinsiz varlık, ruh, hayalet, cin')

KM büte- 'örtülmek, kaplanmak; (yara) kapanmak, iyileşmek' (OM ${ }^{\text {MGT }}$ büte'tıkalı olmak', Hlh. бүmэx, Ma. butule- ‘örtmek, kaplamak, tıkamak') || GT büt- bit'(ses) kesilmek, kaybolmak; (yara) iyileşmek, kapanmak'

KM bütü- 'oluşmak, şekillenmek; gerçekleşmek' (OM ${ }^{\mathrm{ME}}$ bütü- 'bitmek', '`M bütē'bitirmek, tamamlamak', ${ }^{\mathrm{R}}$ būta- 'tamamlamak, bitirmek', ${ }^{\mathrm{PH}}$ bütü- 'gerçekleşmek', Hlh. бүтэх, Ma. -) || GT büt- bit- '(ot) bitmek, büyümek; (arzu, dilek) yerine gelmek; bitmek, tamamlanmak, sona ermek', BT *büt- (?) 'bitmek, tükenmek, yok olmak, sona ermek' (> Çuv. pĕt-) (krş. Mac. ağ. bütü büt 'bir şeyin künt ucu' $\leftarrow$ BT *bütüg)

KM bütün 'bütün, tüm' (OM ${ }^{\mathrm{ME}}$ bütün, ${ }^{\mathrm{RS}}$ bütün, ${ }^{\mathrm{PH}}$ bütün, Hlh. бүməн, Ma. -) || GT bütün ‘bütün, tüm', BT *bütüm ‘bütün, tüm' (> Çuv. pětěm) 


\section{$J(\Theta)$}

C

KM cabay-a 'kötü koku; tatsızlık, anlamsızlık' (OM ${ }^{\mathrm{BY}}$ cabān 'tatsız', Hlh. заваан, Ma. -) || GT yavgan (?< 'yav- $\left.{ }^{118}\right)$ 'yavan, etsiz'

KM (k.ö.) cad 'yabanc1, diğer' (OM ${ }^{\mathrm{MGT}}$ cat, Hlh. -, ?Ma. cata 'vasat (kişi), yeteneksiz, işe yaramaz') || GT yāt 'yad, yabanc1' (Çuv. yut yută 'yabanc1' $\leftarrow$ Tat. yat 'yabanc1, yad')

KM cada 'büyü yoluyla yağmur yağdırma' (OM ${ }^{\mathrm{MGT}} c a d a$, Hlh. зad, Ma. -) || GT yat yāt 'yağmur ya da rüzgâr getirmek için taşlarla yapılan kamlık' (krş. Soğd. c $\delta-(w) j / c ̧ a \delta(u)$ 'büyü’, Hot. Sak. çāya- 'büyü, büyücülük', EFar. yātum 'büyü (?)', OFar. cādūg 'büyücü, sihirbaz')

KM cadaçi- (< *cada-) 'çözmek, açmak' (OM -, Hlh. зadчux, Ma. -), KM cadalcadala- 'açmak, çözmek, yaymak; parçalarına ayırmak, tahlil etmek' (OM -, Hlh. задлах, Ma. -), KM cadara- (< *cada-) 'açmak, çözmek, gevşetmek' (OM -, Hlh. задрах, Ma. -) || GT yād- 'yaymak, açmak'

$\mathrm{KM}$ cayan ‘fil' (OM ${ }^{\mathrm{HY}} c a^{\prime} a n,{ }^{\mathrm{BY}} c a g a n,{ }^{\mathrm{ZY}} c a^{\prime} a n,{ }^{\mathrm{ME}} c a^{\prime} a \bar{n} n,{ }^{\mathrm{NK} 1} c a h a n,{ }^{\mathrm{NK} 2} c a h u n,{ }^{\mathrm{PH}} c a^{\prime} a: n$, Hlh. заaн, Ma. -) || GT yaya yagan yayan (< *yay+ga/gan) 'fil' ( $\leftarrow$ Çin. 象 xiàng 'fil')

KM cazar cizar 'misk' (OM ${ }^{\mathrm{ME}}$ ca'ār cār, Hlh. zaapb, Ma. carin) || GT yıpar 'misk' (krş. Mac. gyopár 'bozağan', Far. إبار ipār 'kekik, çördük')

KM cak-a 'kenar; yaka' (OM ${ }^{\mathrm{MGT}}$ caqa,${ }^{\mathrm{HY}}$ caqa, ${ }^{\mathrm{BY}}$ caqa, ${ }^{\mathrm{ZY}} \mathrm{caqa},{ }^{\mathrm{ME}}$ caka ciga $a,{ }^{\mathrm{SL}} \mathrm{cika}$, ${ }^{\mathrm{RS}}$ caka, Hlh. sax, Ma. caka) || GT yaka 'yaka, taraf, yan', BT *caka 'yaka' (> Çuv. śuha)

KM calaza 'püskül; sorguç, ibik' (OM -, Hlh. залаa(н), Ma. -) || GT (DLT) yahg 'ibik'

KM calayu 'genç; gençlik' (OM ${ }^{\mathrm{MGT}}$ cala'ui, ${ }^{\mathrm{BY}}$ calawu, ${ }^{\mathrm{ME}}$ cala'u calū, ${ }^{\mathrm{TA}}$ calawu, ${ }^{\text {SL }}$ calau, ${ }^{\mathrm{RS}}$ calawu, ${ }^{\mathrm{iM}}{ }^{\mathrm{M}}$ cala'ū ${ }^{\mathrm{iM}}$ calū $\sim$ calūn 'hizmetçi, köle', ${ }^{\mathrm{RM}}$ calawū 'efendi, prens', ${ }^{\mathrm{RM}}$ calū 'kız çocuğu', Hlh. зaлyy, Ma. -) \|| GT yāsş 'genç, çocuk, bebek'

$\searrow \mathrm{KM}$ nilk-a

\footnotetext{
${ }^{118}$ Krş. GT yav-ız 'kötü', yav-lak 'kötü', *yavman > yaman 'kötü'.
} 


\section{J(৫)}

KM calbari- 'yalvarmak' (OM ${ }^{\mathrm{MGT}}$ calbari-, ${ }^{\mathrm{ME}}$ calbari-, ${ }^{\mathrm{iM}}$ calbari-, ${ }^{\mathrm{PH}}$ calbari-, Hlh. залбирах залбарих, Ma. calbari-) || GT yalvar- 'yalvarmak'

KM cali 'alev; ruh' (OM ${ }^{\mathrm{im}} c \bar{a} l,{ }^{\mathrm{SL}} c \bar{a} l$ 'odun', ${ }^{\mathrm{RS}} c \overline{a l}$ 'odun', ${ }^{\mathrm{PH}}$ cali 'ihtişam', Hlh. заль, Ma. -) || GT yalın yalı 'alev', BT *calım 'alev' (> Çuv. śulăm)

KM calikay ( < *alka) 'güvenilmez, aldatıc1; umursamaz, tembel' (OM ${ }^{\mathrm{HY}} \mathrm{ca}-$ liqai 'tembel, umursamaz', Hlh. залхай зальхай, Ma. -), KM calkazu(u) (< *calıka) 'tembel, aylak' (OM -, Hlh. залxyy, Ma. -) || GT yaşık 'cılız, zayıf, sıska, yağsız' veya GT *yaşıgan ${ }^{119}$ 'tembel'

$\searrow$ KM naşiğay

KM calira- (<*calı.ra-) 'kaytarmak, tembel olmak, ilgisiz olmak; sakinleşmek' (OM ${ }^{\mathrm{MGT}}$ calira- 'öfkesi dinmek, sakinleşmek', Hlh. зaлupax, Ma. -) || GT yaşı- ${ }^{120}$ 'yorulmak, zayıf düşmek; sakinleşmek; uysallaşmak'

$\searrow$ KM nalayi-

KM calka- 'korkmak, ürkmek; bıkmak, usanmak; bir alışkanlıktan vazgeçmek' (OM ${ }^{\mathrm{MGT}}$ calqamşigtan 'korkunç, korkutucu', Hlh. зaлxax, Ma. -) || GT yalk- 'aşağllamak, iğrenmek; bıkmak, usanmak’

$\mathrm{KM}$ cançi- $\sim$ cangçi- ${ }^{121} \sim$ nançi- 'vurmak, dövmek' (OM ${ }^{\mathrm{MGT}}$ cançi-, ${ }^{\mathrm{ME}}$ cançi-, ${ }^{\mathrm{TA}-}$ cançi-, Hlh. занчих жанчих, Ma. -) || GT yanç(l)- 'ezmek; dövmek; kırmak'

KM cang 'karakter, kişilik, huy, yaradılış' (OM -, Hlh. зан(2), Ma. -) || GT yay $\sim y \bar{a} \eta^{122}$ 'tarz, usul; kalıp, örnek' (? $\leftarrow$ Çin. 樣 yàng 'görünüş, dış görünüş, tür, cins')

$\mathrm{KM}$ canggi 'bilgi, haber, söylenti' ( $\mathrm{OM}{ }^{\mathrm{MGT}}$ canggi 'anlaşma', ${ }^{\mathrm{ME}}$ canki 'düğüm', Hlh. занги, Ma. -) || GT yagı yäni 'yeni, taze', BT *ceni 'yeni, taze' > (Çuv. śĕnĕ) (krş. Mac. gyenge 'zayıf, cllız, güçsüz')

\footnotetext{
119 Alt. yajagan 'tembel' (Verbitskiy 1884: 66a), Leb. yajagan 'tembel', Tub. yajıan 'tembel', Küer. yajay 'tembel' (R III 253, 255), Hak. çazay '(at için) tembel; uyuşuk, dingin'.

120 'Sakinleşmek, uysallaşmak' anlamları için bk. Yak. sıhıy- '(at, hayvan) insanlara alışmak, evcilleşmek; (insan) uysallaşmak'. Krş. ME yallt- (? yalık-) 'bıkmak, usanmak'.

121 Bu biçimde KM cang 'sopa' ismiyle benzeşme söz konusudur.

122 Hlç. ya:ng ya: $n^{g}$, Yak. say.
} 


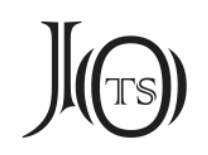

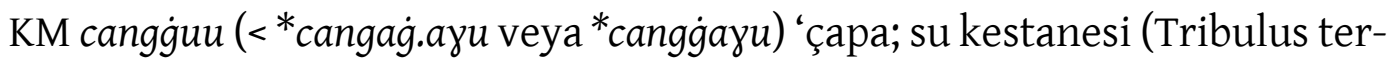
restris)' (OM ${ }^{\mathrm{BY}}$ cangǵau, Hlh. зангуy, Ma. -) || GT yagak yayak yaygak 'ceviz'

KM canu- 'korkutmak, gözdağı vermek, tehdit etmek' (OM ${ }^{\mathrm{ME}}$ canu-, Hlh. занах, Ma. саnu-) || GT yan- yant- yana- 'tehdit etmek'

KM carag̀ 'gerekli olan, ihtiyaç' (OM ${ }^{\mathrm{MGT}}$ carag ‘önemli şeyler', Hlh. zapaz, Ma. -) || GT yarag 'yakışan, gereken; fırsat, imkân; silah, teçhizat'

KM carim 'biraz; bir şeyin yarısı veya bir parçası' (OM ${ }^{\mathrm{MGT}}$ carim, ${ }^{\mathrm{HY}}$ carim, ${ }^{\mathrm{ME}-}$ carim, ${ }^{\mathrm{i}}{ }^{\mathrm{c}}$ carim (I) 'bazı, bir kısım', ${ }^{\mathrm{i}}{ }^{\mathrm{C}}$ carim (II) 'yarım, buçuk', ${ }^{\mathrm{RM}}$ cārim, Hlh. зapuм, Ma. -) || GT yarım 'yarım, yarı'

KM carlig 'ferman, emir, buyruk' (OM ${ }^{\mathrm{MGT}}$ carlig, ${ }^{\mathrm{ME}}$ carlik, ${ }^{\mathrm{SL}}$ carlig, ${ }^{\mathrm{iM}}$ yarlig, ${ }^{\mathrm{PH}}$ carliq, Hlh. зарлиг, Ma. -) || GT yarlig 'ferman, emir, buyruk'

KM carma 'kabuksuz tahıl, kaba öğütülmüş tahıl, kepek' (OM -, Hlh. зарам, Ma. -) \| GT yārma 'yarma, kalın taneli un'

KM cayidang (< *apıtay) 'eyersiz' (OM -, Hlh. зайдан(2), Ma. -) || GT yapitak (?< yapı 'eyer örtüsü' + täk) 'eyersiz, çıplak, palansız (at)'

KM cayig 'Ural nehri' (OM ${ }^{\mathrm{MGT}}$ cayag, Hlh. -, Ma. -) || GT yayık ${ }^{123}$ 'Ural nehri' (krş. Ptolemaios $\Delta \alpha^{\prime} i ̈ \xi$, Menandros $\Delta$ åî̀, Konstantinos VII. Porphyrogennetos Гعńx, İbn Faḍlān جيخ cayih).

KM cayil- cayilu- ( ${ }^{*}$ cayi-) 'çalkalamak, yıkayıp temizlemek' (OM -, Hlh. зайлах, Ma. -), cayimu- (<' cayi-) 'sallanmak, titremek' (OM -, Hlh. займах, Ma. -) || GT yay- yāy-124 'sallamak, sarsmak, titremek; çalkalamak, çitilemek; meylettirmek’, GT *çay- ${ }^{125}$ 'çalkalamak, yıkamak; sallamak’, BT *cay-ı (veya *çay-ı) ‘şamata, velvele, karmaşa; dert, sorun' (> Çuv. śuy)

$\searrow$ KM nayigiu-

\footnotetext{
${ }^{123}$ Tat. cayěk, Bşk. yayık, Kzk. jayık, Kmd. d'ayık.

${ }^{124}$ EUyg. yay-, DLT yay-, Tuv. çay-, Tkm. yāy- 'yayık yaymak', Hlç. yāa- 'yağ yapmak'.

${ }^{125}$ Osm. çalka-, Trk. çalkala-, Tkm. çayka-, Tat. çayka-, Bşk. sayka-, Krç.-Blk. çayka-, Kmk. çayka-, Nog. şayka, Kzk. şayka-, YUyg. çayki-, çuv. çühe- çüke- ( $\leftarrow$ Tat.).
} 


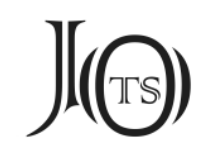

KM cebe 'ok başı, temren, mizrak ucu' (OM ${ }^{\mathrm{MGT}}$ cebe 'savaş aleti, silah', ${ }^{\mathrm{HY}}$ cebe 'silah', ${ }^{\mathrm{ME}}$ körte cebe 'zırh', ${ }^{\mathrm{ME}}$ cebetü 'mizrakl1', ${ }^{\mathrm{ME}}$ cebeten 'mizrakl1', Hlh. зэв, Ma. -), KM cebele- (< cebe.le-) 'silahlandırmak, donatmak' (OM ${ }^{\mathrm{MGT}}$ cebele- 'savaşmak, çarpışmak', Hlh. -, Ma. cebele 'ok kıllf1, kubur') || GT yäp ${ }^{126}$ 'alet edavat, silah', GT (EUyg.) yävälä- 'zırhla donatmak, zırhlandırmak'

KM cebseg ${ }^{127}$ 'silah; alet, araç, donanım' (OM ${ }^{\mathrm{MGT}}$ cebseg, ${ }^{\mathrm{ME}}$ cebsek 'zırh (= Çağ. sagıt)', iм ${ }^{\text {cemsek }}$ 'küçük balta, nacak' (?), Hlh. зэвсэг, Ma. -) || GT (EUyg.) yev- 'donatmak', (EUyg.) yeväg 'teçhizat, donanım, malzeme', (EUyg.) yevig 'donatma, teçhizat, süs, süsleme', (EUyg.) yeviş 'destek, yardım' (krş. Yak. säp 'alet edavat, araç gereç, teçhizat; silah; eşya', Dolg. häp säp 'araç gereç; koşum takımı; aksesuar, ekipman')

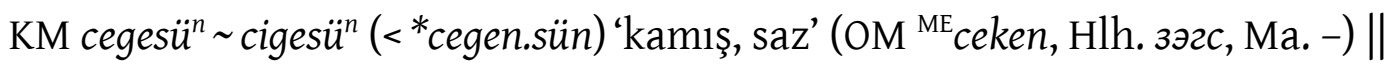
GT yäkän yekän 'hasır, kamış, saz', BT *cäkän 'hasır, kamış, saz' (> Çuv. çakan) (krş. Mac. gyékény 'saz, hasırotu, kamış', Os. дзеген, дзегейнс 'hasır', Udm. śakan 'hasır, hasır örtü, çul')

KM ceGen 'kutup porsuğu' (OM -, Hlh. -, Ma. -) || GT yēgän ${ }^{128}$ (<yē-gän) ‘kutup porsuğu, Gulo gulo'

KM ceyeg ceg ( $<$ *epek) 'sırmalı şerit, bir nesnenin çevresine sarılı ip' (OM -, Hlh. зээг, Ord. DžēG, Ma. -) || GT yıp yip yep 'ip, iplik, sicim, urgan’ (krş. Mac. gyeplő 'dizgin') veya GT (EUyg.) yipäk ${ }^{129}\left(\sim\right.$ yipkä $\left.{ }^{130}\right)$ 'ip, halat'

$\searrow \mathrm{KM}$ deresïn

\footnotetext{
${ }^{126}$ Yak. säp 'alet edavat, araç gereç, teçhizat; silah; eşya', Dolg. häp säp 'araç gereç; koşum takımı; aksesuar, ekipman'.

${ }^{127}$ Moğolca sözcüğün karşıllı̆̆ Türkçede tanıklanmamıştır. Moğolca sözcük muhtemelen tanıklanmamış bir *cevşäk (= GT *yev-iş+äk) veya *cevzäk (= GT *yev-iz+äk) biçiminden alıntıdır. Diğer olasılık ise Moğolca kelimenin Türkçe *ceväg (= GT yeväg) sözcüğünden *cebeg şeklinde alıntılanmış olup bir benzeşme sonucu cebseg biçimini almış olmasıdır.

${ }^{128}$ Alt. Tel. yä̋kän (R III 318), Alt. (Aşağı Biy, Aşağı Kondom) yeeken yeken (Verbitskiy 1884: 87), Tel. d'eeken, Yak. siän 'etobur; kurt; vahşi hayvanların av1', Dolg. hiegen.

129 Sözcük, Harezm Türkçesinden itibaren 'ipek’ anlamıyla tanıklanmıştır.

${ }^{130}$ TT VIII F 14 (T III M 145-1) yipkä 'iplik, ince ip' (Gabain 1954: 47, 103).
} 


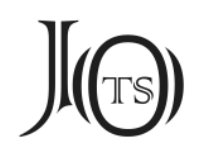

$\mathrm{KM}$ ceyerde cerde (?< *cegerne) 'k1z1l, kırmızl, kestane rengi' (OM ${ }^{\mathrm{MGT}} c e^{\prime} e r d e$, ${ }^{\mathrm{BY}} \mathrm{ce} e r d e,{ }^{\mathrm{ZY}} \mathrm{ce} r d e,{ }^{\mathrm{RS}} \mathrm{cerde}$, Hlh. зээрд, Ma. cerde) || GT yägrän 'kestane rengi', BT *cägrän 'kızıl, al' (> Çuv. süüren)

$\mathrm{KM}$ ceyer-e $e^{n}$ 'antilop, ceren, ceylan' (OM ${ }^{\mathrm{HY}}$ cēren, ${ }^{\mathrm{ME}} c \bar{e} r e n,{ }^{\mathrm{TA}}$ ciyren, ${ }^{\mathrm{IM}}$ cerēn, ${ }^{\mathrm{RS}}$ cerēn, ${ }^{\mathrm{NK} 1}$ cērĕn, ceiran, ${ }^{\mathrm{NK} 2}$ cēren, Hlh. зəэр, Ma. ceren, Cür. ceri) || GT yägir ${ }^{131}$ 'antilop, ceylan'

KM cele 'hayvan kösteklerinin bağlandığı yere gerili halat, hayvanların bağlandığı yer' (OM ${ }^{\mathrm{BY}}$ cele, ${ }^{\mathrm{RS}}$ calā [oku: cele], Hlh. зәл, Ma. -) \|| GT yälü (? yälö) 'tayları bağlamak için kullanılan ip’

KM cemdeg (<* cemV-) 'sakat, kötürüm, topal' (OM ${ }^{\mathrm{MGT}}$ cemdeg, Hlh. зэмдэг зэмтэг, Ma. -) || GT yämir-132 (< *yäm-ir- < *yäm-) 'yıkmak, parçalamak, mahvetmek, harap etmek', BT *cemür- 'yıkmak, parçalamak, bozmak' (> Çuv. śĕmĕr-)

KM cem-e 'leş' (OM -, Hlh. -, Ma. -) || GT yèm 'yem, yemek, yiyecek' veya GT *yēmä ${ }^{133}$ (< *yē-mä) 'yiyecek', BT cēmä 'yemek, yiyecek, erzak; yem' (> Çuv. śime)

$\mathrm{KM}$ cemis $\sim$ cimis $\sim$ cimes 'yemiş, meyve' $\left(\mathrm{OM}^{\mathrm{HY}}\right.$ cemiş, ${ }^{\mathrm{ME}}$ cimiş, ${ }^{\mathrm{BY}}$ cemis, ${ }^{\mathrm{RS}}$ cemiş, ${ }^{\mathrm{im}}$ yimiş yemiş, ${ }^{\mathrm{PH}}$ cemiş, Hlh. wumc, Ma. -) \|| GT yemiş 'yemiş, meyve', BT *cimi(l)ç ‘yiyecek, meyve’ (> Çuv. śiměś) (krş. Mac. gyümölcs 'meyve')

KM cer (cebe, cebsek) ‘silah, cephane’ (OM ${ }^{\mathrm{MGT}}$ cer cebsek, Hlh. зэр зэрсэг, Ma. ) || GT yäz 'bakır, pirinç, bronz' (? $\leftarrow$ Toh. B yasa 'altın')

$\searrow \mathrm{KM}$ ces $\sim$ cis $\sim$ ced

$\mathrm{KM}$ ces $\sim$ cis $\sim$ ced 'bakır' $\left(\mathrm{OM}^{\mathrm{HY}} \mathrm{ces},{ }^{\mathrm{ZY}} \mathrm{ces},{ }^{\mathrm{BY}} \mathrm{ces},{ }^{\mathrm{iM}} \mathrm{cez}\right.$ 'bakır, pirinç', ${ }^{\mathrm{RS}} \mathrm{ciz}, \mathrm{Hlh}$. зэc, Ma. -) || GT yäz 'bakır, pirinç, bronz' (? $\leftarrow$ Toh. B yasa 'altın')

$\searrow$ KM cer

${ }^{131}$ Küli Çor Yazıtı 18 y(ä)g(i)r, SUyg. yizır yizer, Alt. yeger yiger yigr 'al (at donu)' (Verbitskiy 1884: 86, 93), Hak. çiğr 'boz, al (at donu)', Yak. siär 'koyu kahverengi (at donu)'.

132 EUyg. yemir-, DLT yämür-, Çă̆. yemür- yümür-, HŞ yemür-, KI yümür-, TZ yümür-, Osm. yemir- yümür-

${ }^{133}$ DLT yämääçü+k 'küçük kese', Hlç. yēmä 'yemek, gıda’. 


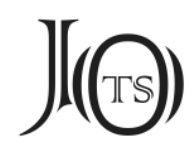

KM cetegene (< cete.gene) 'çilek' (OM -, Hlh. зәдгэнэ, Kalm. zed’gən ’bir tür yemiş', Ma. -) || GT *yedläk134 (< *yed+läk) 'çilek, yemiş', BT *cedläk 'çilek, yemiş’ (> Çuv. śrla) (krş. Mac. szőlo” 'üzüm, üzüm bağı')

KM ciçi 've, hem, ve dahi, ayrıca, üstelik, özellikle' (OM ${ }^{\mathrm{HY}}$ ciçi 'tekrar, yine, aynı şekilde, ayrıca', Hlh. ж̌ч, Ma. -) || GT yiçä 'yine, yeniden, tekrar'

- Kit. 水水 〈çi.çi * *çiç(i) 'ile birlikte, ve saire' (Kane 2009: 54; Wu-Janhunen 2010: 175)

KM cidkü- cidke- (< *cegtü-) 'araba vb. çekmek; gayret etmek, çabalamak' (OM ${ }^{\mathrm{MGT}}$ cikdü- ciktü- 'arabayı çekmek', ${ }^{\mathrm{MGT}}$ citgü'ül- 'arabayı çektirmek', ${ }^{\mathrm{ME}}$ cidkü'niyet etmek, gayret etmek', Hlh. зүтгэх, Ma. -) || GT yēt- '(at, insan vb.) yanında götürmek, çekerek peşinden götürmek', BT *cägt- > *cägVt- '(elinden tutup) götürmek' (> Çuv. śavăt-)

KM cigeye (<cekepe) 'kutup porsuğu' (OM -, Hlh. зэгəэ, Ma. -) || GT *yekpä135 'kutup porsuğu'

KM cigir- 'korkuyla sarsılmak, titremek; soğuktan titremek' (OM ${ }^{\mathrm{ME}}$ cigir- 'ĭgrenmek', Hlh. -, Ma. -) || GT (OTi) yäkir- ${ }^{136}$ 'kızmak, hiddetlenmek, azarlamak, paylamak'

KM cigsi- 'iğrenmek, nefret etmek, tiksinmek; sevmemek, hoşlanmamak; ürkmek' (OM -, Hlh. жcuzmux, Ma. ceksi- cekşe- 'sevmemek, hoşlanmamak; ürkmek, korkmak') || GT (ÇTi) yäksi- ${ }^{137}$ (< yäk+si-) 'tiksinmek, iğrenmek; ürkmek, çekinmek, korkmak'

134 Tat. cilek, Bşk. yilek, Kmk. ciyelek, Krç.-Blk. cilek, Kzk.jiydek, Tuv. çestek-kat, Hak. çistek, Alt. cilek ciilek, Alt. yestek yistek (Verbitskiy 1884: 90, 94), Tel. d'iilek.

${ }^{135}$ Tuv. çekpe 'kutup porsuğu'. Radloff (R III 320), Koybal Türkçesinden bir yäkpä biçimi vermekte ve "= јӓккӓн” diye not düşmektedir. Ne yazık ki bu eşitliğin yäkän yäkkän 'hasır otu' sözcüğüne mi yoksa yä̋kän 'kutup porsuğu' sözcüğüne mi gönderme yaptığı tam olarak anlaşllamamaktadır.

136 Çağ. yiKir-, Kİ yekir- yikir-, KK yigir-, İMS yigir-('öfkelenmek') igir-('tiksinmek'), Tat. cikĕr-, Bşk. yĕkĕr, Tkm. yekir-, Kum. yekir-, Nog. yekir-. Ayrıca bk. ESTYa (IV 173-174).

137 Tat. ciksě-, Alt. yeksin- (Verbitskiy 1884: 87), Tel. d'eksin-, Hak. çॅ̆gs̆- $(\leftarrow$ Mo.), Tuv. çeskin-. Ayrıca bk. ESTYa (IV 171). 


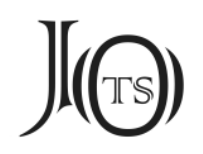

KM cize 'kız evladın ve kız kardeşin çocuğu' (OM ${ }^{\mathrm{MGT}} c e^{\prime} e \sim c e,{ }^{\mathrm{HY}} c e^{\prime} e,{ }^{\mathrm{BY}} c \bar{e}, \mathrm{Hlh}$. зээ, Ma. -) || GT yegän 'yeğen’

- Kit. 水炎〈eč.ee〉 *cee ‘kız kardeşin çocuğu, yeğen’ (Ōtake 2017: 201)

KM cizura- cuyura- 'yoğurmak, karıştırmak' (OM ${ }^{\mathrm{MGT}}$ ci'ure-, ${ }^{\mathrm{ME}}$ cūra- cuğra, ${ }^{\text {iM }}$ cugurar-, Hlh. syypax, Ma. -) || GT yugur- 'yoğurmak', BT * cugur- > *cūr- 'yoğurmak, karıştırmak' (> Çuv. śăr-) (krş. Mac. gyúr 'yoğurmak')

KM cil 'yll, sene' (OM ${ }^{\mathrm{MGT}} c i l,{ }^{\mathrm{HY}} c i l,{ }^{\mathrm{TA}} c i l,{ }^{\mathrm{PH}} c i l$, Hlh. жwuл, Ma. - ) || GT yll 'yll, sene'

KM cilbi ‘sihir, büyü’ (OM -, Hlh. -, Ma. -) || GT yelvi 'sihir, büyü’

$\checkmark \mathrm{KM}$ yilbi $\sim$ yelbi $\sim$ yilvi

KM cildam 'yetenekli kayakçı' (OM -, Hlh. жৈaлdaм, Ma. ilda- 'kıvrak zekâlı olmak, çevik olmak, zeki olmak') || GT (OTi) ıldam yıldam 'hızlı, çevik, atik', BT *ltam ‘zarif, çevik, atik' (> Çuv. yălttam) (krş. Mac. ildom ‘düzgün davranış')

$\searrow \mathrm{KM}$ ildam

KM cilgü- cülgü- 'silmek, parlatmak, tozunu almak; sürtmek, sürtünmek, değmek, sıyırmak' (OM -, Hlh. зүлгэx, ?Ma. cilki- 'keteni vb. artıklardan arındırmak için dövmek, vurmak' [Hauer 2007: 282], ?Ma. culhū- 'ok milini eğe talaşıyla, kılla veya tiftikle cilalamak') || GT (DKPAM) yilkä- '(boynuzuyla) yeri karıştırmak, eşelemek'

KM cilǵ-a cilaǵ-a 'koyak, vadi, oyuk, havza, hendek, su yolu' (OM ? ${ }^{\mathrm{MGT}}$ cölke 'ortasından nehir geçen vadi', ME cilgas ‘vadi, koyak, Hlh. «̌anza, Ma. -) || GT yūlak (<yūl) 'küçük su pınarı, derecik'

KM ciloza $\left(<*\right.$ cilayu $\left.{ }^{138}\right)$ 'yular' (OM ${ }^{\mathrm{MGT}}$ cilo'a $\sim$ cilu'a, ${ }^{\mathrm{ME}}$ cila'u, ${ }^{\mathrm{TA}}$ cilawu, ${ }^{\mathrm{iM}}$ colā, ${ }^{\mathrm{RS}}$ cilau, ${ }^{\mathrm{RM}}$ cilāwū, Hlh. жколоo, Ma. culhū, Sol. ciluya [SSTYa I/257]) || GT yular 'yular'

${ }^{138}$ Alınt1, PM *clazu < PPM *claru $\leftarrow$ Tü. * cularŭ şeklinde gerçekleşmiş olabilir. İkinci hecedeki $r>\gamma$ değişimi, $l$ sesi yanında bir aykııılaşma olarak açıklanabilir. Diğer bir açıklama için Ölmez’e (1991: 180) bakılabilir. 


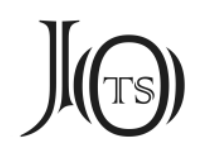

KM cilu- culu- 'kaçmak, sıvışmak' (OM -, Hlh. -, Ma. -), KM ciliyi- 'kaçmak; yolunu şaşırmak' (OM -, Hlh. жилиŭx, Ma. -), KM culbu- 'kaçmak, kaçıp kurtulmak' (OM -, Hlh. зулбах ‘kaçmak', Ma. -) || GT yîl-139 ‘sürünmek, kaymak, uzaklaşmak, hareket etmek, ilerlemek'

KM cimiyi- (?<* ${ }^{*}$ crml-yl-) '(dudak) büzülmek' (OM -, Hlh. жмимийx, Ma. -) $\|$ GT $y ı m^{-140}$ (> yum- yüm- yim-141) '(göz, ağız, yumruk) yummak, kapamak'

KM cincü̈̈ 'inci, boncuk' (OM -, Hlh. жкинжүүY, Ma. -) \| GT yinçü 'inci' ( $\leftarrow$ Çin. 真珠 zhēn-zhū 'gerçek inci') (krş. Mac. gyöngy 'inci', Rus. жеммчyz 'inci', ERus. женчугъ 'inci')

KM cingǵurçag̀ ‘semer, kürtün’ (OM ${ }^{\mathrm{MGT}}$ inggirçag, Hlh. -, Ma. -) || GT ııırçak yııırçak 'semer, kürtün, eyer'

$\searrow$ KM yanggirç̧ág $\sim$ yanggiy-a

KM cirbayi- 'zıplamak, oynamak, gülüp eğlenmek' (OM -, Hlh. -, Ma. -) || GT (DLT) yarp 'biri neşe içinde olduğu zaman yüzünü kaplayan 1şıldama', GT yarpay142 'üstünlük taslamak, kibirlenmek; güzel görünmek, güzelleşmek; içtenlikle gülmek'

$\searrow \mathrm{KM}$ darbi-

KM cirim 'olong'un tokalarından geçirilen, eyerin sol yanındaki iki deri kayıştan biri' (OM ${ }^{\mathrm{BY}}$ cerim/cirim 'eyerin deri kayışları', ${ }^{\mathrm{ME}}$ cirim 'deri şerit, kayış', Hlh. жирэм, Ma. -) || GT (DLT) yerim 'herhangi bir şeyden kesilmiş şerit, bir şeyin yaris1'

KM cirin ( ${ }^{*}$ ci.r.in $<{ }^{*}$ ci) 'iki (eski metinlerde kadınlar için kullanılan sayl)' (OM ${ }^{\mathrm{MGT}}$ cirin, Hlh. -, Ma. curu 'çift, çifte', PTg. *cör 'iki' [Doerfer 1978: 75]), KM cirmüsün 'hamile' (OM -, Hlh. жиирэмсэн, Ma. cursu 'iki katmanlı, çift; hamile'), KM citüger ( ${ }^{*}$ ci(r).tüger) 'kıskançlık, nefret; çok eşli evliliklerde kadınların birbiri için kullandığı hakaret sözü' (OM ${ }^{\mathrm{ME}}$ citür 'kıskançlık', ${ }^{\mathrm{R} S}$ citür 'cariye, ikinci eş', Hlh.

\footnotetext{
139 Uzun ünlü, Yak. sil- ve Dolg. hïl- şekillerine dayanmaktadır.

140 Leb. yım- (R III 500).

141 Yak. sim-, Hlç. yim-.

${ }^{142}$ Tat. yarpay-, Bşk. yarpay-, Kırg. carbay-.
} 


\section{$J(\Theta)$}

жетгер, Ma. -) || GT yigirmä yigirmi yigärmi yegirmi ${ }^{143} \sim$ *yügürmä ${ }^{144}(<$ *yi *ye) ‘20', BT *cegärmi ‘20' (> VB ciyermi ceyermi, Çuv. śirĕm)

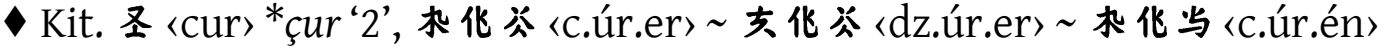
'ikinci' (Kane 2009: 115, 124), 圣 〈cur〉 *cur '2' (Shimunek 2014: 114), 水化〈ci.ur〉 cür '2' (Róna-Tas 2016: 127)，水化〈ç.ur〉～执夜〈ç.ur〉 *çur-～去化〈c.ur〉～圣〈cur〉 *cur- '2' (Shimunek 2017a: 232-236, 334-335), 丁 *cüri (Róna-Tas 2016: 133), 丁 «curi *curi '20' (Shimunek 2017b: 265, 267).

KM cirke (?< *irske) ‘çizgili sincap, Tamias sibiricus Laxmann' (Tsevel 1966: 248) (OM ${ }^{\text {BY }}$ cürgi 'yarasa', Hlh. жcupx, Ma. -) || GT yärsgü *yarsgu ${ }^{145}$ 'yarasa'

KM cirmaGay 'balık yumurtası, havyar' (OM ${ }^{\text {MGT }}{ }^{\text {ciramut }}{ }^{146}$ 'küçük balıklar', ${ }^{R S}$ carçi calasun 'tutkal, ökse', Hlh. зарам 'küçük balık, yavru balık', Dag. carəm, Ma. -) || GT *yaru 'balık, balık yumurtası, balığın iç organları (?)' > GT (EUyg., DLT) yaru yelim 'balık tutkalı'

$\mathrm{KM}$ ciroya ( $<{ }^{*}$ coriga) 'rahvan, eşkin (at)' (OM ${ }^{\mathrm{ZY}}$ curā,${ }^{\mathrm{BY}}$ coriya,${ }^{\mathrm{TA}}$ coriya, ${ }^{\mathrm{SL}}$ coria, Hlh. wsopoo, Ma. coran) || GT yorıga 'rahvan (at)', BT *corlka 'rahvan' (> Çuv. śărha)

KM ciru- '(resim, çizgi) çizmek' (OM ${ }^{\mathrm{ME}}$ ciru- ${ }^{\mathrm{iM}}$ cila- 'boyamak, süslemek', Hlh. зурах, Ma. cusu- 'kâğıda çizgi çizmek', PTg. *níru- 'çizmek ${ }^{147}$ ) || GT yaz- 'yazmak', BT *car- 'yazmak, çizmek' (> Çuv. śrr-)

\footnotetext{
${ }^{143}$ Tuv. çeerbi.

${ }^{144}$ Yak. sürrbä.

${ }^{145}$ DLT yärsgü, Tuv. çaskl (<*yarsku).

${ }^{146}$ MGT ciramut sözcüğgü, ${ }^{*}$ ciram 'küçük balık' sözcüğünün çokluk şeklidir.

${ }^{147}$ PTg. *ńiru- 'çizmek' (> Ma. niru- 'çizmek, resmetmek', Nan. ńiru- iru- 'yazmak', Orok nứi- ńirunúru-, Ulça ńuri- ńuru- 'yazmak', Oroç ńiru- ńuru-, Neg. niyu-, Sol. niruyan [SSTYa I/600]) sözcüğü, muhtemelen Moğolca *niru- aracılığıyla ulaşmış Bulgar Türkçesi kökenli bir sözcüktür. Ancak Moğolcada böyle bir fiil tanıklanmamıştır. Aynı şekilde, Ma. cusu- sözcüğü de tanıklanmamış Mo. *cusu- (< *cisu-) şekli üzerinden Genel Türkçeden gelmektedir. Mançucadaki bu iki sözcük, bizi BT *ńiaru- ve GT *ciazu- şekillerine götürür.
} 


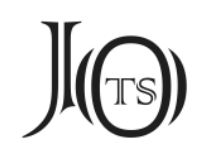

- Kit. 水 〈çi〉 *cir- 'yazmak' (Róna-Tas 2019: 296) ${ }^{148}$, Kit. 圣与 «cur.en〉 *curon (çoğ.) 'resimler, çizimler' (Shimunek 2014: 104, 114; Shimunek 2017a: 220, 346) < Kit. *cur 'resim, çizim' < *cirug 'resim, çizim'

KM ciruǵba $\left(<{ }^{*}\right.$ cirbuǵa < ${ }^{*}$ ciarpurka $\left.{ }^{149}\right)$ 'nane' (OM -, Hlh. -, Ma. -) || GT yarpuz $\sim$ yarpuç ${ }^{150}$ 'yarpuz, nane'

$\mathrm{KM}$ cirüke ${ }^{n}\left({ }^{*}\right.$ cürekü ${ }^{n}$ ?) 'kalp, yürek' (OM ${ }^{\mathrm{MGT}}$ cürügen cirüge $(n),{ }^{\mathrm{HY}}$ cürüken, ${ }^{\mathrm{BY}}$ cürken, ${ }^{\mathrm{ZY}}$ cürüken, ${ }^{\mathrm{ME}}$ cürüken, ${ }^{\mathrm{IM}}$ cürüke, ${ }^{\mathrm{RS}}$ cirüke, Hlh. зүрx(ән), Ma. -) || GT yüräk ${ }^{151}$ 'yürek, kalp’, BT *cüräk (?) ‘yürek, kalp’ (> Çuv. çěre).

KM cise- cese- 'nöbet tutmak, beklemek, korumak' (OM -, Hlh. зэсэx, Ma. ) || GT yezä- 'devriye gezmek', GT yezäk 'öncü birlik, ileri kol'

KM cisü- 'uzunlamasına kesmek, șeritler hâlinde kesmek, dilimlemek, didiklemek, hakketmek' (OM ${ }^{\mathrm{MGT}}$ cisü- 'yarmak', ${ }^{\mathrm{ME}}$ cisü- 'dilimlemek, didiklemek', Hlh. зүсэх, Ord. cusw-, Bur. zühe-, Kalm. züs- ${ }^{152}$, Ma. cisu- 'deri veya benzer bir malzemeyi düz bir çizgide kesmek') || GT yüz- 'derisini yüzmek'

KM cisün '(hayvan ve insanlarda) renk, görünüş, cilt' (OM ${ }^{\mathrm{MGT}}$ cisü(n), Hlh. зүс(эн), Ma. -, Sol. cisū 'renk'), KM cisüm '(hayvanlarda) renk' (OM -, Hlh. зүсэм, Ma. -) || GT yü̈z 'yüz, çehre, surat'

$\mathrm{KM} \operatorname{coçin}\left(<\right.$ *colçin) 'konuk, misafir, ziyaretçi' (OM ${ }^{\mathrm{MGT}}$ Coçi 'kişi adı', ${ }^{\mathrm{HY}} \operatorname{coçin}$, ${ }^{\mathrm{BY}}$ coçin, ${ }^{\mathrm{ZY}} \operatorname{cocin,}{ }^{\mathrm{ME}}$ coçin, Hlh. зочuн, Ma. -) \|| GT yolçı 'yolcu; rehber, kılavuz'

KM coǵdur (< cog̀tu.r) 'devenin boynundaki uzun kıllar; aslan yelesi' (OM -, Hlh. зогдop, Ma. -) || GT yogdu (Br. yogto) '(aslan) yele(si); devenin çenesinin altındaki uzun tüyler; gerdan' (? Çuv. śıtar 'yastık') (krş. KS AoX'kTopł 'yastık' $\leftarrow$ BT *cogtor)

\footnotetext{
${ }^{148}$ Shimunek (2014: 114) aynı fiili Eski Çince 書 shū ‘yazmak’ sözcüğünden bir alıntı olarak göstermektedir.

149 Moğolca sözcüğün kökeni, BT *crrpurıkă veya *ciarpurıă 'nane' şekli olmalıdır.

${ }^{150}$ Hlç. yarpıç 'nane'.

151 Tkm. yürek, Yak. süräx, Dolg. hüräk süräk hürök.

${ }^{152}$ Çă̆daş Moğol dillerindeki bu biçimler, ${ }^{*}$ cüsü- biçimine işaret etmektedir.
} 


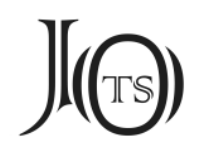

KM coyog cog 'yemek, öğün; zevk, eğlence; yürüyüş̧' (OM -, Hlh. 3002, Ma. -

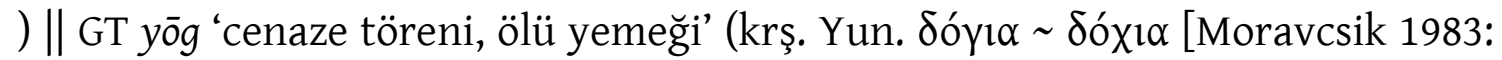
II/119], Os. dūğ doğ 'yarış, koşu')

KM coyori 'bodrum, kiler, mahzen' (OM -, Hlh. 30opb, Ma. -) \| GT yogrı 'çanak, geniş bir kâse' veya GT çokur çukur 'çukur' (krş. DLT çugurdān 'uçurum, suyun önüne çekilen set')

KM coki- 'uymak, uygun olmak, yakışmak, yakışır olmak' (OM ${ }^{\mathrm{MGT}}$ coki- 'uymak, uygun olmak, doğru olmak, iyi durumda olmak', ${ }^{\mathrm{PH}}$ cokis 'uygunluk, kolaylık', Hlh. зохих, Ma. cohi- '(çıban veya yara) iyileşmek, kapanmak', Evk. дёке- cokeдёки- coki- 'uyum sağlamak, memnun etmek; düzeltmek, tamir etmek; kabul etmek, rıza göstermek; (üzerinde) denemek, prova etmek', Sol. cohi- 'adil olmak, vermek, sunmak, sağlamak; uygun olmak') || GT yokl- yoka- ${ }^{153}$ 'teslim olmak, itaat etmek'

KM col 'şans, talih, başarı' (OM -, Hlh. 30л, ?Ma. culgen 'talih, şans') \| GT yol ${ }^{154}$

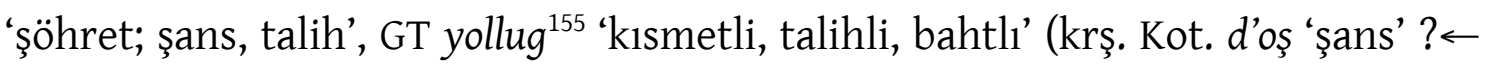
GT *oş = GT yol [Stachowski 1996: 102-103])

- Kit. 祝君統 zhù-jūn-tǒng ${ }^{156}$ *coltun 'mutluluk, himaye' (Talpe 2010: 88)

KM colga- 'karşılaşmak, kendini tanitmak' (OM ${ }^{\mathrm{MGT}}$ colqa- coluqa-, ${ }^{\mathrm{HY}}$ coloqacoluqa-, ${ }^{\mathrm{ME}}$ colka-, Hlh. золгох, Ma. -) || GT yoluk- 'karşılaşmak, rastlamak', BT *coluk'karşılaşmak, rastlaşmak' (> Çuv. śulăh-)

KM coli- 'fidye verip kurtarmak, rehinden kurtarmak' (OM ${ }^{\mathrm{MGT}}$ coli'a 'fidye, tazminat', Hlh. золих, Ma. coldo-, Evk. coldon-) || GT yul- 'rehinde bulunan bir şeyi kurtarmak, esirlikten kurtarmak, fidye ödemek, fidyeyle kurtarmak'

$\searrow$ KM doli-

\footnotetext{
${ }^{153}$ EUyg. (Kuanşi İm Pusar 37) yokıl- 'teslim olmak' (Tekin 1993: 10, 26, 53), CC yogo- 'itaat etmek'. Tekin (1993: 26, 53) yokıl- sözcüğünü ‘sanık olarak tutulmak' şeklinde anlamlandırmıştır.

154 AY 444/5.

${ }^{155}$ KT G 13, KT G-D, KT G-B, BK G-B, TT V B103.

${ }^{156}$ EMand. tsy-kyn-t ${ }^{\mathrm{h}}$ ung (Pulleyblank 1991: 310, 415, 168).
} 


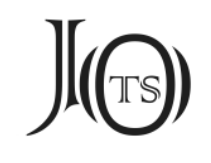

KM comog்ol (< comogjo.l < *conag்a) 'yonga, talaş' (OM -, Hlh. зомгол, Ma. -) \|| GT yonga (<yon-) 'yonga, kıymık, talaş’, BT *conka 'yonga, talaş' (> Çuv. śunka, śunkav)

KM conggila- 'birleştirmek; toplamak, yığmak' (OM -, Hlh. -, Ma. -) || GT (HtPek 21a 3) yoyla- ${ }^{157}$ ‘birleştirmek, uyumlu hâle getirmek' $(\leftarrow$ Çin. 雍 yōng ‘birleşmiş, uyum içinde')

KM cori- 'yönelmek, -e doğru hareket etmek; çabalamak, niyet etmek' (OM ${ }^{\mathrm{MGT}}{ }^{\mathrm{C}}$ cori- ${ }^{\mathrm{HY}}{ }^{\mathrm{HY}}$ cori-,${ }^{\mathrm{ME}}$ cori- ${ }^{\mathrm{PH}}{ }^{\mathrm{C}}$ cori-, Hlh. sopux, Ma. cori- 'işaret etmek, göstermek') \| GT yort- (? yōrt- $\left.{ }^{158}\right)$ 'yürümek'

KM coso 'aşıboyası' (OM ${ }^{\mathrm{MGT}}$ cosotu 'bir atın adı', ${ }^{\mathrm{ME}}$ cuşa, Hlh. 3oc, Ma. -) || GT yoşa $a^{159}$ 'aşıboyası' (krş. EUyg. ışu 'kırmızı kil', DLT aşu 'kızıl toprak')

KM cöye- cöyeye- 'bir şeyi bir yerden bir yere hareket ettirmek, nakletmek, taşımak' (OM ${ }^{\mathrm{HY}}$ cögelge-, ${ }^{\mathrm{HY}}$ cöge'ül-, Hlh. $3 ө \theta x$, Dong. cue- çue-, Ma. cuwe-) $\|$ GT *yü160 'taşımak, yüklenmek', BT *cü̈̈̈-d- > *cü̈̈̈r- ${ }^{161}$ 'taşımak'

- Kit. 万方 〈y.eu〉 *yew- ${ }^{162}$ 'taşımak, götürmek, nakletmek' (徙) (Kane 2009: 108; Shimunek 2007: 379; Shimunek 2017b: 263, 268), 万丸 〈ey.aw〉 *yaw- 'yönlendirmek' (Ōtake 2017: 202)

KM cud cid 'kötü hava ve benzeri yüzünden ortaya çıkan afet; açlık, kıtlık; hayvan vebası' (OM -, Hlh. syd, Ma. -) \|| GT yūt 'açlık, kıtlık, felaket'

\footnotetext{
${ }^{157}$ HtPek 21a 1-3 (2026) ıdok ätözi tümän kutlugı birlä elin uluşın amırtgurup ywglap [...]. Röhrborn (1991:172, 259), bu fiili yunla- olarak okumaktadır.

${ }^{158}$ DLT yort- yōrt-, Hlç. yộri-.

159 ME yuşa (oku: yoşa ?), Trk. ağ. yoşa, Kırg. coşo, Tel. yojo (R III 446), Yak. soho.

160 GT yü̈-d- 'taşımak', GT yü-k 'yük'.

${ }^{161}$ krş. Nagyszentmiklós Yunan harfli yazıtı $\Delta$ YГ€- düä(r)- [cüär-] 'taşımak' (Erdal 1988: 229-230).

162 Shimunek (2017: 263, 268), bu fiili OM yabu- 'gitmek' fiiliyle ilişkilendirmektedir. Bizce, Kit. *yew- (< *yewü-) fiili, göçüşmeyle *yüwe- biçiminden gelmektedir. Bu biçim de Tü. *yüe- biçiminden alınmıştır. Diğer yandan, Kitanca sözcük Moğolca *yeü- 'bir sıvıyı bir kaptan diğerine boşaltmak' (Nugteren 2011: 546) fiiliyle de ilişkilendirilebilir.
} 


\section{J(৫)}

KM cula 'sşık, lamba, mum' (OM ${ }^{\mathrm{HY}}$ cula, ${ }^{\mathrm{ME}}$ cula $\sim$ culan, ${ }^{\mathrm{iM}}$ cula, ${ }^{\mathrm{SL}} \mathrm{cula},{ }^{\mathrm{RS}} \mathrm{cula}$, ${ }^{\mathrm{PH}}$ cula, Hlh. зул, Ma. -) || GT yula 'meşale, lamba, kandil' (? $\leftarrow$ Çin. 燭蠟 zhú-là 'mum')

KM culaġa 'ş̧ık, lamba, mum' (OM -, Hlh. -, Ma. -) \|| GT (EUyg.) yulka ${ }^{163}$ yulgak ${ }^{164}(?<$ yula+gak) 'meşale, lamba'

KM culbu- 'deri değiştirmek; tüy dökmek' (OM -, Hlh. зулбах, Ma. -), KM culmu- 'kuşun tüylerini yolmak; deri değiştirmek, tüy dökmek' (OM -, Hlh. зулмах, Ma. -), KM cuma culma 'tüyden arındırılmış, haşlanmış' || GT yul- '(tüy, k1l vb.) yolmak, koparmak'

KM culġa- 'çekmek, çekip çıkarmak, çekerek koparmak, yolmak' (OM -, Hlh. зулгаaх, Ma. -), KM cilgura- cilbura- culgura- culġara- '(saç, tüy) dökülmek' (OM -, Hlh. зулzарах, Ma. -) || GT yulk- 'yolmak, koparmak, sıyırmak, kazımak' (krş. Mac. gyilkos 'katil')

KM curam-a curum (<* cumara) 'bir çeşit tarla sincabı, Citellus citillus' (OM ${ }^{\mathrm{HY}}$ cumuran, ${ }^{\mathrm{BY}}$ cumbura, ${ }^{\mathrm{RS}}$ cumran, Hlh. sypam, Ma. cumara, cumargan) \| GT yumran 'tarla sincabı, köstebek, büyük sıçan'

KM cuta- 'açlık veya yoksulluk çekmek; zayıflamak' (OM -, Hlh. symax, Ma. ) || GT yūta- ${ }^{165}(<y \bar{u} t)$ 'açlık çekmek'

$\searrow \mathrm{KM}$ duta-

KM cüde- 'çalışmaktan veya baskıdan dolayı yorgun olmak, bitkin olmak, tükenmiş olmak; zorluk çekmek; bir şeyi yaparken zorlanmak' (OM -, Hlh. зүдэx, Ma. -) || GT (ÇTi) *yütä-166 (<yūt+a-) 'acınacak hâlde olmak, zorda olmak, yokluk çekmek, zayıflamak, c1lızlaşmak, kederli olmak; salgın hastalıkta ölmek'

KM cüg (?< *cü.g < *cü) 'yön; rota; yönünde, -e doğru' (OM ${ }^{\mathrm{MGT}} c \ddot{g} g,{ }^{\mathrm{HY}} c \ddot{k} k(=$ cüg), ${ }^{\mathrm{ME}}$ cük, ${ }^{\mathrm{PH}}$ cüg, Hlh. зүг, Ma. cugūn 'yol, sokak') || GT *yü (? *yü) ‘ön, karşı' (>

\footnotetext{
163 T M 309, 6 yūlqa (Gabain 1954: 69, 104).

164 T II D 176 yulgak (Özertural 2008: 215).

165 Kirg. yuta-, Alt. Tel. yuda-, Tat. yuda-, Koyb. Kç. yuda- (R III 562-563), Yak. sutaa-, Dolg. hūttā- hutā-.

166 Leb. Küer. Tar. Kom. Tel. yüdä- (R III 612), Alt. Bar. yüdö- (R III 613), Tuv. çüde-, Tof. çüde-.
} 


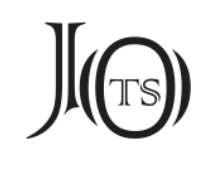

EUyg. yügärü yüügärü 'mevcut, göz önünde', EUyg. yülüg yüülüg 'karşıda, karşısında, -e dönük olarak') veya GT yȫon ${ }^{167}$ 'yön, taraf, yan, istikamet'

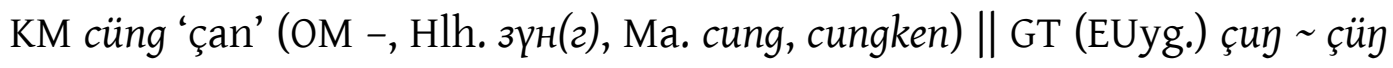
'çan' ( $\leftarrow$ Çin. 鐘 zhōng 'çan')

KM cürm-e 'yonga, talaş; ince et şeritleri; sucuk, sosis gibi doldurulmuş et' (OM -, Hlh. зүрәм, Ma. -) || GT yörmä ${ }^{168}$ 'işkembe ya da bağırsakla yapılan bir tür yemek', BT *cörmä 'bağırsağa doldurulmuş etle yapılan bir tür yemek' (> Çuv. sürme)

167 Sözcük, ilk kez Karahanlı Türkçesinde (TİEM 73) tanıklanmıştır.

168 Krç.-Blk. cörme, Bşk. yürme, Tuv. çöreme. 


\section{$J(\Theta)$}

\section{Ç}

KM (k.ö.) çab 169 'ün, şan, şöhret' (OM -, Hlh. -, Ma. -) || GT çāv 'ün, şöhret'

$\searrow \mathrm{KM}$ çuu

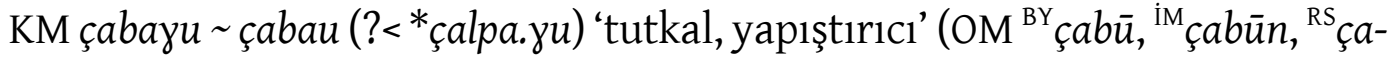
bag่un, Hlh. u̧aвyy, Ma. -) || GT çalpa- ${ }^{170}$ 'yapıştırmak'

KM çabçi- (< çab.çi-) 'vurmak, kesmek, yontmak, doğramak' (OM ${ }^{\mathrm{MGT}}$ çabçi-,

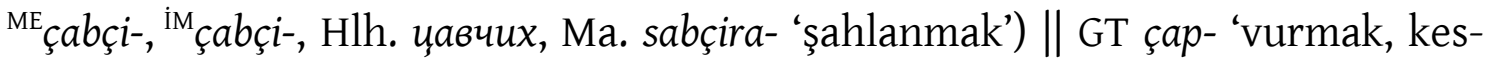
mek, parçalamak, saldırmak', BT *çäp- 'vurmak, dövmek' (> Çuv. śap-)

$\mathrm{KM}$ çaçar (< *çatır) ‘büyük çadır’ (OM ${ }^{\mathrm{MGT}}$ çaçir, ${ }^{\mathrm{ME}}$ çaçir, ${ }^{\mathrm{ME}}$ çadur, ${ }^{\mathrm{RS}}$ çaçir, ${ }^{\mathrm{PH}}$ çaçartan 'çadırlı', Hlh. u̧au̧ap, Ma. çaçari, Cür. caçili, çaçari) || GT çātır 'çadır' (krş. Mac. sátor [şātor] 'çadır', Far. ج̧ çādir, çādur, çādar 'çadır; kumaş, peçe')

KM çaçirġana çiçarǵana çaçarǵana (? < *taçirǵana < *tatırgana) 'Hippophae rhamnoides (bir tür çalı)' (OM ${ }^{\mathrm{MGT}}$ çiçigina171 'bir bitki kökü’, Hlh. чаu̧apzaнa, Ma. ) II GT *tatırgan ${ }^{172}$ 'bitki adı, ot adı (yabanturpu, hardal, Crambe)' (krş. Mac. tátorján 'birçok bitki için kullanılan bir isim')

KM çad- (< *çod- <*tiod-) 'doymak, doyana kadar yemek' (OM ${ }^{\mathrm{MGT}}$ çat-, ${ }^{\mathrm{HY}}$ çat-,

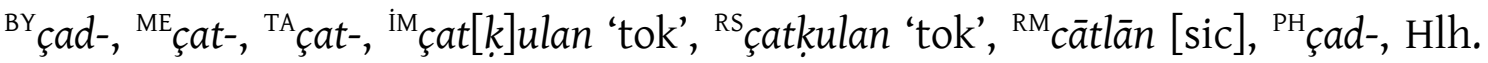
u̧adax, Ma. -) || GT tod- ( tōd-) ${ }^{173}$ (< *tiod-) 'doymak', BT *tod- 'doymak' (> Çuv. tăran-)

KM çadig çedig 'yaşam öyküsü, bir Buda'nın veya Budist bir azizin önceki vücut buluşlarının hikâyesi; şecere, soy ağacı' (OM -, Hlh. u̧aduг u̧ədəə, Ma. -) || GT (EUyg.) çatik ‘Buda’nın önceki doğumu, Buda’nın önceki doğumu üzerine bir

169 Chang. 53, HS 33b5 (aldar çab ikilemesinde), Pañc. 6b (aldar çab ikilemesinde). Kelimeye dair ayrıntılı bir tartışma için bk. Cleaves (1955).

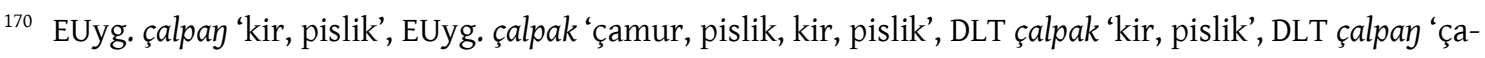
mur', çalpuş (? çalpaş) ‘meyvelerin yapışkan özü’, Trk. ağ. çalpala- 'yoğurt, pekmez vb. şeyleri suland1rarak ezmek', YUyg. çapli- (<çalpa-) 'yapıștırmak'.

171 Rachewiltz (2004: 356-357), MGT’de geçen sözcüğü KM giçigene 'kaz parmakotu, Potentilla anserina' sözcüğüyle ilişkilendirmektedir.

172 Az. tatıran, Tkm. dadran tatran $\sim$ tatıran, Nog. tatıran, Krm. Tat. tatran, Kar. tatran, Krç.-Blk. tatıran.

173 DLT tōd-, Tkm. doy-, Hlç. tod-, Yak. tot-, Dolg. tot-. 


\section{$J(\Theta)$}

hikâye, Budist edebiyatın on iki türünden biri' $(\leftarrow$ Toh. A jātak 'Buda'nın önceki vücut buluşlarının hikâyesi', Toh. B jātak 'Buda'nın önceki vücut buluşlarının hikâyesi' $\leftarrow$ Sk.jātaka 'Gotama Buddha'nın önceki bir hayatının hikâyesi')

$\mathrm{KM}$ çag̀ 'zaman, süre, vakit, çağ, devir' (OM ${ }^{\mathrm{MGT}} c ̧ a g,{ }^{\mathrm{HY}} c ̧ a q,{ }^{\mathrm{BY}} c ̧ a[q],{ }^{\mathrm{ME}} c ̧ a k,{ }^{\mathrm{RS}} c ̧ a k$, ${ }^{\mathrm{As}}$ çag̀ 'saat', ${ }^{\mathrm{PH}}$ çaq, Hlh. u̧az, Ma. -) || GT çak ${ }^{174}$ 'tam, tam olarak, az evvel, demin; doğru' (krş. EUyg. çakdakı 'şu anda')

KM çaǵarig 'çember, halka, kasnak' (OM -, Hlh. u̧azapuz, Ma. -) \|| GT çıgrı çıkır çıkrık çakrık 'çıkrık, küçük çark, su çarkı' ( $\leftarrow$ Soğd. cxr-çaxr cүr-çaxr ckkr çakr 'teker, çıkır, daire')

KM (k.ö.) çaǵsabad çaǵşabad çig̈sabd çigsşabd saġsabad 'dinî disiplin, kurallar' (OM -, Hlh. шагmaавad, Ma. -) \|| GT (EUyg.) ç(a)hşap(a)t çahşap(a)t ç(a)hşaput ç(a)hşap (a)d 'emir, ahlak kaidesi, dinî niyet, disiplin, yasak; oruç; sonuncu ayın adı' $(\leftarrow$ Man.-Soğd. cxš̀) $\delta \sim$ cxš)pt 'ahlaki kural, emir' $\leftarrow$ Man.-Part. cxš̌byd $\sim$ cxš̌ byyd çaxşābed 'kural, emir, kaide' $\leftarrow$ Sk. śikșāpada 'ahlaki emir')

KM çaki- 'çakmak, çakmaktaşıyla ateş çıkarmak' (OM ${ }^{\mathrm{ME}}{ }_{\text {çaki- }}{ }^{\mathrm{iM}}{ }_{\text {tengri çakimuy }}$ 'şimşek', 'içagür 'çakmak', ${ }^{\mathrm{RS}}$ çaḳūr 'çakmak', Hlh. u̧axux, Ma. -) || GT çak- 'çakmak, vurmak' (krş. Mac. csákány 'kazma, gürz, küçük balta, savaş çekici')

KM (k.ö.) çakiravard ${ }^{175} \sim$ çakravarti ${ }^{176} \sim$ (Less.) çikravart çakravar 'imparator, cihan hükümdarı' (OM -, Hlh. -, Ma. -) || GT (EUyg.) çakravart '(Buda'nın öğretisinin) tekerleğini çeviren; yeryüzünün hükümdarı' $(\leftarrow$ Soğd. ckrßrt $\sim \operatorname{ckkr} \beta r t$ 'cakravartin kralı' veya Toh. B cakravārt 'cihan hükümdarı' $\leftarrow$ Sk. cakravartin 'her yere engelsizce yuvarlanan, imparator, cihan hükümdarı')

KM (k.ö.) çaķurazulçi ${ }^{177} \sim$ çaḳurǵalag̣çi 'çömlekçi' (OM ${ }^{\mathrm{HY}}$ çaqurasun 'kilden yapılan bir şey; kiremit', Hlh. -, Ma. -) || GT çıru- 'basılmak, ezilmek, ezilerek sertleşmek'

\footnotetext{
${ }^{174}$ ŞU K4 çak 'tam olarak', EUyg. çak ‘tam, az evvel, demin', DLT çak 'bir şeyin kesin ve öz hâlini vurgulayan sözcük'.

175 Sub. 7a (16).

${ }^{176}$ Lal. 19b, 20a, 23a.

${ }^{177}$ Lal. 5a.
} 


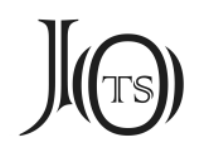

KM çalgi- (?<çal.gi-) '(bir kapta taşınan sıvı vb.) sıçramak; (dalgalar vb.) vurup ıslatmak; üstüne dökülmek' (OM -, Hlh. u̧aлzux, Ma. çalgi- ‘taşmak, dalga dalga ilerlemek') || GT tāşs(l) ${ }^{178}$ 'taşmak'

KM çalig̀ şalig ' ç̧apkın, hovarda, bayağı, açık saçık, müstehcen' (OM ${ }^{\mathrm{BY}}$ çalgi (morin) 'tırıs giden at (?)', ${ }^{\mathrm{RS}}{ }^{\prime}$ çalitu 'acele', Hlh. maлuг, Ma. -) \| GT çalı 'gafil, haşarı, deli divane, şiddetli, tezcanlı' (krş. Rus. maлumь 'yaramaz olmak')

KM (k.ö.) çambu ${ }^{179} \sim$ (Less.) dzambu 'gül elması ağacı (Eugenia Jambu)' (OM , Hlh. -, Ma. -) || GT (EUyg.) çambu 'jambol, Java eriği (Eugenia cumini, Druce, Eugenia jambolana)' ( $\leftarrow$ Toh. A jambu-, Toh. B jambu- [tek başına tanıklanmamıştır] $\leftarrow$ Sk. jambu jambū 'gül elması ağacı (Euginia Jambulana veya diğer türler), gül elması')

KM çambudvib dzambutib 'Budist kozmografide efsanevi Meru dağını çevreleyen yedi dünyadan en güneyde olanı' (OM -, Hlh. замбуутив, Ма. -) \| GT (EUyg.) çambudvip çambudivip 'bir yer adı' ( $\leftarrow$ Toh. A jambudvip 'Jambudvīpa (Hindistan)', Toh. B jambudvīp 'Jambudvīpa (Hindistan)' $\leftarrow$ Sk. Jambudvīpa 'Meru dağını çevreleyen yedi kıtadan merkezî olanı')

$\mathrm{KM}$ çamça (< *çama.ça) 'gömlek' (OM ${ }^{\mathrm{MGT}}$ çamça, ${ }^{\mathrm{HY}}$ çama 'ipekli kumaş', ${ }^{\mathrm{ME}}$ çamçai, ${ }^{\mathrm{ME}}$ çeme 'kumaş, bez', ${ }^{\mathrm{RS}}$ çamça, Hlh. u̧aмu, Ma. çamçi 'kadınlarda elbisenin altına giyilen bir giysi', Ma. çimçi 'gömlek') || GT (EUyg.) çama 'elbise' ( $\leftarrow$ Far. جامه cāme 'giysi, elbise, iç gömleği, ceket')

KM çamkag 'kule, taret, burç; kale; süslü hafif yap1'180, (k.ö.) çamkaktu (ger) 'kulesi olan (ev)' (OM -, Hlh. u̧aмxaz 'kule, taret, burç; kemer, geçit', Ma. çamhan 'tak, sokaklara geçici olarak kurulan, yazılarla süslenen kemer') || GT (EUyg.) çamgak 'tencere, kazan'

\footnotetext{
${ }^{178}$ Kmk. taşı-, Nog. tast-, Tat. taşıl-, Kırg. taşı-, KKlp. tast-, Kzk. tast-, Tkm. dāşs-, Tuv. dajı-, Yak. tahıy-'.

${ }^{179}$ Lal. 40b.

180 Bu sözcüktekine benzer bir anlam değişimine KM coyori 'bodrum, kiler, mahzen' kelimesinde de rastlanmaktadır.
} 


\section{J(৫)}

KM (k.ö.) çamkug $\dot{g}^{181}$ ‘bir tür çalg1’ (OM -, Hlh. -, Ma. -) \|| GT (EUyg.) çımkuy 'flüt; simbalom, bir tür zil'

KM çana 'kar ayakkabısı, kayak, kızak' (OM -, Hlh. u̧aнa, Ma. -) \| GT çana 'kızak, kayak', BT *çana 'kızak' (> Çuv. śuna) (krş. Mac. szán 'kızak')

KM çandan çandana candan dzandan 'sandal ağacı' (OM -, Hlh. зандан, Ma. -) || GT çıntan çından 'sandal ağac1' ( $\leftarrow$ Toh. B cantāṃ candāṃ 'sandal ağac1' veya Soğd. cntn candan 'sandal ağacı' $\leftarrow$ Sk. candana 'sandal ağac1')

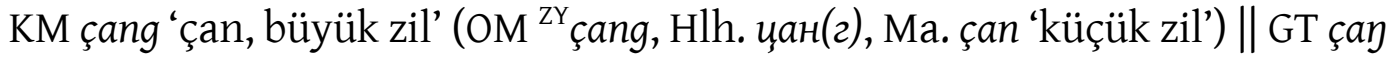
'çan, zil, büyük zil' ( $\leftarrow$ Çin. 鉦 zhēng 'küçük çan', Çin. 錚 zhēng 'bir tür çan' veya Far. جُ çang 'arp, ut')

KM çanggis 'bir tür kızılcık' (OM -, Hlh. u̧aнzuc, Ma. -) || GT (ÇTi) çayış̧ 'kartopu'

KM çara- çar- (<*tıra-) 'önlemek, engellemek, önüne geçmek' (OM -, Hlh. u̧apax, Ma. -) || GT tìd-183 'engel olmak, engellemek, alıkoymak', BT *tîr- ${ }^{184}$ (?) ‘durdurmak, alıkoymak' ( ${ }^{*}$ çir- > Çuv. çar-)

KM çarma- ( * *trma-) 'toynaklarla toprağı tekmelemek, toprağı kazımak, karı kaldırmak' (OM -, Hlh. u̧apмax, Ma. -) || GT tarma- tırma tırna- 'tırmalamak, yeri eşmek, kazmak', BT *tırmala- 'tırmalamak' (> Çuv. tărmala-, çărmala-, çĕrmele)

KM (k.ö.) çay ${ }^{185}$ 'yemek, ziyafet’ (OM -, Hlh. u̧aŭ 'yemek, ziyafet’, Ma. -) || GT (EUyg.) çai ‘oruç tutma; rahiplerin yemeği, yemek, ziyafet, öğün’ ( $\leftarrow$ Çin. 齋 zhāi 'oruç, vejetaryen perhiz')

181 Lal. 11a biba, bilir, kenggerge, çinggil, çamkug .

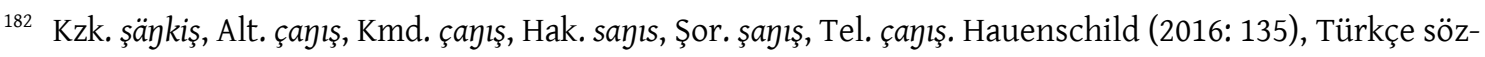
cüğün Moğolcadan alıntı olabileceğini dile getirmektedir.

183 GT tìd- fiili, genellikle Mo. çida- ‘yapabilmek, muktedir olmak' sözcüğüyle karşılaştırılmıştır.

184 Bulgar Türkçesinde erken */-d-/ > */-r-/ değişiminin diğer bir tanığı olarak PS *ker *kerô- 'giymek' (Janhunen 1977: 68) gösterilebilir. Aikio (2002: 18-20; 2006: 29), bunu Türkçeden bir alıntı olarak değil, Proto-Uralca *käri- 'dolamak, sarmak' kökenli bir sözcük olarak görmektedir.

185 Lal. 43a Nandi Nandibali ner-e-ten ökid edür-tür naiman cayun biraman-nuyud-ta çai baricu [...]. Ayrıca bk. Shōgaito (1991: 37, 46; 2003: 124-126). 


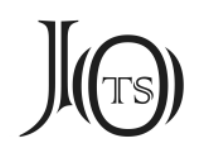

$\mathrm{KM}$ çeçeg çiçig seçeg 'çiçek' ( $\left(\mathrm{OM}{ }^{\mathrm{HY}}\right.$ çeçek, ${ }^{\mathrm{ZY}}$ çeçe $[\mathrm{k}],{ }^{\mathrm{BY}}$ çeçe $[g],{ }^{\mathrm{ME}}$ çeçek, ${ }^{\mathrm{i}}{ }^{\mathrm{M}}$ çeçek, ${ }^{\mathrm{RM}}$ çiçak, Hlh. u̧əu̧ə2, Ma. -) || GT çäçäk 'çiçek', BT çäçäk 'çiçek' (> çuv. śeśke) (krş. Mac. csécs 'kızamık, çiçek hastalığı, çiçek bozuğu')

KM (k.ö.) çeçeglig (Less.) çeçerlig (< *çeçeglig) 'çiçek bahçesi' (OM -, Hlh. и̧эи̧әрләг, Ma. -) || GT çäçäklik 'çiçek bahçesi'

KM çene- '(ağırlık olarak) çekmek, tutmak; değerlendirmek, tahmin etmek' (OM ${ }^{\mathrm{HY}}$ çene- 'ölçmek', Hlh. u̧энэx, ?Ma. çele- '(cetvel ile) ölçmek', ?Ma.çende- 'kontrol etmek, doğrulamak, denemek, test etmek', ?Şib. çende- 'kontrol etmek, rekabet etmek'), KM çine- 'ölçmek, tartmak' (OM ${ }^{\mathrm{ME}}$ çinē-, Hlh. -, Ma. -) \|| GT (OTi) çenä(<çen 'ölçü') 'ölçmek, değerlendirmek, tahmin etmek'

KM çengge- (?< çangga-) 'sevinçten havalara uçmak, mutlu olmak, neşeli olmak, eğlenmek, zevk almak' (OM -, Hlh. u̧энгэx, Ma. -) \|| GT (EUyg.) çııı- '(sevinçten) hoplamak, zıplamak'

$\mathrm{KM}$ çerig çirig 'savaşçı, asker; ordu' ( $\mathrm{OM}{ }^{\mathrm{MGT}}$ çerik, ${ }^{\mathrm{HY}}$ çerik, ${ }^{\mathrm{BY}}$ çeri $[g]$ ], ${ }^{\mathrm{ME}}$ çerik, ${ }^{\mathrm{TA}}$ çirik, ${ }^{\mathrm{IM}}$ çerik, ${ }^{\mathrm{PH}}$ çerig, Hlh. u̧əрəг, Ma. -) || GT çärig 'askerî bölük, ordu', BT *çärig 'ordu' (> Çuv. śar) (krş. Mac. sereg 'ordu; sürü, yığın')

KM çib- 'batmak, (suya) dalmak' (OM -, Hlh. чивэх, Ma. -), KM cib- '(suda) batmak' (OM -, Hlh. жкивэx, Ma. -), KM çibki- 'suya batırmak, daldırmak, suya düşürmek' (OM -, Hlh. чuвхuŭx 'damlayan su sesi çıkarmak', Ma. -) || GT çom- çöm$\sim$ çüm-186 $\sim$ çim- ${ }^{187}$ 'batmak, dalmak, suya gömülmek, suya bütün vücuduyla girip çımak'

KM çibag்- $a^{n} \sim$ çibug $-a^{n}$ 'hünnap' (OM ${ }^{\mathrm{HY}}$ çibuqan, ${ }^{\mathrm{BY}}$ çibuga, ${ }^{\mathrm{ZY}}$ çi[ba]qa $\sim c ̧ i[b u] q a$ çi[b]qa, Hlh. чавгa(H), Ma. -) || GT çipıkan çipııan 'hünnap şekerlemesi, çıban', BT *çıp(l)gan 'çıban' (> Çuv. śăpan)

$\searrow \mathrm{KM}$ çizika

\footnotetext{
186 Tkm. çüm-.

187 TİEM 73 çimülgü ‘yıkanma', Kİ çim-, Osm. (17. yy.) çim-, Trk. ağ. çim- cim- çum- çüm-, Az. çim-.
} 


\section{$J(\Theta)$}

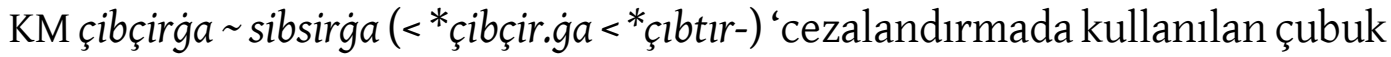
veya değnek' (OM ${ }^{\mathrm{ME}}$ çipçurğa [oku: çibçurg̉a], ${ }^{\mathrm{RM}}$ çabçirǵan 'atları dehlemek için kullanılan değnek', Hlh. чавчирга, Ma. sibsika 'ince esnek dal') || GT çıpırt- ${ }^{188}$ 'yaş dalla dövmek, kırbaçlamak' (krş. çı 'ince dal'), GT çıbır(t)kl ${ }^{189}$ 'kırbaç'

KM çibe (?<çibek) 'erkeklik organı, penis' (OM -, Hlh. чив '(hayvanların) erkeklik organı', Ma. -) || GT *çüväk çübäk *çüvük ${ }^{190}$ 'erkeklik organı'

KM çiçaǵ-a (<*slçaka) 'ishal, sulu dışkı' (OM ME çiçi- 'sıçmak', Hlh. чau̧za, Ma. ) || GT sıçgak 'bağırsakları düzenli çalışan; ishal'

KM (k.ö.) çiçir ${ }^{191}$ 'aytaşı' (OM -, Hlh. -, Ma. -) || GT (EUyg.) şsisirir 'akik taşı' ( Çin. 瑟瑟 sèsè ‘turkuaz taş1, firuze’)

KM çiçire- çeçere- (<*titire-) 'titremek, sallanmak' (OM -, Hlh. чичрэх, Ma. ) || GT titrä- 'titremek', BT *titrä- 'titremek' (> Çuv. çĕtre-)

KM çig 'sargı, bandaj' (OM -, Hlh. чuz, Ma. -) || GT çık- çıg- çig- 'bağlamak, düğümlemek, sarmak', BT *çık- 'bağlamak, düğümlemek, sarmak' (> Çuv. ślh-) (krş. Mac. ağ. csekél '(bir şeyi) bağlamak')

KM çigecei sigeçi sigecei 'serçe parmağı' (OM ${ }^{\mathrm{ME}}$ şikçi [oku: şikcei ?], Hlh. чигчий шигчий, Ma. -) || GT *çıça(lak) çäçä çiçe 'serçe parmak'

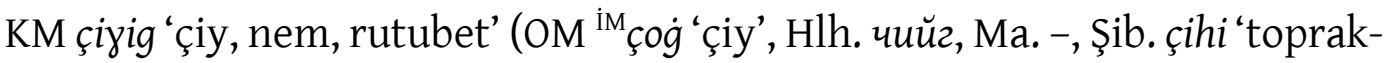
taki nem, nem') || GT çîk $(<c ̧ \bar{\imath}+k)$ 'çiy, nem, rutubet'

KM (Kow.) çizika 'yara, şirpençe, kan çıbanı' (OM ${ }^{\mathrm{i} M}$ çiġan [oku: çig̈an], Hlh. -, Ma. -) || GT çīıkan çipıgan 'hünnap şekerlemesi, çıban', BT *çıp(ı)gan 'çıban' (> Çuv. śăpan)

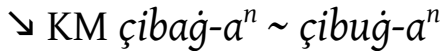

\footnotetext{
${ }^{188}$ DLT çııırt-, Krm. Tat. çıbır-, Hlç. çıpur-.

${ }^{189}$ Krç.-Blk. sıbırthı 'kırbaç', Tat. çıbırkı 'kırbaç' (R III 2102).

${ }^{190}$ EUyg. (Br.) çüçäksäk veya çüväksäk (?) ‘penis, erkek cinsel organı’, DLT çüpäk (? çübäk) ‘penis’, Ki çük 'erkeklik uzvu', Trk. çük 'erkeklik uzvu'.

${ }^{191}$ Turf. 46a3.
} 


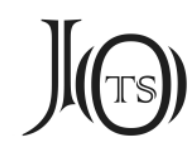

KM çizirag (< *tıgırak? *çıgıruk?) ‘kuvvetli, güçlü; katı, sağlam' (OM ${ }^{\mathrm{HY}}$ çi'iraq, Hlh. чиŭрэг, Ma. çira 'sert, katı, hızlı; otoriter, haşin; güçlü (at)') || GT tıgrak ‘dayanaklı, güçlü (adam)' veya GT çıgruk 'sert, katı (zemin)', BT *çıgruk ‘sık, gür, koyu, yoğun' (> Çuv. śăra) (krş. Mac. sürü '(orman veya çorba için) yoğun, sık' $\leftarrow$ BT *çiräy)

$\mathrm{KM}$ çizirsü̈ (< çizi.r.sün <*çigi) ‘saman veya sazdan hasır' ( $\mathrm{OM}{ }^{\mathrm{HY}}$ çiq ‘yağmura karşı korunmak için kullanılan bambu örgü', ${ }^{\mathrm{HY}}$ çi' 'ülsün, ${ }^{\mathrm{ZY}}$ cirsu [sic], ${ }^{\mathrm{ME}}$ çik 'çalıllk', Hlh. чиŭрc(эн), Ma. çikeku 'saz veya pirinç saplarından örülmüş hasır') || GT çigg 'sazdan yapılmış bir perde, çubuklardan örülmüş paravan' (krş. Mac. cigle [tsigle] 'bir cins sögüt')

KM çike çeke 'doğru, düz; açık sözlü, dürüst, dobra' (OM -, Hlh. u̧эx, Ma. -) \|l GT tik dik 'dik' (?

KM çiki- (<*tıkı-) 'sıkıştırmak, tıkıştırmak, itmek; karnını tıka basa doyurmak' (OM ${ }^{\mathrm{ME}}$ çiki-, Hlh. чuxэx, Ma. çiki-) || GT tık- 'tıkmak, tıkıştırmak, tıkamak; yemek yemek', BT *tık- 'tıkınmak, hapur hupur yemek' (> Çuv. çıh-) (krş. Mac. dug 'sıkıştırmak, içine tıkmak')

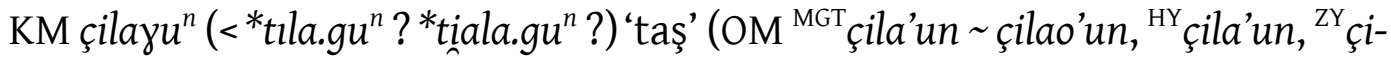
lau çilawun, ${ }^{\mathrm{BY}}$ çilawun, ${ }^{\mathrm{RS}}$ çilaun, ${ }^{\mathrm{PH}}$ çila'u:n, Hlh. чyлyy(н), Ma. -, OKor. 돓 twolh 'taş') \| GT tāşs 'taş', BT *tiāl 'taş, kaya' (> Çuv. çul) (krş. PY [W] *t'ì's 'taş', PY [S] *č́t's 'taş')

KM çile- ${ }^{192}\left(?<* c ̧ c l e<*\right.$ çerle-) 'rahatsızlanmak, hastalanmak' (OM ${ }^{\mathrm{MGT}}$ çile- 'bitkin olmak', ${ }^{\mathrm{ME}}$ çer 'irin', ? ${ }^{\mathrm{PH}}$ çar 'hastalık', Hlh. чилэx, ?Ma. çele- 'uzun bir yolculuktan sonra yorulmak') || GT çär 'hastalık; bedenin ağırlaşması', GT çärlig 'zayıf, c1lız', GT çärlän- 'hastalanmak'

KM çimad- 'suçlamak, azarlamak, paylamak; iftira etmek, kötülemek; hoşnutsuz olmak, şikâyetçi olmak' ( $\mathrm{OM}^{\mathrm{MGT}}$ çimad- ‘sinirlenmek, azarlamak; az bularak reddetmek', Hlh. -, Ma. -) || GT (EUyg.) çımat- ${ }^{193}$ 'sinirlenmek, öfkelenmek'

${ }^{192}$ Moğolca sözcük, Poppe'nin (1976: 467) iddia ettiği gibi Evk. muлa- tlla- 'zayıf düşmek, gücünü kaybetmek', Ev. mūл- tìl 'büyümesi durmak, tökezlemek' fiilleriyle bağlantılıysa daha eski bir *tıla- şekline geri gitmektedir. Bu durumda, Türkçe çärlä- fiiliyle bir ilişkisi yoktur.

${ }^{193}$ Krş. Osm. çımkır- 'kötü ve sert söylemek, azarlamak', Trk. ă̆. çımkır- 'karşı gelmek, sert cevap vermek'. 


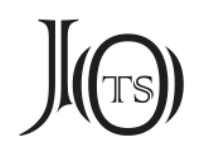

KM çime- 'süslemek, bezemek, donatmak' (OM ${ }^{\mathrm{ME}}$ çime-, ${ }^{\mathrm{PH}}$ çime-, Hlh. чимэx, Ma. -) || GT (EUyg.) timä- 'hazırlamak, hazırlık yapmak'

KM çimki- 'kıstırmak, çimdiklemek; hadım etmek' (OM -, Hlh. чимхэх, Ma. ), KM çimki '(tuz, tütün vb. için) tutam, çimdik' (OM -, Hlh. чuмx, Ma. -) || GT (EUyg.) çımkl- 'kesmek, parçalamak' (krş. GT çımdl- çimdi- 'çimdiklemek')

$\mathrm{KM}$ çimöge $e^{n} \sim$ çömöge ${ }^{n 194}$ 'ilik, ilikli kemik' (OM ${ }^{\mathrm{HY}}$ çimegen, ${ }^{\mathrm{ME}}$ çimegen, ${ }^{\mathrm{RS}}$ çimge, Hlh. чөмөг, Dag. şimə૪ şimug, ?Ma. çimeke giranggi 'hayvanın ayak kemikleri') \|

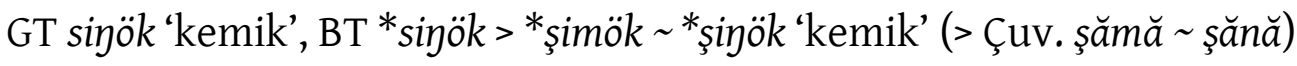

KM çinar (<*tına.r) 'nitelik, özellik; öz, varlık, ruh; tabiat, huy, karakter' (OM ${ }^{\mathrm{MGT}}$ çinar 'hisler, sevgi, hoşlanma', ${ }^{\mathrm{PH}}$ çinar 'nitelik', Hlh. чанар, Ma. -) \| GT tın tìn 'can, ruh; nefes, soluk', BT tın > *tim > *çim 'nefes, soluk; hayat' (> Çuv. çĕm)

KM çindamani 'dilekleri yerine getiren mücevher (efsanevi)' (OM -, Hlh. чандмань, Ma. çindamani) || GT (EUyg.) çintamani 'istek mücevheri' ( $\leftarrow$ Toh. A cintāmaṇi (cindāmaṇi), Toh. B cintāmaṇi 'sahibinin bütün dileklerini gerçekleştiren efsanevi mücevher' veya Soğd. cynt'mny cynt'm’ny çintāmanī 'istek müchevheri' $\leftarrow$ Sk. cintāmaṇi ‘sahibinin bütün dileklerini gerçekleştirdiği söylenen efsanevi bir mücevher')

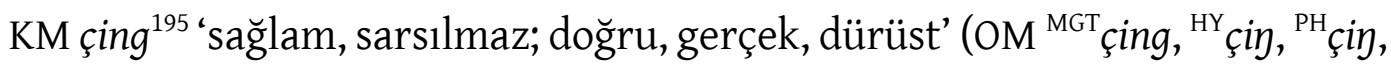
Hlh. чин, Ma. çin 'dürüst, açık sözlü') || GT tı๊ 'güçlü, sağlam, sert', BT *tı 'pek, gayet, çok, en' (> Çuv. çăn ${ }^{196}$ )

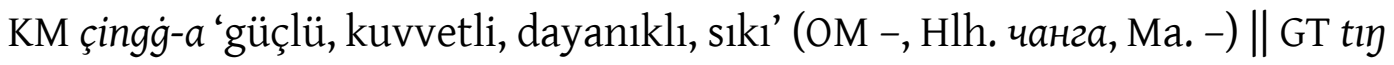
'güçlü, sağlam, sert', BT *tı 'pek, gayet, çok, en' (> Çuv. çăn)

KM çingla- çingna- (<*tılla-) 'dinlemek, kulak misafiri olmak' (OM -, Hlh.

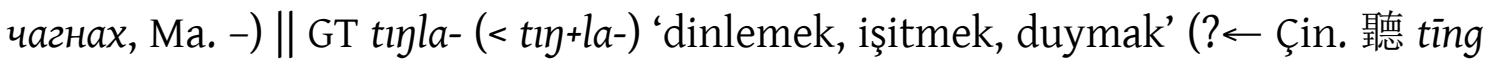
'dinlemek')

\footnotetext{
194 Moğolca sözcük gerçekten Türkçe kökenliyse, alıntı, PPM *şimöke $e^{n} \leftarrow$ BT *şimökă şeklinde gerçekleşmiş olmalıdır. Bu noktada, Bulgar Türkçesinde $s>s$ değişiminin ve $\eta>m$ değişiminin kronolojisini belirlemek gerekmektedir.

${ }^{195}$ Haenisch (1939: 28), sözcüğün kökenini Çin. 誠 chéng ‘dürüst; gerçek’ olarak göstermektedir.

196 'Gerçek, doğru' anlamındaki Çuv. çăn sözcüğü, Tat. çın 'gerçek, hakiki' sözcüğünden alınmıştır.
} 


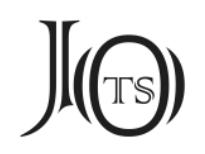

KM çirǵa- (< *tırka-) 'tıkamak, zapt etmek, tutmak' (OM -, Hlh. -, Ma. çirga-

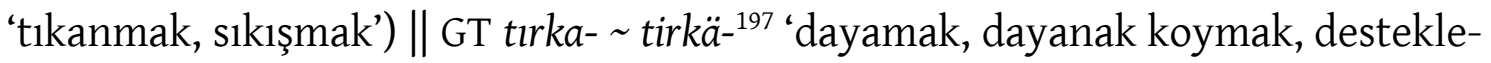
mek', GT (Osm.) tırkaç tırkas tırkaz 'kapı sürgüsü’, BT tergä- (?) > terä- (?) ‘desteklemek, dayamak' (> Çuv. těre-)

KM çirkire- 'gürültü çıkarmak, bağırmak' (OM -, Hlh. -, Ma. -) || GT çıkraçîkır- 'gıcırdamak, bağırıp çağırmak'

KM (k.ö.) çitiri ${ }^{198}$ '(mücevher için) 1şıltıllı, parlak, çok renkli' (OM -, Hlh. -, Ma. -) || GT (EUyg.) çitri 'renkli, farklı' ( $\leftarrow$ Sk. citra 'parlak, berrak, açık renkli; ala, alaca, benekli, çeşit çeşit, farklı, değişik')

KM (k.ö.) çivaçivag ${ }^{199}$ 'bir tür sülün' (OM -, Hlh. -, Ma. -) || GT (EUyg.) çivaçivak 'bir tür kuş (bir sülün)' $(\leftarrow$ ? $\leftarrow$ Sk. jivvajīvaka 'bir tür sülün')

KM çiy (I) ‘bozkır kirazı’ (OM -, Hlh. чuŭ, Ma. -) || GT çäyä çiyä200 ‘kiraz’

KM çiy (II) (< *çið) ‘Çin uzunluk ölçüsü’ (OM -, Hlh. чuŭ, Ma. -) || GT çìg çıg $\sim$ çik 'arşın, endaze' ( $\leftarrow$ Çin. 尺 ch ̌ 'uzunluk ölçüsü, metrenin üçte biri')

$\mathrm{KM}$ çog 'köz, kor, sönmekte olan ateş' (OM ${ }^{\mathrm{MGT}}$ çogtai ‘soylu, asil (kadın)', ${ }^{\mathrm{ME}}$ çok 'köz, sıcaklık', ${ }^{\mathrm{RS}}$ çoktu 'büyük gözlü, güzel gözlü', ${ }^{\mathrm{PH}}$ çoqtu 'muhteşem, gösterişli', Hlh. u̧or, Ma. çokto 'kibirli') || GT çōg 'kor, köz; ateş, alev; parlaklık' (?૯ Çin. 燭 zhú 'meşale, mum'201)

KM çoki- 'vurmak, dövmek, darbe indirmek; (kapı) çalmak, tıklatmak; (kuş) gagayla toplamak' (OM ${ }^{\mathrm{MGT}}$ çoki- 'delmek', Hlh. u̧oxux, Ma. çoki- 'toprağa saplamak', Evk. çōk- 'kazmak') || GT tokl- 'vurmak, dövmek, ezmek; sokmak; (kapı) çalmak;

\footnotetext{
197 EUyg. tirä-, DLT tirä-, Çă̆. tirgä- (PdC 213), Çağ. tıra- tirä- (Kúnos 1902: 190), MG tirä-, Osm. dirgä-n-, Tkm. dýre-

198 Lal. 29b, 61 b.

199 Lal. 46b.

200 TiEM 73 çäyä, Trk. ağ. çiğe çiye, Tat. çiye, Bşk. seyä, Nog. şiye, KKlp. şiye, Kırg. çiye, Kzk. şiye.

${ }^{201}$ Uçar'ın (2014) iddia ettiği gibi, GT çōg sözcüğünün *çō- fiilinden türemiş olması daha muhtemeldir.
} 


\section{$J(\Theta)$}

(kumaş) dokumak' veya GT çok- '(hayvanı) kesmek, öldürmek, boğazlamak; (kuş) saldırmak; toplanmak, yığılmak; gagalamak ${ }^{202}$

$\searrow \mathrm{KM}$ doki-

KM çokimag 'ağır ahşap tokmak' (OM -, Hlh. u̧oxuмог, Ma. -) || GT tokımak ‘tokmak, çekiç’ veya GT (ÇTi) çokmak ${ }^{203}$ 'tokmak, topuz’ (krş. Mac. csomak ‘uzun saplı marangoz baltası')

KM çoḳoro- 'toplanmak, yoğunlaşmak, sürü hâlinde toplanmak, kaynaşmak, üşüşmek' (OM -, Hlh. u̧oxpox, Ma. -) || GT çokura- çokra- 'kaynamak, fokurdamak'

KM çolbon çolmon çolman 'Venüs' (OM ${ }^{\mathrm{RS}}$ çolban, Hlh. u̧олмон, Ma. -) \| GT çolpan 'Venüs'

KM çomur- 'buzda kayıp düşmek' (OM -, Hlh. -, Ma. -) || GT çomur- çömür(<çom-) '(suya) daldırmak, batırmak, batmak'

$\mathrm{KM}$ çookor ${ }^{204} \sim$ çoḳor (<*çopakar) 'alaca, benekli, desenli, lekeli' (OM ${ }^{\mathrm{ZY}}$ çouqor

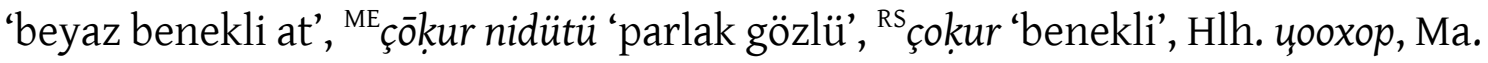
çohoro 'benekli') || GT *çopgar > çopar ${ }^{205}$ 'ala, alaca, karışık renkli, benekli' (Çuv. çăpar $\leftarrow$ Tat.)

KM çöb ‘tortu, telve' (OM -, Hlh. u̧өв, Ma. -) || GT çöp çō̄p (Br. çüb) 'tortu, çökelti, çöp’, BT *çöp $(V)$ 'çöp, süprüntü’ (> Çuv. śüp süüpĕ) (krş. Mac. csepü, csöpü 'pislik, kıtık, saman tozu') (? $\leftarrow$ OFar. çöb 'tahta, çubuk')

KM (k.ö.) çöGöngki206 'tembel, uyuşuk, gevşek' (OM -, Hlh. -, Ma. -) || GT (EUyg.) çökä 'dejenere, yoz, yozlaşmış’ veya GT (EUyg.) çöküg (Br. çökög) ‘diz çöken; cesareti kırılmış'

${ }^{202} \mathrm{KM}$ çokima $\dot{g}=$ GT tokımak denkliği, KM çoki- = GT tokt- denkliğini daha muhtemel kılmaktadır. Yine de Moğolca /o/ ünlüsü önündeki $t$ - >ç- değişimini açıklamak güçtür.

203 Trk. ağ. çokmak 'tokmak', YUyg. çokmak 'topuz, gürz'.

204 Yak. çuogur, Dolg. çuogur çūgur ve Sol. sōhor biçimleri, Moğolca sözcüğün ilk hecesindeki (ikincil) ünlü uzunluğunun tanıklarıdır.

${ }^{205}$ Bu sözcükte kuralsız bir /g/ düşmesi söz konusudur: Çağ. çobar, İM çobar, Osm. çapar, Krm. Tat. çubar, Tüm. çibar, Tat. çuar, Kzk. şıbar.

206 Sub. 59b (204). 


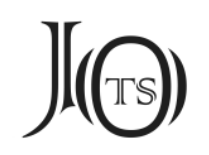

KM çöyebüri (çinu-a) 'çakal' (OM ${ }^{\mathrm{MGT}} c ̧ o ̈ ' e b o ̈ r i i^{207}$ [Rachewiltz 1972: 211], ${ }^{\text {HY }}$ çü'eberi, Hlh. u̧өөвөp, Ma. -) || GT *çögä208 'çakal'; GT böri 'kurt' (Çer. pire 'kurt' $\leftarrow$ Çuv. *berä?)

KM çökö- çöke- 'umutsuzluğa düşmek, umudunu yitirmek, başa çıkamamak, üstesinden gelememek' (OM ${ }^{\mathrm{MGT}}{ }^{\mathrm{M} o ̈ k o ̈}{ }^{209}$ [Rachewiltz 1972: 211], ${ }^{\mathrm{ME}}$ çöke'(deve) çökmek', Hlh. u̧өxөx, Ma. çuku- 'yorgun olmak, bitkin olmak', Ma. çukū'(başını) eğmek, aşağı bakmak, boyun eğmek, yüzükoyun yatmak') || GT çök- 'çökmek, yere düşmek, yılmak, umutsuzluğa düşmek, cesaretini kaybetmek'

KM çug 'ile birlikte, ile beraber, ortaklaşa' (OM ${ }^{\mathrm{MGT}}$ çugtai 'demet, deste', Hlh. uyz, ?Ma. çulga- 'bölükleri teftiş etmek; toplantı yapmak') || GT çūg (< çū- 'bağlamak') 'demet, bağ, heybe, bohça', GT çūglan- 'toplanarak bir araya gelmek'

KM çuu (< *çau) 'gürültü, patırtı; yankı; söylenti; şöhret, şan' (OM -, Hlh. uyy, Ma. -), KM çayuriya çuuray 'yankı' (OM -, Hlh. uyypua, Ma. -), KM çauray 'yankı; ün, şöhret' (OM -, Hlh. uyypaŭ, Ma. -) || GT çāv 'ün, şöhret', GT (Osm.) çavır 'haber, ilan'

$\searrow \mathrm{KM} c ̧ a b$

KM çü 'büyük çivi, cıvata' (OM -, Hlh. u̧ץY, Ma. -) || GT (çTi) *çıv çiv (> çuv $\sim c ̧ u ̈ v \sim c ̧ u ̈ y)^{210}$ “çivi”

KM çüGürgene 'bir tür çekirge' (OM ${ }^{\mathrm{H}}$ çeürge [Lewicki: çürge], ${ }^{\mathrm{ME}}$ çü'ürtken, ${ }^{\mathrm{TA}}$ çegirge, Hlh. -, Ma. -, Şib. çirku çitku 'cırcır böceği') || GT çäkürgä çökürgä çükürgä 'çekirge'

KM çülüGed- (< çülüGe.d-) 'çürümek, bozulmak' (OM -, Hlh. -, Ma. -) || GT çülük_-211 (? çölük-) 'hırpani olmak, perişan vaziyette olmak'

\footnotetext{
207 Sözcük, Haenisch (1939: 92) tarafından jo'ebori 'Wolf, Schakal ?' olarak okunmuştur.

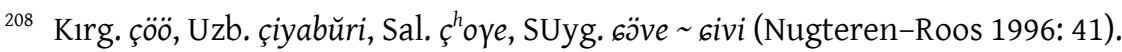

${ }^{209}$ Sözcük, Haenisch (1939: 92) tarafindan jokole'ai olarak okunmuştur.

${ }^{210}$ KI çuvu, Erm. Kıp. çüv, Trk. çivi, Trk. ağ. çüy çüyü, Az. çiv, Tkm. çüy, Krç.-Blk. çüy, Tat. çöy, Bşk. söy, Nog. şüy, Krm. Tat. çüy çiv, Krmç. çuv, Kar. çuy çüy ç’uv. Ayrıca bk. Tenişev (2001:398-399).

${ }^{211}$ DLT çẅlük-, Çă̆. çüllä-, Kırg. çölük-, Hak. sülek-.
} 


\section{$J(\Theta)$}

D

KM dabusang dabasag் dabusag் dabisa $(<*$ dabısa) 'mesane, idrar kesesi; karnın alt kısmı; kasık bölgesi' (OM MEdabasun, Hlh. давсан, Ma. -) || GT yamız yomuz 'kasık' (krş. GT yämdü 'kasık tüyü', Far. يياس yabās 'cinsel organ, kasık; utanç, ayıp; aksi kadın')

KM daya $\dot{g}-a^{n} \sim$ dag $-a^{n}(<*$ dapakan) 'bir ile iki yaş arasında olan tay' (OM ${ }^{\mathrm{MGT}}$ da'aqan 'iki yaşında tay', ${ }^{\mathrm{BY}}$ dāga 'iki yaşında tay', ${ }^{\mathrm{ZY}}$ dāqan 'iki yaşında tay', ${ }^{\mathrm{ME}}$ dägan 'tay', Hlh. daaza(H), Ma. dahan) || GT yapaku (> yapakı yapaka) '(sütten kesilmemiş, iki yaşına varmamış) tay' (krş. Rus. dazaн 'iki yaşındaki tay')

KM dayaki (<*dapakl) 'karışıklık, dolaşıklık, düğüm, yumak' (OM ${ }^{\mathrm{ME}}$ dākiki, Hlh. daaxb, Ma. -) || GT yapaku 'kırpık yün, yapağı; keçeleşmiş, dolanmış saç; sık, birbirine girmiş' (krş. Mac. gyapjú 'yün')

KM dayara- 'üşümek; soğuk almak, üşütmek' (OM ${ }^{\mathrm{BY}}$ dāra-, ${ }^{\mathrm{ME}}$ dāra-, Hlh. daapax, Ma. dar seme 'titreme, ürperme') || GT yagra-212 ‘soğukta üşümek, titremek, donmak', BT *cagırçan- > *agıçan- > *agçan- 'titremek, ürpermek, soğuktan titremek' (> Çuv. śüśen-)

KM dayari dayir (<*dagırı) 'eyer veya semer yarası' (OM ${ }^{\mathrm{MGT}} d a$ 'ari, ${ }^{\mathrm{ME}} d \bar{a} r i$, ${ }^{R S}$ dāritu 'yağırı olan (at)', Hlh. daŭp, Ma. -) || GT yagır 'hayvanın sırtındaki yara, yağır’

KM *dayari- (I) 'atın sirtı yara olmak' (OM -, Hlh. -, Ma. dari- 'atın sırtı yara olmak'), KM dayarin (<*dayari.n <*dayari-) 'atın sırtındaki yara' (OM-, Hlh. -, Ma. darin)|| GT yagrt- ${ }^{213}$ 'atın sırtı yara olmak; (deri) su toplamak'

KM dazari- (II) (<*daparl-) 'geçerken vurmak veya yıkmak, üstünden geçmek, çiğnemek; geçerken uğramak, bir yere uğramak; karşılaşmak; sözle saldırmak, dolaylı olarak incitmek, (hastalık veya bela için) birini bulmak' (OM ${ }^{\text {мGт }} d a^{\prime}$ ari-, ${ }^{\text {HY}} d a$ 'ari-, Hlh. daŭpax, Ma. dari- 'bir yere uğramak, bir yere giderken

${ }^{212}$ Kzk. javra-, KKlp.javra-, Özb. ă̆. cavra- (ESTYa IV 20).

${ }^{213}$ IB yagrt-, DLT yagrt-, IN yagrt-. 


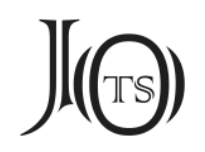

yolda bir iş halletmek, alay etmek') || GT yapır-214 'yıkmak, tahrip etmek, (zemini) düzleştirmek, dümdüz etmek; rencide etmek'

KM dayu $u^{n} \sim$ dayuu $^{215}$ 'ses, gürültü; insan sesi; müzik sesi; şarkı' (OM ${ }^{\text {MGT }} d a^{\prime} u(n)$, ${ }^{\mathrm{HY}}$ da’un, ${ }^{\mathrm{ME}}$ da’un, Hlh. дyy(H), Ma. -) || GT tavış tavuş 'ses, gürültü’ (krş. Far. تاوش tāvuş, تاوش tāvūşs 'ses, ayak sesi')

KM daku 'dış tarafı kürklü manto' (OM ${ }^{\mathrm{MGT}}$ daqu 'kürk', ${ }^{\mathrm{ZY}}$ daqu, Hlh. dax, Ma. dahū, Evk. daku) || GT yaku 'yağmurluk, kürk, gocuk' (krş. Mac. ağ. daku 'kürk ceket, kısa kış paltosu')

$\mathrm{KM}$ dalay 'okyanus, deniz, büyük göl' (OM ${ }^{\mathrm{MGT}}$ dalai, ${ }^{\mathrm{HY}}$ dalai, ${ }^{\mathrm{ME}}$ dalai, ${ }^{\mathrm{BY}}$ dalai, ${ }^{\mathrm{ZY}-}$ dalai, ${ }^{\mathrm{PH}}$ dalayi, Hlh. daлaŭ, Ma. -) \| GT taloy 'deniz, okyanus' (? $\leftarrow$ Çin. 大 dà 'büyük' + 漯 lěi 'nehir adı' veya Çin. 大流 dàliú 'büyük akıntı')

KM dalang (<*dala.y) '(hayvanlarda) ense, (atın) iki kürek kemiği arasındaki yer; toprak şeridi; saban izi; dikdörtgen yığın veya yükselti; set, bent; hendek,

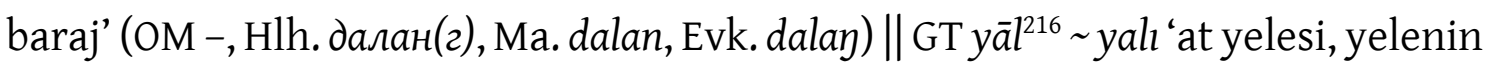
uzadığı bölge'

KM dalbayi- (<*dalba.yl-<*dalpa) 'geniş ve düz olmak' (OM ${ }^{\mathrm{MGT}}$ dalbaru çabçi'kesip açmak', Hlh. dалбaŭx, Ma. -) || GT yalpı 'derinliği olmayan, geniş nesne'

KM dalda ${ }^{217}$ ( ${ }^{*}$ daluta) 'gizli, saklı, gizlice' (OM ${ }^{\mathrm{MGT}}$ dalda 'koruma', ${ }^{\mathrm{ME}}$ dalda 'gizli yer', Hlh. daлd, Ma. dali- '(önünü) kapatmak, gizlemek, korumak', Ma. dalda, Şib. dali- d'ali- 'gizlemek, örtmek' [Kałużyński 1977: 130]) || GT yaşut (<yaş-) 'gizli, sakl1, gizlice; giz, sır' (krş. UÇS yaltan- 'gizlenmek, saklanmak; korkmak')

${ }^{214}$ EUyg. yapır-, DLT yapur-, Tel. yabır- 'rencide etmek' (R III 280), Koyb. Kç. yabır- 'alçak olmak, alçalmak'. Ayrıca krş. Osm. yaprı 'düşük, sarkık', Trk. ağ. yaprı yapru 'büyük ve yassı (kulak için)', Tat. yabırl'bir şeyin üzerine atılmak, saldırmak' (R III 280), Tel. yabırla- 'yok etmek' (Verbitskiy 1884: 468).

${ }^{215}$ Moğolca sözcük, Tü. *tavuş *davuş benzeri bir biçimden *dayus olarak alınmış ve bu biçimin sonundaki /s/ ünsüzü çokluk eki olarak algılanarak yanlış ayırmayla dayu ${ }^{n}$ şekli ortaya çıkmış olabilir.

${ }^{216}$ DLT yāl, Tkm. yāl, Yak. sāl, Hlç. yāa $\sim$ yāl.

${ }^{217}$ Alıntı, PPM *daluta 'gizli, gizlice' $\leftarrow$ BT *dalută 'gizli, gizlice' şeklinde gerçekleşmiş olmalıdır. 


\section{$J(\Theta)$}

KM dalu (<*daru $\left.{ }^{218}\right)$ 'kürekkemiğg' (OM ${ }^{\mathrm{BY}}$ dalu, ${ }^{\mathrm{ZY}}$ dalu, ${ }^{\mathrm{ME}}$ dalu, ${ }^{\mathrm{IM}}$ dalu, ${ }^{\text {SL }}$ dalū, ${ }^{\mathrm{RS}}$ dālu, ${ }^{\mathrm{RM}}$ dālū 'avuç', Hlh. daл, Ma. -) || GT yarın 'kürekkemiği', BT *carun > *carum 'kürekkemiği' (> Çuv. śurăm 'sırt, arka')

KM darayi- (<*darayl-<*darapt-) 'sertleşmek, katılaşmak' (OM -, Hlh. dapaŭx, Ma. -) || GT yarp 'sağlam, güçlü', BT *carp > *carıp 'sağlam, sert' (> Çuv. sírĕp) (krş. Mac. gyarapodik, gyarapszik 'kilo almak, güçlenmek', Çer. serâp 'ağır ve aynı zamanda küçük, sert, yoğun (nesne)')

KM (k.ö.) darbalca- ${ }^{219} \sim$ (Less.) dalbalca- (< dalba.lca-) '(bayrak, yele, yelken) dalgalanmak, sallanmak' (OM ${ }^{\mathrm{MGT}}$ darbalca- 'titremek, sallanmak', Hlh. далбалзах, Ma. -) || GT talpt- 'kanat çırpmak, dalgalanmak, sallanmak'

KM darbi- 'gürültülü bir kalabalık karşısında sevinçli ve heyecanlı olmak' (OM -, Hlh. дарбих, Ma. -) || GT (DLT) yarp 'biri neşe içinde olduğu zaman yüzünü kaplayan 1ş1ldama', GT yarpay-220 'üstünlük taslamak, kibirlenmek; güzel görünmek, güzelleşmek; içtenlikle gülmek'

$\searrow$ KM cirbayi-

KM darkan 'esnaf, zanaatkâr' (OM ${ }^{\mathrm{MGT}}$ darqad, ${ }^{\mathrm{BY}}$ darqan 'lider, kumandan', Hlh. дархан, Ma. darhan) || GT tarkan tarhan 'yüksek bir unvan' (krş. Bugut Yazıtı 〈tryw’n〉 tarxwan) ( $\leftarrow$ Çin. 達官 dàguān ‘yüksek rütbeli memur').

KM dayin (< * dayı.n < *dagı) 'savaş; düşmanlık' (OM ${ }^{\mathrm{MGT}}$ dayin, ${ }^{\mathrm{ME}}$ dain, ${ }^{\mathrm{iM}}$ dayn, Rs*dain, Hlh. daŭH, Ma. dain) || GT yagl 'düşman', BT *cagl 'düşman' (> Çuv. śuçarmăs, śu-çăvaş)

• Kit. 全斗〈ed.ää〉 *dää ‘düşman’ (Ōtake 2017: 201, 204), Kit. 父斗〈d.ia〉 deya ‘düşman’ (Róna-Tas 2019: 296)

\footnotetext{
${ }^{218}$ Moğolca sözcük Türkçeden alıntı ise, ${ }^{*}$ darun benzeri bir biçimden alınmış olmalıdır. Moğolca biçim bir yandan son sesteki - $n$ ünsüzünü yitirirken diğer yandan -r- >-l- değişikliğine uğramış görünmektedir.

${ }^{219}$ Lal. 29b.

220 Tat. yarpay-, Bşk. yarpay-, Kırg. carbay-.
} 


\section{$J(\Theta)$}

KM dayir (< *dayır < *dagır) 'doru (at)' (OM ${ }^{\mathrm{MGT}}$ dayir, Hlh. daŭp бyza 'erkek

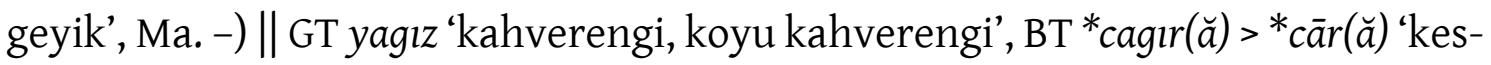
tane rengi, açık kestane rengi' (> Çuv. śrră)

$\mathrm{KM}$ dayisu ${ }^{n}$ ( * dayı.sun < *dagl) 'düşman, hasım; tehdit, gözdağı' (OM ${ }^{\mathrm{MGT}} d a-$

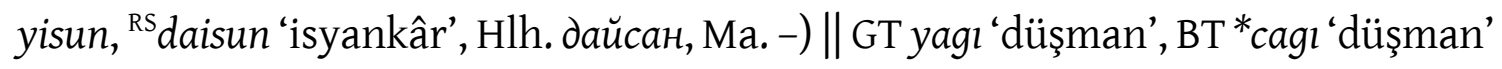
(> Çuv. śu-çarmăs, śu-çăvaş)

KM debi- (<*delpi-) 'dalgalanmak; (kanat) çırpmak; yellemek, yelpazelemek' (OM ${ }^{\mathrm{ME}}$ delbü-, ${ }^{\mathrm{ZY}}$ delbür (?) 'yelpaze', Hlh. дэвэx, Dag. dəlbur, Ma. debsi- debşe-, Şib. delbişe-, Sol. dẹwi-, Udh. dəf-) || GT yēlpi- yǟlpi- 'yelpazelemek, yelpazelenmek; dalgalanmak'

KM debeGe 'bataklık yer, nemli veya yaş bölge, dağ otlakları' (OM -, Hlh. дэвәг 'çayır, dağ otlakları', дэвээ дэвхээ 'sulak çayır', ?Ma. debeye orho 'yosun, liken') || GT (EUyg.) täpirgän 'diken çölü’

KM debke- (< *deb-) 'atlamak, sıçramak' (OM -, Hlh. -, Ma. -), KM debse- (< *deb-) 'ayağıyla sertçe vurmak, ayakla çiğnemek' (OM ${ }^{\text {MGT }}$ debse- 'dans etmek', Hlh. дэвсэх, Ma. -) || GT täp- 'tekmelemek, ayakla vurmak, basmak, ezmek; hücum etmek'

KM debte- debtü- ( $<$ deb.te $-<*$ debi.de $-<*$ debi-) '(bir siviyla) 1slanmak, sırılsıklam olmak, şişmek' (OM -, Hlh. dəঞmэx '(bir sıvıyla) ıslanmak; yumuşamak', Ma. -) || GT (OTi) yipi- '1slanmak; (suda) yumuşatmak, nemlendirmek', GT (DLT) yipä 'yaş, sslak, nemli' (krş. Çuv. śěve 'kesik süt')

KM debter 'kitap, cilt; yazı defteri' (OM ${ }^{\mathrm{MGT}}$ debter, ${ }^{\mathrm{ME}}$ defter, Hlh. дəвтээ, Ma. debtelin) || GT täptär däptär däftär 'defter' ( $\leftarrow$ Far. دفر daftar 'kitap, kayıt, sicil,

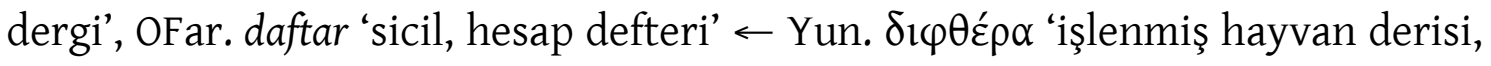
gön')

KM deyedü 'yukarı, daha yüksek' (OM ${ }^{\mathrm{PH}} d e$ 'e:dü, Ma. -), KM deyer-e 'üst, üstünde, yüksek' (OM ${ }^{\mathrm{MGT}}$ de'ere, ${ }^{\mathrm{ME}}$ dehere, ${ }^{\mathrm{HY}}$ de'ere, ${ }^{\mathrm{SL}} d \bar{e} r e,{ }^{\mathrm{BY}}$ eère, ${ }^{\mathrm{ZY}}$ dère, ${ }^{\mathrm{PH}} d e$ e'e:re, Ma. ), KM degci- 'yükselmek, iyileşmek, gelişmek' (OM -, Hlh. dəгжих, Ma. dekce-), KM degde- 'yükselmek' (OM -, Ma. dekde-), KM deyegsi 'yukarıya, yukarı' (OM ${ }^{\mathrm{MGT}}$ de'egşi, ${ }^{\mathrm{PH}}$ de’e:gşi, Ma. -) \|| GT täpä (? täpö) ‘tepe, doruk, zirve; baş’ veya GT yēg 'daha iyi' 


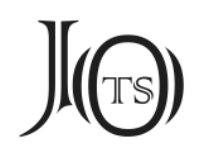

- Kit. 鐵擺 tiě-bǎi *tebe(y)/*debe(y) 'dağ gibi yüksek, heybetli’ (Franke 1976: 177; Vovin 2003: 241; Shimunek 2007: 98), Kit. 令㕕 〈te.ge〉 *tege- 'ölmek (sayg1 ifadesi)' (Róna-Tas 2017: 184)

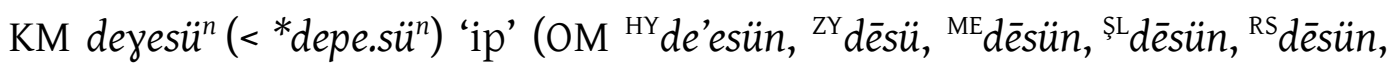
${ }^{\mathrm{RM}}$ daișūn, Hlh. дээс(эн), ?Ma. desihi 'samur ve benzer hayvanlar için tuzak', Evk. desun) || GT yıp yip yäp 'ip, iplik, sicim, urgan’, BT *cep 'iplik' (> Çuv. śip) (krş. Mac. gyeplö 'dizgin')

\section{$\triangle \mathrm{KM}$ ceyeg $\sim$ ceg}

KM deyüli- 'belli bir mesafeye atlamak, üzerinden atlamak, sıçramak' (OM MEdüli-, Hlh. дүүллэx, Ma. -) || GT (DLT, KB) täg- 'göğe doğru atılmak, havada süzülmek'

KM del 'yele, hayvan yelesi' (OM ${ }^{\mathrm{MGT}} d e l,{ }^{\mathrm{HY}} d e l,{ }^{\mathrm{BY}} \mathrm{del},{ }^{\mathrm{ME}} d e l$, ${ }^{\mathrm{iM}}$ deltü 'yeleli', ${ }^{\mathrm{TA}}$ deltü 'yeleli', ${ }^{\mathrm{NK} 2}$ deltü 'sırtlan', Hlh. dəл, Ma. delun, Evk. delin, delsun, Sol. dẹl) || GT yēl 'yele, at yelesi', BT *cēlkä 'yele' (> Çuv. śilhe)

KM dele- 'dalgalanmak, (kanat) çırpmak; yelpazelemek' (OM -, Hlh. дәлэх, Ma. -) || GT yellä- yällä- (< *yell+lä-) 'havalandırmak, yele tutmak, yelpazelemek, körüklemek; teşvik etmek'

KM deleng 'inek memesi' (OM -, Hlh. дәлэн(2), Ma. delen 'inek memesi') \| GT yelin yälin 'hayvan memesi', BT *yeli 'hayvan memesi' (> Çuv. śilĕ) (krş. PY [W] *den 'kadınlarda meme ucu', PY [S] *de(')n 'meme ucu, süt')

$\mathrm{KM}$ deresü̈ (< dere.sün) 'sorguç otu' (OM ${ }^{\mathrm{MGT}}$ deresün, Hlh. дәрc(эн), Ma. deresu) \| GT ye $\bar{z}^{221}$ 'Lasiagrostis splendens, kamıştan daha ince ve yumuşak bir bitki’ (krş. Far. يز yaz 'çadırların etrafına çit olarak çekilen dikenli bir bitki, șumām bitkisi')

KM diyan 'meditasyon' (OM -, Hlh. дияан даяан, Ma. -) || GT (EUyg.) dyan diyan 'meditasyon, yoğunlaşma' ( $\leftarrow$ Toh. A/B dhyāṃ ‘meditasyon' ve Soğd. סy’”n

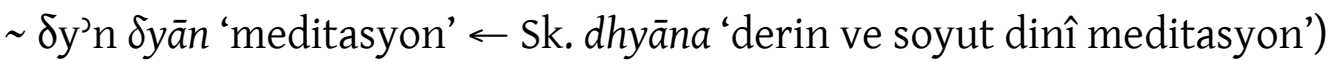

${ }^{221}$ Zieme (2007: 316), bu sözcüğü EUyg. yürüy yigsäk ‘beyaz kurtboğan' ile bir ve aynı saymaktadır. 


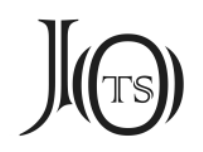

KM dobo 'tepe, tümsek' (OM -, Hlh. дов, Ma. -) \| GT toma ( tömä tümä) 'tepe, tümsek, çıkıntı', BT *tömä 'küçük tepe, tümsek' (> Çuv. těme), BT *tomka(k) 'küçük tepe, tümsek' (> Çuv. tumha tumhah)

KM doboyi- toboyi- (< doma.yl- ? toma.yl- ?) 'kabarık, çıkıntılı olmak; şişmek, kabarmak' (OM -, Hlh. doвоŭx, Ma. -) || GT tom- töm- tüm-222 'kabarmak, şişmek'

KM dog்dur 'turnabalığ1, levrek' (OM -, Hlh. dozdop, ?Ma. curhū 'turnabalığ1 yavrusu') || GT (OTi) togı 223 'bir tür balık' (krş. Mac. tok 'mersin balığı, Acipenser sturio')

KM doġsin 'vahşi, yırtıcı; acımasız, şiddetli; haşin' (OM ${ }^{\mathrm{MGT}}$ Bai Şingqor Dogşin

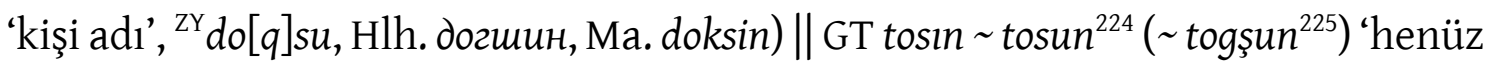
binilmemiş, vahşi, haşarı (tay veya at)'

KM doki- 'işaret etmek, çağırmak; davul çalmak, vurmak' (OM ${ }^{\text {MGT }}$ doki-, Hlh. doxux, Ma. -) || GT tokı- 'vurmak, dövmek, ezmek; (kapı) çalmak; (kumaş) dokumak'

$\searrow \mathrm{KM}$ çoki-

KM doli- 'takas etmek, değiş tokuş etmek; fidye verip kurtarmak' (OM -, Hlh. -, Ma. -) \|| GT yul-226 (Br. yulug) 'rehinde bulunan bir şeyi kurtarmak, esirlikten kurtarmak, fidye ödemek, fidyeyle kurtarmak', BT *cul- 'kurtarmak, salıvermek, serbest bırakmak' (> çuv. śăl-)

$\checkmark \mathrm{KM}$ coli-

KM dom 'hastalık ve belalardan kurtulmak için yapılan büyü veya tören; sihirli formül' (OM -, Hlh. doм, Ma. -) || GT yom 'büyü, sihir; fal'

${ }^{222}$ KB (3288) tom-, Osm. tomur-, Osm. tüm-, Trk. ă̆. tüm-, Trk. ă̆. töm-, Tkm. tommar- tümmer-. Fiil, GT toma tömä tümä 'çıkıntı, tepe, tümsek' sözcüğünün köküdür.

${ }^{223}$ TZ togu 'balık yavrusu', Tkm. dokı 'mersin balığı', Sib. Tat. togı 'mersin balığı', Tob. tugu 'mersin ballı̆ı' (R III 1432), Şor. tog 'levrek' (R III 1157).

${ }^{224}$ EUyg. tosin toosin, DLT tosun.

${ }^{225}$ HŞ togşun tohşun. Sözcük, Moğolcadan geri ödünçlemedir.

${ }^{226}$ Krş. CC yul-, Tat. yol-. 


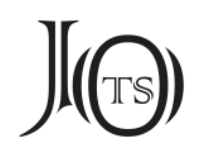

KM domog (<*domag்) 'efsane, masal; tarihî hikâye; fikra' (OM ${ }^{\text {MGT }}$ domogçi 'geveze, boşboğaz', Hlh. domor, Ma. -) || GT yomak 'hikâye, masal'

KM doro (< *dora) 'zayıf, güçsüz, yetersiz; niteliksiz' (OM -, Hlh. dop, Ma. -), KM doroy (<*dora.yl) 'zayıf, güçsüz, bitkin; aklı zayıf; değersiz; geri kalmış, kültürsüz' (OM -, Hlh. dopoŭ, Ma. -) || GT yoz (? yōzz'27) 'kısır; zayıf, bitkin, bakımsız, iyi beslenmemiş; kaba; tembel; değeri düşük, niteliksiz' (krş. DLT yoza- 'kısır olmak')

$\mathrm{KM}$ dorog்o ${ }^{n} \sim$ dorg்o (<*dorakan) 'porsuk' ( $\mathrm{OM}^{\mathrm{BY}}{ }^{\mathrm{B}}$ torqo,${ }^{\mathrm{TA}}$ dorkan 'gelincik', ${ }^{\mathrm{NK} 2}$ doriġan, Hlh. dopzo, Ma. dorgon, Evk. dorokon) \|| GT yorakan 228 'porsuk, dağ faresi' veya GT torsuk ${ }^{229}$ 'porsuk'

KM döl 'yamaç, bayır, meyil' (OM -, Hlh. дөл, Kalm. дөлән, Ma. -) \| GT töş ${ }^{230}$ 'yamaç, bayır'

KM dölöyen dölizen dölgen (<*dölegen) 'yumuşak(ça), nazik(çe), sakin(ce)' (OM ${ }^{\mathrm{HY}}$ dölö’en, Hlh. дөлгөн, Ma. -) \|| GT töläk ‘sessiz, rahat, sakin, yumuşak huylu, durgun, dingin'

KM duġtuy (< *dugu-) 'kapak, kılıf, sarg1; kitap kapağı, zarf' (OM -, Hlh. дугтуŭ, Ma. -), KM duyulga (<*dugu-) 'miğfer, başlik' (OM ${ }^{\mathrm{BY}} t \bar{u} l a ' a,{ }^{\mathrm{ZY}}$ dūlqa, RS*dūlġan, Hlh. дуулга, Ma. -) || GT *yog- 'örtmek, kaplamak' > GT yogurkan 'yorgan', GT yogun yogan (Br. yogon) 'kalın; hantal'

KM durm-a 'farklı şekillerde yoğrularak dinî törenlerde tanrılara yiyecek olarak sunulan hamur' (OM -, Hlh. -, Ma. -) \|| GT (EUyg.) dorma torma toorma 'kurban' $(\leftarrow$ Tib. gtor ma 'tanrılara sunulan hamur işi')

KM durusun (<*duru.sun) 'ağaç kabuğu, huş ağacı kabuğu' (OM -, Hlh. dypc, Ma. -) || GT tōz 'huş ağacı kabuğu'

227 Sözcük DLT'de ve Türkmen Türkçesinde kısa ünlülü olmasına rağmen, Dankoff-Kelly'nin (1982-1985: III/228-229) gösterdiği gibi, kökünün *yō- (> ET yōd-, GT yōk) fiili olduğu varsayılırsa *yōz olarak da tasarlanabilir.

${ }^{228}$ Alt. yorokon 'porsuk' (R III 421), Alt. corokon 'porsuk', Leb. torokon 'porsuk' (R III 1181), Hak. çoraha 'dağ faresi'.

${ }^{229}$ Tkm. torsuk 'porsuk', Kzk. torsıktay 'tombul, sağlıklı (bebek)'.

${ }^{230}$ Az. döş, Nog. tös, Kırg. töş, Özb. tŭş, YUyg. töş, Hak. tös, Tuv. dö”ş. Kısa ünlülü GT töş 'yamaç, bayır’ kelimesi, uzun ünlülü GT tô̄ş ‘göğüs, bağır' sözcügünnden ayrı tutulmalıdır. 


\section{J(৫)}

$\searrow \mathrm{KM}$ toos

KM dusu- 'damlamak, sizmak' (OM ${ }^{\mathrm{ME}}$ dusu- tusu- 'damlamak', 'iM tus- 'dökmek', Hlh. dycax, Ma. -, ?Şib. dushure- 'silerek temizlemek') || GT yuş- yüş- (? yus-) '(bira, sirke vb.) akıtmak, dökmek, dökmek, yıkayarak temizlemek'231

KM duta- 'yetersiz olmak, az olmak, kıt olmak; eksikliğini duymak' (OM IMduta-, ${ }^{\text {iM }} d u t \bar{u}$ 'eksik', ${ }^{\mathrm{RM}} d \bar{u} t a_{-},{ }^{\mathrm{RS}} d u t \grave{g} \bar{u}$ 'azalma, kayıp', Hlh. dymax, Ma. -) || GT yūta232 (< yūt) 'açlik çekmek'

$\searrow$ KM cuta-

KM düil- (?<*düli-) 'tıraş etmek, tüy yolmak veya kesmek' (OM ${ }^{\mathrm{ME}}$ düil- düyil-

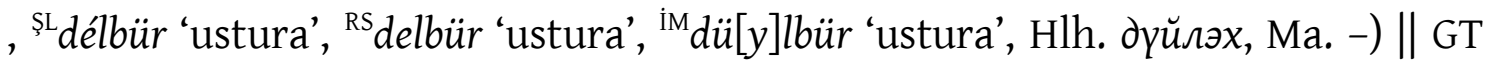
yüli- 'tıraş etmek, saç sakal kesmek'

KM düli 'yarım, ara, orta; günün veya gecenin ortası' (OM ${ }^{\mathrm{MGT}} d \ddot{u} l i,{ }^{\mathrm{BY}} d \ddot{u} l i$,

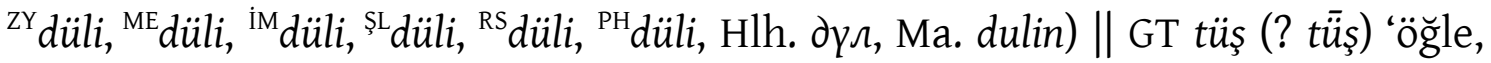
öğle vakti' (krş. Mac. dél 'güney; öğle, gün ortası' $\leftarrow$ BT *dül)

KM düri 'biçim, kontur, figür; sima, görünüş' ( $\mathrm{OM}{ }^{\mathrm{PH}}$ düri 'görünüş, biçim', Hlh. dyp, Ma. durun, Evk. durun) || GT yüz 'yüz, çehre, sima', BT *cür 'ağ1z (?)' (> Çuv. śăvar) veya GT tör tür 'tür, çeşit, nev'

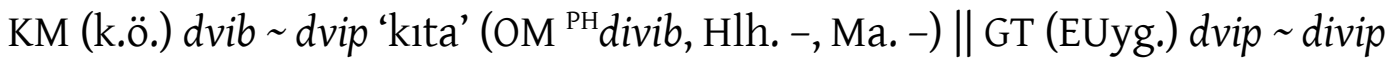
'kıta; ada' ( $\leftarrow$ Toh. A dvip 'ada', Toh. B dvip 'ada' $\leftarrow$ Sk. dvipa 'ada, yarımada, kumsal; yeryüzünün bir bölümü’)

${ }^{231}$ DLT yuş- yüş- 'akıtmak', İM yusla- ‘dökülmek', Alt. Tel. yus- 'yıkayıp temizlemek' (R III 566).

${ }^{232}$ Kırg. yuta-, Alt. Tel. yuda-, Tat. yuda-, Koyb. Kç. yuda- (R III 562-563), Yak. sutaa-, Dolg. hūttāa- hutā-. 


\section{J(৫)}

\section{Kısaltmalar}

AG = Aknerli Grigor'un Okçu Milletin Tarihi adlı eserindeki Moğolca isim ve terimler.

ağ. = ă̆ızlarda.

AGT = XIV yüzyıl anonim Gürcüce tarih kitabındaki Moğolca hayvan yılı adları.

$\mathrm{AH}=$ Atebetü’l-Hakayık.

Ak. = Akatça

Alt. = Altay Türkçesi.

Ar. $=$ Arapça .

Arc. $=$ Arcay Mağaraları'nda bulunan duvar yazıtları

AS = Bibliothèque Nationale Paris, Fonds Arabe No. 6040.

$\mathrm{AY}=$ Altun Yaruk (Suvarṇaprabhāsasottama Sūtra).

Az. = Azerbaycan Türkçesi .

$\mathrm{B}=$ bat1 (yüzü).

Bakt. $=$ Baktrice

BAMR = Luvsandendev-Tsedendamba 2001-2002.

Bao. = Baoan Moğolcası.

Bar. = Baraba Türkçesi.

BK = Bilge Kagan Yazıtı.

bk. = bakınız.

BM = Bulġatü'l-Muştaḳ fī Luġati’t-Türk ve'l-Ḳifcāḳ.

Bo. $=$ Boberg 1954-1955.

Bod. = Olon Süme'de bulunan Bodhicaryāvatāra .

BodT . = Bodhicaryāvatāra'nın Moğolca Tancur Versiyonu.

Br. = Brāhmī yazılı Eski Uygurca metinler.

Bşk. = Başkurt Türkçesi.

BT = Bulgar Türkçesi (1/r-Türkçesi). 


\section{J(৫)}

Bur. = Buryat Moğolcası

BY = Beilu Yiyu 北虜譯語.

Çă̆. = Çağatay Türkçesi.

$\mathrm{CC}=$ Codex Cumanicus .

Çer. $=$ Çeremisçe .

Chang. $=$ Chang Ying-cüi Yazıtı.

Cig. $=$ Cigüntei Yazıtı.

Çin. = Çince.

çoğ. = çoğul.

ÇTi = Çağdaş Türkçeden itibaren (tanıklanmış sözcük).

Cür. = Cürçence.

Çuv. = Çuvaş Türkçesi.

$\mathrm{D}=\operatorname{doğ} u$ (yüzü).

Dag. = Dagur Moğolcas1.

DKPAM= Daśakarmapathāvadānamālā.

DLT = Dīvānü Lugàati’t-Türk.

DM = Ed-Durretü'l-Mudiyye Fi'l-Lugati't-Türkiyye.

Dolg. = Dolgan Türkçesi.

Dong. = Dongxiang (Santa) Moğolcas1.

$\mathrm{EÇ}=$ Eski Çince.

EDPT $=$ Clauson 1972.

EFar. = Eski Farsça.

Eİr. = Eski İranca.

$\mathrm{EKBÇ}=$ Eski Kuzeybat 1 Çincesi (Old Northwest Chinese).

EMac. $=$ Eski Macarca.

EMand. = Erken Mandarin Çincesi (Yuan dönemi).

Erm. Kıp. = Ermeni Kıpçak Türkçesi. 


\section{J(৫)}

ERus. = Eski Rusça.

ESTYa $=$ Sevortyan et al. 1974-2003.

ET = Eski Türkçe.

ETŞ = Arat 1991 .

EUyg. = Eski Uygur Türkçesi.

Ev. = Evence (Lamutça).

Evk. $=$ Evenkice .

Far. $=$ Farsça.

$G=$ güney (yüzü).

Gag. = Gagauz Türkçesi.

GK $=$ Genceli Kirakos.

$\mathrm{GOÇ}=\mathrm{Geç}$ Orta Çince

Gol. = Golstunskiy 1893-1895.

GT = Genel Türkçe (ş/z-Türkçesi).

Hak. $=$ Hakas Türkçesi.

$\mathrm{HC}=$ Hsiao-Ching .

HKT = Harezm Türkçesi satır arası Kur'an tercümesi.

Hlç. $=$ Halaç Türkçesi.

Hlh. = Halha Moğolcası.

Hmg. = Hamnigan Moğolcası.

Hor. = Horasan Türkçesi.

Hot. Sak. $=$ Hotan Sakacas 1.

HŞ = Ḥusrev u Şīiñ (Kutb).

HTKL = Hotanca-Türkçe Kelime Listesi.

HY = Hua Yi Yiyu 華夷譯語.

$\mathrm{IB}=$ Irk Bitig.

İH = El-İdrak Haşiyesi. 


\section{J(৫)}

İM = İbni Mühenna Lügati (Kitāb Hilyetü'l-İnsān ve Helbetü'l-Lisān).

İMS = İrşādü'l-Mülūk ve's-Selātin.

İN = Kitāb Fī İlmi'n-Nüşşāb.

$\mathrm{K}=$ kuzey (yüzü).

k.ö. = klasik öncesi.

Kalm. $=$ Kalmuk Moğolcas 1 .

Kar. $=$ Karay Türkçesi

$\mathrm{KB}=$ Kutadgu Bilig.

Kç. = Kaça Türkçesi.

KE = Kı̣șașüll-Enbiyā (Rabğuzī).

Kgc. $=$ Kangcia Moğolcası .

Kİ = Kitābu'l-İdrāk li-Lisāni'l-Etrāk.

Kırg. = Kırgız Türkçesi.

Kit. $=$ Kitanca (Kitayca).

KK = El-Kavānīnü'l-Külliyye li-Żabți'l-Luġati't-Türkiyye.

KKlp. $=$ Karakalpak Türkçesi.

$\mathrm{KM}=$ Klasik Moğolca .

Kmd. $=$ Kumandı-Kiji Türkçesi.

Kmk. = Kumuk Türkçesi.

Kom. $=$ Koman Türkçesi.

Kor. $=$ Korece .

Kot. $=$ Kotça (Kott).

Kow. = Kowalewski 1844-1849.

Koyb. $=$ Koybal Türkçesi.

Krç.-Blk. = Karaçay-Balkar Türkçesi.

Krm. Tat. = Kırım Tatar Türkçesi.

Krmç. $=$ Kırımçak Türkçesi. 


\section{J(G)}

KRS = Muniyev 1977.

krş. = karşılaştırınız.

KS = Kilise Slavcas 1 .

KT = Kül Tegin Yazıtı

Küer. = Küerik Türkçesi.

Kzk. = Kazak Türkçesi.

Lal. $=$ Lalitavistara

Leb. = Lebed Türkçesi (Kuu-Kiji).

Less. = Lessing 1995 .

Ma. = Mançuca .

Mac. = Macarca

Mait. = Maitrisimit

Man.-Part. = Maniheist Partça.

Man.-Soğd. = Maniheist Soğdca.

$\mathrm{ME}=$ Mukaddimetü'l-Edeb.

MG = Münyetü'l-Ǵuzāt.

Mgr. = Monguor Moğolcası .

MGT = Moğolların Gizli Tarihi (Mongqolun Niuça Tobça'an).

$\mathrm{MM}=\mathrm{Mu}$ ‘̄inü’l-Mürīd.

Mo. $=$ Moğolca .

Mog. = Mogol Moğolcası.

Mord.$=$ Mordvince .

MYYC = Sūn Zhú 1990.

Neg. = Negidalca .

NF = Nehcü'l-Ferādīs .

NK = Nüzhetü’l-Ḳulūb (Ḳazvīnī).

Nog. = Nogay Türkçesi. 


\section{$J(\Theta)$}

OÇ = Orta Çince .

OFar. = Orta Farsça.

OKD = (Uygur harfli) Oğuz Kağan Destanı .

OKor. $=$ Orta Korece .

$\mathrm{OM}=$ Orta Moğolca.

Ord. = Ordos Moğolcası .

Os. $=$ Ossetçe .

Osm. = Osmanlı Türkçesi.

OTi = Orta Türkçeden itibaren (tanıklanmış sözcük).

OTWF = Erdal (1991.

Özb. = Özbek Türkçesi.

P1283 = 1283 numaralı Tibetçe Pelliot el yazması.

Pañc. = Pañcarakșā.

Part. $=$ Partça.

$\mathrm{PdC}=$ Courteille 1870 .

PH = 'Phags-pa yazılı Moğolca kaynaklar.

PHA = Proto-Hint-Avrupa dili.

$\mathrm{PM}=$ Proto-Moğolca .

$\mathrm{PP}=$ Proto-Permce .

PPM = Pre-Proto-Moğolca .

PS = Proto-Samoyedce .

PTg. = Proto-Tunguzca.

PToh. $=$ Proto- Toharca .

PY = Proto-Yeniseyce .

PYuk. $=$ Proto-Yukagirce .

$\mathrm{R}=$ Radloff 1893-1911.

RH $=$ Golden et al. 2000. 


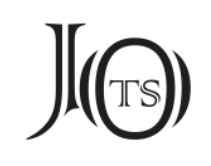

RKT = Karahanlı Türkçesi Kur'an Tercümesi Rylands Nüshası.

RM = Roma El Yazmas1 (Biblioteca Corsini).

RS = Altı dilli Resūlī Sözlüğü (Resūlī Hexaglot).

Rus. = Rusça.

Sag. = Sagay Türkçesi.

Sal. $=$ Salar Türkçesi .

SHÇ = Sonraki Han Çincesi (Later Han Chinese).

Shō. = Shōgaito 1991; 2003.

Şib. = Şibe (Çağdaş Mançu).

Sib. Tat. = Sibirya Tatar Türkçesi.

Sk. = Sanskrit.

ŞL = Şāmilü'l-Lugia.

Soğd. = Soğdca.

Sol. $=$ Solonca .

Şor. $=$ Şor Türkçesi.

SSTYa $=$ Tsintsius 1975-1977.

ŞU = Şine Usu Yazıtı.

Sub. = Subhāṣitaratnanidhi.

SUyg. = Sarı Uygur Türkçesi.

ŞYug. = Şira Yugur Moğolcası.

TA = Kitāb-1 Mecmū'-1 Tercümān-1 Türkī ve 'Acemī ve Mugalī.

Tabg. = Tabgaçça .

Tar. $=$ Tarançi Türkçesi.

Tat. $=($ Kazan $)$ Tatar Türkçesi.

$\mathrm{TB}=$ Tuna Bulgar Türkçesi.

Tefs. = Orta Asya Anonim Tefsiri.

Tel. = Teleüt Türkçesi. 


\section{$J(\Theta)$}

Tib. $=$ Tibetçe

TIEEM 73 = Türk ve İslam Eserleri Müzesi 73 numarada kayıtlı Türkçe Kur'an Tercümesi.

Tkm. = Türkmen Türkçesi.

TMEN = Doerfer 1963-1975.

Tob. $=$ Tobol Türkçesi.

Tof. $=$ Tofa Türkçesi .

Toh. $=$ Proto-Toharca .

Toh. $\mathrm{A}=$ Toharca $\mathrm{A}$.

Toh. $\mathrm{B}=$ Toharca $\mathrm{B}$.

Toń. = Tońukuk Yazıtı.

Trk. $=$ Türkiye Türkçesi.

Tü. $=$ Türkçe .

Tüm. $=$ Tümen Türkçesi.

Turf. = Turfan koleksiyonundaki Moğolca el yazmaları .

Tuv. = Tuva Türkçesi.

TZ = Et-Tuhfetü'z-Zekiyye Fi'l-Lūgati't-Türkiyye.

UÇS = Ming dönemi Uygur Türkçesi-Çince Sözlük (高昌館譯語 Gāochāng guǎn Yì yǔ).

Udh. = Udihece .

$\mathrm{Udm} .=$ Udmurtça.

UW = Röhrborn 1977-1998.

UW Nb. I/1 = Röhrborn 2010.

VB = Volga Bulgar Türkçesi.

vd. = ve diğerleri.

VEWT = Räsänen 1969.

Yak. = Yakut (Saha) Türkçesi. 


\section{J(৫)}

Yun. $=$ Yunanca .

YUyg. = Yeni Uygur Türkçesi.

ZY = Zhiyuan yiyu 至元.

\section{Kaynakça}

AALTo, P. (1961). Qutuү-tu Pañcarakșā Kemekü Tabun Sakiyan Neretü Yeke Kölgen Sudur, nach dem Stockholmer Xylograph 15.1.699, Wiesbaden: Harrassowitz.

AALTO, P. (1976). "G. J. Ramstedts Onkor-Solonisches Wörterverzeichnis, Bearbeitet und herausgegeben von Pentti Aalto", Rocznik Orientalistyczny, 38: 31-41.

Aalto, P. (1977). "G. J. Ramstedts Onkor-Solonisches Wörterverzeichnis, Bearbeitet und herausgegeben von Pentti Aalto II”, Rocznik Orientalistyczny, 39:55-84.

ABAYEV, V. İ. (1958-1989). İstoriko-Etimologiçeskiy Slovar' Osetinskogo Yazıka IIV, Moskva-Leningrad: Nauka.

ADAms, D. Q. (2013). A Dictionary of Tocharian B. Revised and Greatly Enlarged, Amsterdam-New York: Rodopi.

AiKIO, A. (2002). "New and Old Samoyed Etymologies", Finnisch-Ugrische Forschungen, 57: 9-57.

AIKIO, A. (2006). "New and Old Samoyed Etymologies (Part 2)", Finnisch-Ugrische Forschungen, 59: 5-34.

ANIKIN, A. E. (2000). Etimologiçeskiy Slovar' Russkih Dialektov Sibiri: Zaimstvovaniya iz Ural'skih, Altayskih i Paleoaziatskih Yazıkov, Moskva-Novosibirsk: Nauka.

AрAтóczKY, Á. B. (2009). Yiyu, An Indexed Critical Edition of a Sixteenth-century Sino-Mongolian Glossary, Folkstone: Global Oriental.

ARAT, R. R. (1951). Atebetü'l-Hakayık, Ankara: Türk Tarih Kurumu Yayınları.

ARAT, R. R. (1979). Kutadgu Bilig, III: İndeks, Haz. K. ERASLAN et al. İstanbul: Türk Kültürünü Araştırma Enstitüsü.

ARAT, R. R. (1991). Eski Türk Şiiri, 3. Baskı, Ankara: Türk Tarih Kurumu Yayınları.

ARAT, R. R. (2008). Kutadgu Bilig, 2. Baskı, İstanbul: Kabalcı Yayınevi.

ARIKoĞLu, E. \& K. KuUlAR (2003). Tuva Türkçesi Sözlüğü, Ankara: Türk Dil Kurumu Yayınları. 


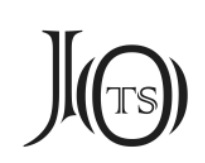

AsAnOv, S. et al. (1988). Krımskotatarsko-Russkiy Slovar', Kiyev: Radyankaya Şkola.

AtA, A. (1997). Nāṣırü'd-dīn Bin Burhānü'd-dīn Rabg்uzī, Ḳıșaṣü'l-Enbiyā (Peygamber Kıssaları), I: Giriş-Metin-Tıpkıbasım, II: Dizin, Ankara: Türk Dil Kurumu Yayınları.

ATA, A. (1998). Nehcü'l-Ferādīs, Uştmaḩlarnıng Açuk Yolı, Cennetlerin Açık Yolu, III: Dizin-Sözlük, Ankara: Türk Dil Kurumu Yayınları.

ATA, A. (2004). Türkçe İlk Kur'an Tercümesi (Rylands Nüshası), Karahanlı Türkçesi (Giriş-Metin-Notlar-Dizin), Ankara: Türk Dil Kurumu Yayınları.

Atalay, B. (1945). Ettuhfet-üz-Zekiyye Fil-Lûgat-it-Türkiyye, İstanbul: Türk Dil Kurumu Yayınları.

AYdin, E. (2008). “Tonyukuk Yazıtındaki Problemli Bir Cümle Üzerine”, Bilig, 45: 91-102.

BAILEY, H. W. (1950). “Irano-Indica III”, Bulletin of the School of Oriental and African Studies, 13/2: 389-409.

Bailey, H. W. (1979). Dictionary of Khotan Saka, Cambridge-London-New YorkMelbourne: Cambridge University Press.

Bammatov, Z. Z. (1969). Kumıksko-Russkiy Slovar', Moskva: Sovetskaya Entsiklopediya İzdatel'stvosu.

BAnG, W. \& G. R. RAhmeti (1936). Oğuz Kağan Destanı, İstanbul: Burhaneddin Bas1mevi.

BASKAKOv, N. A. \& T. M. ToşÇAKov (1947). Oyrotsko-Russkiy Slovar', Moskva: Ogiz.

BASKAKOV, N. A. (1958). Karakalpaksko-Russkiy Slovar', Moskva: Gosudarstvennoye İzdatel'stvo İnostrannih i Natsional'nıh Slovarey.

BASKAKOv, N. A. (1963). Nogaysko-Russkiy Slovar', Moskva: Gosudarstvennoye İzdatel'stvo İnostrannıh i Natsional'nıh Slovarey.

BASKAKOv, N. A. (1973). Gagauzsko-Russko-Moldavskiy Slovar'. Moskva: Sovetskaya Entsiklopediya.

BASKaKov, N. A. (1991). Gagauz Türkçesinin Sözlüğü, Çev. İ. KAYNAK \& A. M. DoĞRU, Ankara: Kültür Bakanlığı Yayınları. 


\section{J(৫)}

BASKAKOv, N. A. et al. (1968). Turkmensko-Russkiy Slovar', Moskva: Sovetskaya Entsiklopediya.

BASKAKov, N. A. et al. (1974). Karaimsko-Russko-Pol'skiy Slovar', Moskva: Russkiy Yazık.

BATTAL, A. (1936). İbnü-Mühennâ Lûgati, İstanbul.

BAzIN, L. (1950). “Recherches sur les parlers T'o-pa ( $5^{e}$ siècle après J. C.)", T’oungPao, 39: 228-329.

BECKWITH, Ch. I. \& G. N. KIYOSE (2018). “Apocope Of Late Old Chinese Short *ă: Early Central Asian Loanword And Old Japanese Evidence For Old Chinese Disyllabic Morphemes", Acta Orientalia Academiae Scientiarum Hungariae, 71/2: 145-160.

BEEKES, R. (2010). Etymological Dictionary of Greek I-II, with the assistance of L. van BEEK, Leiden-Boston: Brill.

BENKŐ, L. (1993-1997). Etymologisches Wörterbuch des Ungarischen I-III, Budapest: Akadémiai Kiadó.

BenZING, J. (1953). Einführung in das Studium der altaischen Philologie und der Turkologie, Wiesbaden: Harrassowitz.

BenZING, J. (1956). Die tungusischen Sprachen, Versuch einer vergleichenden Grammatik, Wiesbaden: Franz Steiner Verlag.

BERTA, Á. (2004). Szavaimat Jól Halljátok... A Türk és Ujgur Rovásírásos Emlékek Kritikai Kiadása, Szeged: Jate Press.

Bíryukoviç, R. M. (1984). Leksika Çulımsko-Tyurkskogo Yazıka, Posobiye k Spetskursu, Saratov: İzdatel'stvo Saratovskogo Universiteta.

BLACK, J. et al. (Ed.) (2000). A Concise Dictionary of Akkadian, (2nd (corrected) printing), Wiesbaden: Harrassowitz.

BoBeRG, F. (1954-1955). Mongolian-English Dictionary I-III, Copenhagen: Ejnar Munksgaard.

BOodBERG, P. A. (1936). “The Language of the T'o-Pa Wei”, Harvard Journal of Asiatic Studies, 1/2: 167-185.

Borovkov, A. K. (1963). Leksika Sredneaziatskogo Tefsira XII-XIII vv., Moskva: İzdatel'stvo Vostoçnoy Literaturı. 


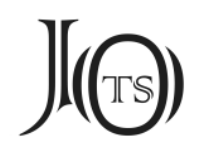

Bosson, J. E. (1969). A Treasury Of Aphoristic Jewels: The Subhāṣitaratnanidhi of Sa Skya Pandita in Tibetan and Mongolian, Bloomington: Indiana University.

BoyLE, J. A. (1963). "Kirakos of Ganjak on the Mongols”, Central Asiatic Journal, 8/3: 199-205, 207-214.

BoyLE, J. A. (1975). "Some Additional Notes on the Mongolian Names in the History of the National of the Archers", Researches in Altaic Languages: Papers read at the 14th meeting of the Permanent International Altaistic Conference (August 22-28, 1971, Szeged), Ed. L. LigETI, Akadémiai Kiadó, Budapest: 33-42.

Budagov, L. (1869-1871). Sravnitel'nıy Slovar' Turetsko-Tatarskih Narěçiy I-II, Sanktpetersburg.

CAFEROĞLU, A. (1931). Abû-Hayyân, Kitâb al-İdrâk li-lisân al-Atrâk, İstanbul.

Cerensodnom, D. \& M. Taube (1993). Die Mongolica der Berliner Turfansammlung, Berlin: Akademie Verlag.

Cheung, J. (2007). Etymological Dictionary of the Iranian Verb, Leiden-Boston: Brill.

CLARK, L. V. (1973). “The Turkic and Mongol Words in William of Rubruck's Journey (1253-1255)", Journal of the American Oriental Society, 93/2: 181-189.

Clauson, Sir G. (1972). An Etymological Dictionary of Pre-Thirteenth-Century Turkish, Oxford: Clarendon Press.

Cleaves, F. W. (1949). "The Mongolian Names and Terms in the History of the Nation of the Archers of Grigor of Akanc", Harvard Journal of Asiatic Studies, 12/3: 400443.

Cleaves, F. W. (1950). “The Sino-Mongolian Inscription of 1335 in Memory of Chang Ying-Jui", Harvard Journal of Asiatic Studies, 13/: 1-131.

Cleaves, F. W. (1951). "The Sino-Mongolian Inscription of 1338 in Memory of Jigüntei", Harvard Journal of Asiatic Studies, 14/1: 1-104.

CleAVEs, F. W. (1955). “Aldar Čab Čab Aldar”, Harvard Journal of Asiatic Studies, 18/1: 221-233.

CoBLIN, W. S. (1994). A Compendium of Phonetics in Northwest Chinese, Journal of Chinese Linguistics Monograph Series 7: 1-117, 119-504.

Courteille, P. de (1870). Dictionnaire Turk-Oriental, Paris. 


\section{J(৫)}

CSÁKI, É. (2006). Middle Mongolian Loan Words in Volga Kipchak Languages, Wiesbaden: Harrassowitz.

Csúcs, S. (2005). Die Rekonstruktion der permischen Grundsprache, Budapest: Akadémiai Kiadó.

ÇEREMISOV, K. M. (1951). Buryat-Mongol'sko-Russkiy Slovar', Moskva: Gosudarstvennoye İzdatel'stvo İnostrannıh i Natsional'nı Slovarey.

Damdinov, D. G. \& YE. V. SunduYeva (2015). Hamnigansko-Russkiy Slovar', İrkutsk: Ottisk.

DANKA, B. (2016). The Pre-Islamic Og்uz-nāmä, A philological and linguistic analysis, Szeged Üniversitesi, Szeged. [Yayımlanmamış Doktora Tezi]

DANKoff, R. \& J. Kelly (1982-1985). Maḥmūd al-Kāšyarī, Compendium of the Turkic Dialects (Dīwān Luүāt at-Turk) I-III, Massachusetts: Harvard University.

DAWLETSChin, T. et al. (1989). Tatarisch-Deutsches Wörterbuch, Wiesbaden: Harrassowitz.

De Smedt, A. \& A. Mostaert (1933). Le Dialecte Monguor parlé par les Mongols du Kansu occidental, IIIe Partie, Dictionnaire Monguor-Français, Pei-p'ing: Imprimerie de l'Université Catholique.

Doerfer, G. \& S. Tezcan (1985). Wörterbuch des Chaladsch (Dialekt von Xarrāb), Budapest: Akadémiai Kiadó.

DoERFER, G. (1963-1975). Türkische und Mongolische Elemente im Neupersischen I-IV, Wiesbaden: Franz Steiner Verlag.

DoERFER, G. (1978). “Urtungusisch *ö”, Tungusica, vol. 1: Beiträge zur nordasiatischen Kulturgeschichte, Eds. G. DOERFER \& M. WeIERS, Harrassowitz, Wiesbaden: 66-116.

DoERFER, G. (1985). Mongolo-Tungusica, Wiesbaden: Harrassowitz.

DoERFER, G. (1987). Lexik und Sprachgeographie des Chaladsch, Textband und Kartenband, Wiesbaden: Harrassowitz.

DOERFER, G. (2004). Etymologisch-ethnologisches Wörterbuch tungusischer Dialekte (vornehmlich der Mandschurei), unter Mitwirkung von M. KNüPPEL, HildesheimZürich-New York: Georg Olms. 


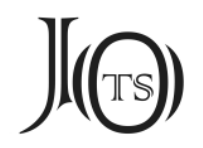

DURKIN-MeISTERERnST, D. (2004). Dictionary of Manichaean Middle Persian and Parthian, (Dictionary of Manichaean Texts, Volume III, Texts from Central Asia and China, Part 1), Turnhout: Brepols.

EDGERTON, F. (1993). Buddhist Hybrid Sanskrit Grammar and Dictionary II: Dictionary, Delhi: Motilal Banarsidass Publishers.

EMMERICK, R. E. \& A. RónA-TAS (1992). “The Turkish-Khotanese Wordlist Revisited”, Central Asiatic Journal, 36: 199-241.

ENKHBAT (1984). Dayur kelen-ü üges / 達斡爾語詞彙 Dáwò’ĕryŭ cíhuì, Hohhot.

ERDAL, M. (1988). “The Turkic Nagy-Szent-Miklós Inscription in Greek Letters”, Acta Orientalia Academiae Scientiarum Hungaricae, 42/2-3: 221-234.

ERDAL, M. (1991). Old Turkic Word Formation: A Functional Approach to the Lexicon I-II, Wiesbaden: Harrassowitz.

ERDAL, M. (1993). Die Sprache der wolgabolgarischen Inschriften, Wiesbaden: Harrassowitz.

ERDAL, M. (2004). A Grammar of Old Turkic, Leiden: Brill.

FEDotov, M. R. (1996). Etimologiçeskiy Slovar' Çuvaşskogo Yazıka I-II, Çeboksarı: Nauka.

Franke, H. (1976). “Two Chinese-Khitan Macaronic Poems”, Tractata Altaica, Ed. W. HEISSIG et al. Harrassowitz, Wiesbaden: 175-180.

FRANKE, H. (1988). "Mittelmongolische Glossen in einer arabischen astronomischen Handschrift von 1366", Oriens, 31: 95-118.

FRANKE, H. (1999). “Notes on Some Jurchen Words”, Language and Literature - Japanese and the Other Altaic Languages, Studies in Honour of Roy Andrew Miller on His 75th Birthday, Ed. K. H. Menges \& N. NAumAnN, Harrassowitz, Wiesbaden: 51-65.

Gabain, A. von (1954). Türkische Turfan-Texte VIII (Abhandlungen der deutschen Akademie der Wissenschaften zu Berlin, Klasse für Sprachen, Literatur und Kunst, Jahrgang 1952 Nr. 7), Berlin: Akademie Verlag.

GaniYeV, F. (1997). Tatarca-Türkçe Sözlük, Kazan-Moskova: İnsan Yayınevi.

GARKAVETS, A. (2010). Qypchaq Written Heritage III: Qypchaq Dictionary, On memorials of 16-17 centuries written by Armenian script, Almaty: Baur-Kasean. 


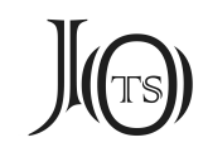

GEORG, S. (2001). “Türkisch/mongolisch tengri 'Himmel, Gott' und seine Herkunft", Studia Etymologica Cracoviensia, 6: 83-100.

GEORG, S. et al. (1999). "Telling general linguists about Altaic”, Journal of Linguistics, 35/1: 65-98.

GHARIB, B. (2004). Sogdian Dictionary (Sogdian-Persian-English), Tehran: Farhangan Publications.

GiLEs, H. A. (1912). A Chinese-English Dictionary, Second Edition, Revised \& Enlarged, Shanghai: Kelly \& Walsh.

Golden, P. B. et al. (2000). The King's Dictionary, The Rasulid Hexaglot: Fourteenth Century Vocabularies in Arabic, Persian, Turkic, Greek, Armenian and Mongol, Translated by Tibor Halasi-Kun, et al. with introductory essays By P. B. GoldEN \& T. T. ALLSEN, Leiden-Boston-Köln: Brill.

GolstUnKiY, K. F. (1893-1895). Mongol'sko-Russkiy Slovar' I-III, Sankt-Peterburg.

Gomвocz, Z. (1912). Die bulgarisch-türkischen Lehnwörter in der ungarischen Sprache, Helsinki: Société Finno-ougrienne.

Granberg, A. (2009). "Classification of the Hunno-Bulgarian Loan-Words in Slavonic", Swedish Contributions of the Fourteenth International Congress of Slavists (Ohrid, 10-16 September 2008), Ed. Per AmBrosiani, Umeå University: 19-31.

GRøNBECH, K. (1942). Komanisches Wörterbuch, Kopenhagen: Einar Munksgaard.

GÜL, B. (2016). Moğolca İbni Mühennâ Lügati, Ankara: Türk Kültürünü Araştırma Enstitüsü Yayınları.

GÜRSOY-NASKALİ, E. \& H. HALÉn (1991). Cumucica \& Nogaica, Helsinki: SoumalaisUgrilainen Seura.

GÜRSOY-NASKALİ, E. \& M. DuRANLI (1999). Altayca-Türkçe Sözlük, Ankara: Türk Dil Kurumu Yayınları.

HAENISCH, E. (1939). Wörterbuch zum Manghol un niuca tobca'an (Yüan-ch'ao Pishi), Leipzig: Harrassowitz.

HANGIN, G. (1986). A Modern Mongolian-English Dictionary, Bloomington: Indiana University.

HAuensCHILD, I. (2016). "Bemerkungen zu teleutischen Pflanzen- und Tiernamen aus einer Quelle des 18. Jahrhunderts", Turkic Languages, 20: 132-150. 


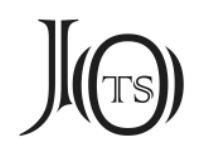

HAUER, E. (2007). Handwörterbuch der Mandschusprache, 2. durchgesehene und erweiterte Auflage, Hrsg. O. CoRff, Wiesbaden: Harrassowitz.

HeISSIG, W. (1976). Die mongolischen Handschriften-Reste aus Olon süme, Innere Mongolei (16.-17. Jhdt.), Wiesbaden: Harrassowitz.

HeLimsKi, E. (1995). “Samoyedic Loans in Turkic: Check-List of Etymologies”, Lautund Wortgeschichte der Türksprachen: Beiträge des internationalen Symposiums (Berlin, 7. bis 10. Juli 1992), Hrsg. von B. Kellner-HeinKele \& M. STACHOWsKi, Harrassowitz, Wiesbaden: 75-95.

İZBuDAK, V. C. (1936). El-İdrâk Haşiyesi, İstanbul: Devlet Basımevi.

JANHUnEN, J. (1977). Samojedischer Wortschatz: Gemeinsamojedische Etymologien, Helsinki: Suomalais-Ugrilainen Seura.

JANHUnEN, J. (1996). "Khamnigan Data on the Turkic Name of Lake Baikal”, Symbolae Turcologicae, Studies in Honour of Lars JoHANSON on his Sixtieth Birthday, 8 March 1996, Eds. Á. BERTA, et al. Uppsala: 139-141.

JANHUnen, J. (2010). “The holy Shamaness: Some Additional Notes on a Turko-Mongolic Etymology”, Pilgrimage of Life: Studies in Honour of Professor René GotHóNI, Eds. R. HÄMÄLÄINEN et al. University of Helsinki, Helsinki: 175-186.

JANHUNEN, J. A. (2012). "Khitan: Understanding the Language behind the Scripts", Scripta, 4: 107-132.

JARRING, G. (1964). An Eastern Turki-English Dialect Dictionary, Lund: CWK Gleerup.

JÄSCHKE, H. A. (1881). A Tibetan-English Dictionary, with Special Reference to the Prevailing Dialects, to which is added an English-Tibetan Vocabulary, London.

KAçALiN, M. S. (1997). “Hüseyinoğlu Hasan'ın Dört Dilli Sözlüğü: Şâmilü’l-Luğa”, Türk Dilleri Araştırmaları, 7: 55-122.

KAŁUŻYŃSKI, St. (1977). Die Sprache des mandschurischen Stammes Sibe aus der Gegend von Kuldscha, I: Muromskis Sibenische Texte, II: Wörterverzeichnis, Warszawa: Państwowe Wydawnictwo Naukowe.

KANE, D. (1989). The Sino-Jurchen Vocabulary of the Bureau of Interpreters, Indiana: Indiana University.

KANE, D. (2009). The Kitan Language and Script, Leiden-Boston: Brill. 


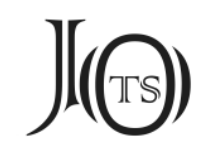

KARI-NiYAZOV, T. N. \& A. K. BoRovKov (1941). Uzbeksko-Russkiy Slovar', Taşkent: İzdatel'stvo Uzbekistanskogo Filiala Akademii Nauk SSSR.

KÁROLY, L. (2005). "Some Remarks on the Turkic word Qart", Studia Etymologica Cracoviensia, 10: 53-64.

KAYA, C. (1994). Uygurca Altun Yaruk, Giriş, Metin ve Dizin, Ankara: Türk Dil Kurumu Yayınları.

KIM, J. et al. (2008). Materials of spoken Manchu, Seoul: Seoul National University Press.

KinCSES-NAgY, É. (2018). Mongolic Copies in Chaghatay, Wiesbaden: Harrassowitz.

KIYOSE, G. N. (1977). A Study of the Jurchen Language and Script, Kyoto: Hōritsubunka-sha

Koç, K. (2003). Kazak Türkçesi-Türkiye Türkçesi Sözlüğü, Türkistan: Turan Yayınevi.

KoWALEWSKI, J. É. (1844-1849). Dictionnaire Mongol-Russe-Français I-III, Kasan: Imprimerie de l'Université.

KRUEGER, J. R. (1978-1984). Materials for an Oirat-Mongolian to English Citation Dictionary I-III, Bloomington: The Mongolia Society, Inc.

KúNOS, I. (1902). Šejx Sulejman Efendi's Čagataj-Osmanisches Wörterbuch, Budapest.

KuRPeŞKo-TANnAGaŞEVA, N. N. \& F. J. APON'KIN (1993). Şor-Kazak pazok Kazak Şor Ürgedik Söstük: Şorsko-Russkiy i Russko-Şorskiy Slovar', Kemerovo.

KurpeşKo-TANnAGaşeVA, N. N. \& Ş. H. AKAlin (1995). Şor Sözlüğü, Adana: Türkoloji Araştırmaları.

LESSING, Ferdinand D. (1995). Mongolian-English Dictionary, Bloomington: The Mongolia Society.

LEWICKI, M. (1959). La langue mongole des transcriptions chinoises du XIV siècle, [1] Le Houa-yi yi-yu de 1389 [= Travaux de la Société des sciences et des lettres de Wroclaw A 29], [2] Vocabulaire-Index, Wrocław: Nakładem Wrocławskiego towarzystwa naukowego.

Ligeti, L. \& GY. Kara (2012). "Vocabulaires Mongols des Polyglottes de Yemen", Acta Orientalia Academiae Scientiarum Hungaricae, 65/2: 137-221. 


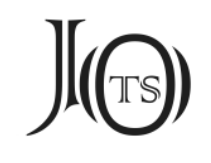

LigeTI, L. (1962). “Un vocabulaire mongol d'Istanboul”, Acta Orientalia Academiae Scientiarum Hungaricae, 14/1: 3-99.

LigeTI, L. (1965). "Le lexique mongol de Kirakos de Gandzak", Acta Orientalia Academiae Scientiarum Hungaricae, 18/3: 241-297.

LIGETI, L. (1966). “Un Vocabulaire Sino-Ouigour des Ming. Le Kao-Tch'ang-Kouan Yi-Chou Du Bureau des Traducteurs", Acta Orientalia Academiae Scientiarum Hungariae, 19/2-3: 117-199, 257-316.

LIGETI, L. (1969). "Glossaire supplémentaire au vocabulaire sino-ouigour du bureau des traducteurs", Acta Orientalia Academiae Scientiarum Hungariae, 22/1: 1-49.

LiGETI, L. (1970). “Le tabghach, un dialect de la langue sien-pi”, Mongolian Studies, Ed. L. LIGETI, Akadémiai Kiadó, Budapest: 265-308.

LIGETI, L. (1990). “Un vocabulaire sino-mongol des Yuan: Le Tche-yuan yi-yu”, Acta Orientalia Academiae Scientiarum Hungaricae, 44: 259-277.

Luvsandendev, A. \& Ts. Tsedendamba (2001-2002). Bol'şoy Akademiçeskiy Mongol'sko-Russkiy Slovar' I-IV, Moskva: Academia.

LuvSANDENDEV, A. (1957). Mongol'sko-Russkiy Slovar', Moskva.

MACKeNZIE, D. N. (1976). The Buddhist Sogdian Texts of the British Library, Leiden: E. J. Brill.

MACKenzie, D. N. (1986). A Concise Pahlavi Dictionary, London-New York: Oxford University Press.

MAISIO, A.\& S. SAARINEN (2008). Tscheremissisches Wörterbuch, Aufgezeichnet von Volmari Porkka, et al. Helsinki: Suomalais-Ugrilainen Seura.

MAUE, D. (1996). Alttürkische Handschriften, Teil 1, Dokumente in Brāhmī und tibetischer Schrift, Stuttgart: Franz Steiner Verlag.

MAUE, D. (2015). Alttürkische Handschriften, Teil 19, Dokumente in Brāhmī und tibetischer Schrift, Stuttgart: Franz Steiner Verlag.

MelioRAnSKiY, P. M. (1903). Arab Filolog o Mongolskom Yazıke, Sanktpetersburg': Trudry Vostoç.

Menges, K. H. (1953). "Titles and Organizational Terms of the Qyțań (Liao) and Qara-Qytaj (Śi-Liao)”, Rocznik Orientalistyczny, 17/2: 68-79. 


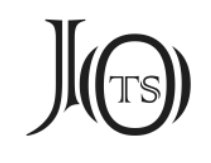

MonASTYRJEW, W. (2006). Jakutisch. Kleines erklärendes Wörterbuch des Jakutischen (Sacha-Deutsch), Wiesbaden: Harrassowitz.

MoniER-WilLIAMS, Sir M. (1899). A Sanskrit-English Dictionary, Etymologically and Philologically Arranged with Special Reference to Cognate Indo-European Languages, Oxford: Clarendon Press.

MoRAVCSIK, Gy. (1983). Byzantinoturcica II: Sprachreste der Türkvölker in den byzantinischen Quellen, 3. unveränderte Auflage, Leiden: E. J. Brill.

MoRIYASU, T. (1980). "La Nouvelle Interprétation des Mots Hor et Ho-yo-hor dans le Manuscrit Pelliot Tibétain 1283”, Acta Orientalia Academiae Scientiarum Hungaricae, 34/1-3: 171-184.

MostaerT, A. (1968). Dictionnaire Ordos, (Seconde Édition), New York-London: Johnson Reprint Corporation.

MostaerT, A. (1977). Le Matériel Mongol du Houa I I Iu 華夷譯語 de Houng-ou (1339), Édité par Igor de Rachewiltz, Bruxelles.

MuniYev, B. D. (1977). Kalmitsko-Russkiy Slovar', Moskva: İzdatel'stvo Russkiy Yazlk.

Necip, E. N. (1995). Yeni Uygur Türkçesi Sözlüğü, Çev. İ. KuRBAn, Ankara: Türk Dil Kurumu Yayınları.

NÉMETH, Gy. (1990). Kumuk ve Balkar Lehçeleri Sözlüğü, Çev. K. AYTAÇ, Ankara: Kültür Bakanlığı Yayınları.

NikolaeVA, I. A. (2006). A Historical Dictionary of Yukaghir, Berlin-New York: Mouton de Gruyter.

NoRman, J. (2013). A Comprehensive Manchu-English Dictionary, with the assistance of K. DEDE \& D. P. BRANNER, Cambridge,-Massachusetts-London: Harvard University Press.

Nugteren, H. \& M. Roos (1996). "Common Vocabulary of the Western and Eastern Yugur Languages, The Turkic and Mongolic Loanwords", Acta Orientalia Academiae Scientiarum Hungaricae, 49/1-2: 25-91.

Nugteren, H. \& M. Roos (2012). "Turkic names of fowl and waterfowl in Western Yugur and Salar", Botanica und Zoologica in der türkischen Welt, Festschrift für I. HAUENSCHILD, Hrsg. M. ERDAL, et al. Harrassowitz, Wiesbaden: 117-131. 


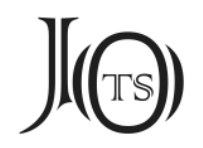

Nugteren, H. (2011). Mongolic Phonology and Qinghai-Gansu Languages, Utrecht: LOT.

ORucov, Ä. et al. (2006). Azerbaycan Dilinin İzahlı Lüğeti I-IV, Bakı: Azerbaycan Milli Elmler Akademiyası.

ŌTAKE, M. (2017). "Reconstructing the Khitan Vowel System and Vowel Spelling Rule Through the Khitan Small Script", Acta Orientalia Academiae Scientiarum Hungaricae, 70/2: 189-206.

Ölmez, M. (1991). “Ana Altayca Sözbaşı *d-”, Türk Dilleri Araştırmaları, 1:167-190.

Ölmez, M. (2007). Tuvacanın Sözvarlığı, Eski Türkçe ve Moğolca Denklikleriyle, Wiesbaden: Harrassowiz.

Ölmez, M. (2008). “Alttürkische Etymologien (2)”, Aspects of Research into Central Asian Buddhism, in Memoriam Kōgi KudARA, Ed. P. ZIEME, Brepols, Turnhout: 229-236.

ÖZERTURAL, Z. (2008). Der uigurische Manichäismus. Neubearbeitung von Texten aus Manichaica I und III von Albert v. LE CoQ, Wiesbaden: Harrassowitz.

ÖzTOPÇU, K. (1989). Munyatu'l-Ghuzāt. A 14th-Century Mamluk-Kipchak Military Treatise, Harvard: Harvard University.

PeKARSKIY, E. K. (1958-1959). Slovar' Yakutskogo Yazıka I-III, Moskova: Akademiya Nauk SSSR.

Pelliot, P. (1931). "Les Formes turques et mongoles dans la nomenclature zoologique du 'Nuzhatu-'l-kulūb"', Bulletin of the School of Oriental Studies, 6/3: 555-580.

Poppe, N. (1925). “Mongol'skiye Nazvaniya Jivotnıh v Trude Hamdallaha Kazvini”, Zapiski Kollegii Vostokovedov pri Aziatskom Muzeye Rossiyskoy Akademii Nauk, Leningrad: 195-208.

Poppe, N. (1927-1928). “Das mongolische Sprachmaterial einer Leidener Handschrift", Izvestiya Akademii Nauk SSSR 1927-1928: 1009-1040, 1251-1274, 55-80.

PopPe, N. (1938). Mongol'skiy Slovar' Mukaddimat al-Adab, Moskva-Leningrad: İzdatel'stvo Akademii Nauk SSSR.

PopPE, N. (1953). "Ein altes Kulturwort in den altaischen Sprachen”, Studia Orientalia, 19/5: 23-25.

Poppe, N. (1954). "A Fragment of the Bodhicaryāvatāra from Olon Süme”, Harvard Journal of Asiatic Studies, 17/3: 411-418. 


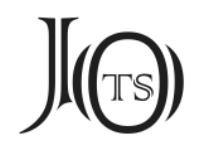

PopPE, N. (1957). The Mongolian Monuments in ḥPags-pa Script, Second edition translated and edited by J. R. KRUEGER, Wiesbaden: Harrassowitz.

PopPE, N. (1965). Introduction to Altaic Linguistics, Wiesbaden: Harrassowitz.

Poppe, N. (1967). The Twelve Deeds of Buddha, A Mongolian Version of the Lalitavistara, Mongolian Text, Notes, and English Translation, Wiesbaden: Harrassowitz.

PopPe, N. (1976). “Ancient Mongolian”, Tractata Altaica, Ed. W. HeIssig et al. Harrassowitz, Wiesbaden: $463-478$.

Poppe, N. (1991). Grammar of Written Mongolian, Wiesbaden: Harrassowitz.

PoPPE, N. N. (1931). Materialı po Solonskomu Yazıku, Leningrad: Nauka.

Poucha, P. (1955). Thesaurus linguae tocharicae dialecti A, Praha: Státní Pedagogické Nakladatelství.

Pulleyblank, E. G. (1991). Lexicon of Reconstructed Pronunciation in Early Middle Chinese, Late Middle Chinese, and Early Mandarin, Vancouver: UBC Press.

Rachewiltz, I. De \& V. Rybatzki (2010). Introduction to Altaic Philology. Turkic, Mongolian, Manchu, (With the collaboration of Hung Chin-fu), Leiden-Boston: Brill.

RACHEWILTZ, I. DE (1972). Index to the Secret History of the Mongols, Bloomington: Indiana University.

RaChewiltz, I. De (1982). “The Preclassical Mongolian Version of the Hsiao-Ching”, Zentralasiatische Studien, 16: 7-109.

RacheWILTZ, I. DE (1984). “Addenda et Corrigenda to I de Rachewiltz 'the Preclassical Mongolian Version of the Hsiao-Ching' in ZAS 16 (1982), 7-109”, Zentralasiatische Studien, 17: 218.

Rachewiltz, I. De (1986). "More About the Preclassical Mongolian Version of the Hsiao-Ching", Zentralasiatische Studien, 19: 27-37.

Rachewiltz, I. DE (1996). The Mongolian Tanjur Version of the Bodhicaryāvatāra, Edited and Transcribed, with a Word-Index and a Photo-Reproduction of the Original Text (1748), Wiesbaden: Harrassowitz.

Rachewiltz, I. De (2004). The Secret History of the Mongols, A Mongolian Epic Chronicle of the Thirteenth Century I-II, Leiden-Boston: Brill. 


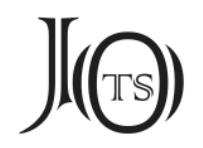

Rachewiltz, I. DE (2006). “Some Remarks on the Chih-Yüan I-Yü 至元譯語 Alias Meng-Ku I-Yü 蒙古譯語, The First Known Sino-Mongol Glossary,” Acta Orientalia Academiae Scientiarum Hungaricae, 59/1: 11-28.

Rachmati, G. R. (1932). “Zur Heilkunde der Uiguren II”, Sitzungsberichte der Preussischen Akademie der Wissenschaften, Jahrgang 1932, Philosophisch-Historische Klasse, Verlag der Akademie der Wissenschaften, Berlin: 401-488.

RAdLOFF, W. (1893-1911). Versuch eines Wörterbuches der Türk-Dialecte I-IV, Sanktpeterburg: Nauka.

Ramstedt, G. J. (1906). “Mogholica, Beiträge zur Kenntnis der Moghol-Sprache in Afghanistan”, Journal de la Société Finno-Ougrienne, 23/4: 1-60.

RAMSTEDT, G. J. (1935). Kalmückisches Wörterbuch, Helsinki: Suomalais-Ugrilainen Seura.

RÄsÄNEN, M. (1969). Versuch eines etymologischen Wörterbuchs der Türksprachen, Helsinki: Suomalais-Ugrilainen Seura.

RASSADIN, V. İ. (1971). Fonetika i Leksika Tofalarskogo Yazıka, Ulan Ude.

RASSADIN, V. İ. (2005). Slovar' Tofalarsko-Russkiy i Russko-Tofalarskiy, Sankt-Peterburg.

REBİ, D. (2004). Krımçakskiy Yazık, Krımçaksko-Russkiy Slovar', Simferopol': Dolya.

RECK, Ch. (2016). Mitteliranische Handschriften, Teil 2, Berliner Turfanfragmente buddhistischen Inhalts in soghdischer Scrift, Stuttgart: Franz Steiner Verlag.

Roвbeк, V. A. \& M. E. Roвbeк (2005). Evensko-Russkiy Slovar', Novosibirsk: Nauka.

RóNA-TAS, A. \& Á. BERTA (2011). West Old Turkic. Turkic Loanwords in Hungarian III, Wiesbaden: Harrassowitz.

RónA-TAS, A. (1988). “Turkic Influence on the Uralic Languages”, The Uralic Languages, Description, History and Foreign Influences, Ed. D. SINOR, E. J. Brill, Leiden-New York-København-Köln: 742-780.

RónA-TAS, A. (2016). "Khitan Studies I. The Graphs of the Khitan Small Script 1. General Remarks, Dotted Graphs, Numerals", Acta Orientalia Academiae Scientiarum Hungaricae, 69/2: 117-138. 


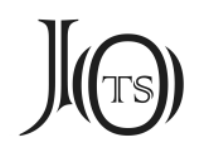

RónA-TAS, A. (2017). “Khitan Studies I. The Graphs of the Khitan Small Script 2. The Vowels", Acta Orientalia Academiae Scientiarum Hungaricae, 70/2: 135-188.

RÓNA-TAS, A. (2019). “Turkic elements in Khitan”, unter dem Bodhi-Baum: Festschrift für Klaus RöHRBORN anlässlich des 80. Geburtstags überreicht von Kollegen, Freunden und Schülern, Hrgs. von Z. ÖZERTURAL \& G. ŞiLFELER, V\&R unipress, Göttingen: 293301.

Roos, M. E. (2000). The Western Yugur (Yellow Uygur) Language, Grammar, Texts, Dictionary, Rijksuniversiteit Leiden, Leiden. [Yayımlanmamış Doktora Tezi]

RozYCKI, W. (1994). Mongol elements in Manchu, Bloomington, Indiana: Indiana University.

RÖHRBORN, K. (1977-1998). Uigurisches Wörterbuch, Sprachmaterial der vorislamischen türkischen Texte aus Zentralasien, Wiesbaden: Franz Steiner Verlag.

RÖHRBORN, K. (1991). Die alttürkische Xuanzang-Biographi VII, nach der Handschrift von Leningrad, Paris und Peking sowie nach dem Transkript von Annemarie v. GABAIN hrsg. übersetzt und kommentiert. Wiesbaden: Harrassowitz Verlag.

RÖHRBORN, K. (2010). Uigurisches Wörterbuch, Sprachmaterial der vorislamischen türkischen Texte aus Zentralasien, Neubearbeitung, I. Verben. Band 1: ab- - äzüglä-, Stuttgart: Franz Steiner Verlag.

RYBATZKI, V. (2010). “Türkische Lehnwörter im Burushaski”, Studia Orientalia, 108: 149-179.

Ryumina-SirkaşEVA, L. T \& N. A. KuçigaşEVA (1995). Teleut-Orus Sözlik, TeleutskoRusskiy Slovar', Kemerova.

SAĞoL, G. (1995). Harezm Türkçesi Satır Arası Kur'an Tercümesi: Giriş, Metin, Sözlük ve Tıpkıbasım, (II. Kısım: Sözlük), Massachusetts: Harvard University.

SAITô, Y. (2006). The Mongolian Words in Kitâb Majmû‘ Turjumân Turkî wa-'ajamî wa Muğalî: Text and Index, Kyôto: Shoukadoh.

SAITÔ, Y. (2008). The Mongolian Words in the Muqaddimat al-Adab: Romanized Text and Word Index (As of January 2008), Tôkyô: The Japan Society for the Promotion of Science.

SAITÔ, Y. (2013). "The Mongolian Words in the Quadrilingual Vocabulary Preserved in the Topkapı Palace Museum Library", Current Trends in Altaic Linguistics, A 


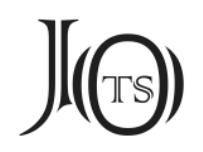

Festschrift for Professor Emeritus Seong BAEG-IN on His 80th Birthday, Eds. K. Juwon \& K. DonGHO, Altaic Society of Korea, Seoul: 305-338.

SchmitT, R. (2014). Wörterbuch der altpersischen Königsinschriften, Wiesbaden: Reichert Verlag.

SchöNIG, C. (2003). “Turko-Mongolic Relations”, The Mongolic Languages, Ed. J. JANHUNEN, Routledge, London-New York: 403-419.

SCHUESSLER, A. (2007). ABC Etymological Dictionary of Old Chinese, Honolulu: University of Hawai'i Press.

SCHUessler, A. (2009). Minimal Old Chinese and Later Han Chinese, A Companion to Grammata Serica Recensa, Honolulu: University of Hawai'i Press.

SchWARZ, H. G. (1992). An Uyghur-English Dictionary, Washington: Western Washington University.

SEÇENÇOGT (1999). Kāngjiāyǔ yánjiū. Shānghăi.

SEVortyan, E. V. et al. (1974-2003). Etimologiçeskiy Slovar' Tyurkskih Yazıkov IVII, Moskva.

SHAW, R. B. (1878). A Sketch of the Turki Language as Spoken in Eastern Turkestan (Kàshghar and Yarkand), Part 1-2, Calcutta: Baptist Mission Press.

SHImuneK, A. (2014). "A New Decipherment and Linguistic Reconstruction of the Kitan-Chinese Bilingual Inscription of 1134 A.D.", Acta Orientalia Academiae Scientiarum Hungaricae, 67/1: 97-118.

SHIMUNEK, A. (2017a). Languages of Ancient Southern Mongolia and North China, Wiesbaden: Harrassowitz.

SHIMUNEK, A. (2017b). “Toward a Decipherment and Linguistic Reconstruction of the 1101 A.D. Kitan Eulogy For Empress Xuanyi, With Notes On Mongolic Cognates: Lines 1-6", Acta Orientalia Academiae Scientiarum Hungaricae, 70/2: 253-272.

SHIMUNEK, A. E. (2007). Towards a Reconstruction of the Kitan Language, with Notes on Northern Late Middle Chinese Phonology, Indiana University, ABD. [Yayımlanmamış Yüksek Lisans Tezi]

SHNitnikiv, B. N. (1966). Kazakh-English Dictionary, The Hague: Mouton \& Co.

ShōGAITo, M. (1991). "On Uighur elements in Buddhist Mongolian Texts", Memoirs of the Research Department of the Toyo Bunko, 49: 27-49. 


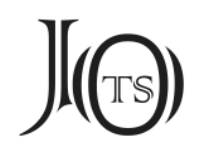

ShōGaito, M. (2003). "Uighur Influence on Indian words in Mongolian Buddhist Texts”, Indien und Zentralasien, Sprach- und Kulturkontakt, Vorträge des Göttinger Symposions vom 7. bis 10. Mai 2001, Hrsg. S. BRETFELD \& J. WilkENS, Harrassowitz, Wiesbaden: $119-143$.

Sims-Williams, N. \& D. Durkin-Meisterernst (2012). Dictionary of Manichaean Sogdian and Bactrian, (Dictionary of Manichaean Texts, Volume III, Texts from Central Asia and China, Part 2), Turnhout: Brepols.

SKVORTSOV, M. İ. (1982). Çuvaşsko-Russkiy Slovar', Moskva.

STACHOWSKI, M. (1993). Dolganischer Wortschatz, Kraków: Uniwersytet Jagielloński.

STACHOWSKI, M. (1996). "Über einige altaische Lehnwörter in den Jenissej-Sprachen", Studia Etymologica Cracoviensia, 1: 91-115.

Stachowsкi, M. (1998). Dolganischer Wortschatz, Supplementband, Kraków: Księgarnia Akademicka.

Starostin, S. A. \& M. Ruhlen (1994). "Proto-Yeniseian Reconstructions, with ExtraYeniseian Comparisons", On the Origin of Languages: Studies in Linguistic Taxonomy, Stanford University Press, Stanford: 70-92.

STARY, G. (1990). Taschenwörterbuch Sibemandschurisch-Deutsch, Wiesbaden: Harrassowitz.

STARY, G. (2017). "Neue Beiträge zum Sibe-Wortschatz", Essays in the History of Languages and Linguistics, Dedicated to Marek STACHOWSKI on the occasion of his $60^{\text {th }}$ birthday, Ed. M. NÉMETH, et al. Księgarnia Akademicka, Kraków: 703-707.

Steingass, F. (1963). A Comprehensive Persian-English Dictionary, including the Arabic words and phrases to be met with in Persian literature, Fifth impression, London: Routledge \& Kegan Paul Limited.

Street, J. (1974). On the Lexicon of Proto-Altaic: A Partial Index to Reconstructions, Madison-Wisconsin.

Subrakova, O. V. (2006). Hakassko-Russkiy Slovar', Hakas-Orıs Söstik, Novosibirsk: Nauka.

SūN ZHú (Ed.) (1990). Měnggǔ Yǔzú Yǔyán Cídiǎn, Běijīng. 


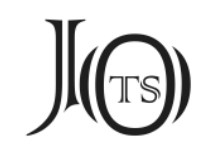

ŞiRin, H. (2008). “Sine Usu Yazıtı'nda Kayıtlı ‘t(a)t(a)r(1)g : (a)y(1)td(1)m’ Cümlesi Üzerine”, International Journal of Central Asian Studies, 12: 183-196.

ŞNEYDER, Ye. R. (1936). Kratkiy Udeysko-Russkiy Slovar', C Prilojeniyem Grammatiçeskogo Oçerka, Moskva-Leningrad: Gosudartvennoye Uçebno-Pedagogiçeskoye İzdatel'stvo.

TALPE, L. (2010). "Some Qidan Words in Chinese Poems", Central Asiatic Journal, 54/1: 79-91.

TAVKul, U. (2000). Karaçay-Malkar Türkçesi Sözlüğü, Ankara: Türk Dil Kurumu Yayınları.

TeKin, Ş. (1980). Maitrisimit nom bitig, die uigurische Übersetzung eines Werkes der buddhistischen Vaibhāṣika-Schule, 2. Teil: Analytischer und rückläufiger Index, Berlin: Akademie-Verlag.

TEKin, Ş. (1993). Kuanşi im Pusar (Ses İşiten İlâh), Vap hua ki atlıg nom çeçeki sudur, (saddharmapunḍarika-sūtra), Ankara: Türk Dil Kurumu Yayınları.

TEKin, T. (1993a). Hunların Dili, Ankara: Doruk Yayınları.

TeKin, T. (1993b). Irk Bitig, The Book of Omens, Wiesbaden: Harrassowitz.

Tekin, T. et al. (1995). Türkmence-Türkçe Sözlük, Ankara: Simurg.

TENişEv, E. R. (1976). Stroy Salarskogo Yazıka, Moskva: Nauka.

TENişEv, E. R. (2001). Sravnitel'no-İstoriçeskaya Grammatika Tyurkskih Yazıkov, Leksika, Moskva: Nauka.

TEZCAN, S. \& P. ZIEME (1994). “Alttürkische Reimsprüche, ein neuer Text”, Journal of Turkology, 2/2: 259-271.

TezCAN, S. (1981). “Kutadgu Bilig Dizini Üzerine”, Türk Tarih Kurumu Belleten, 178: $23-78$.

THomas, W. (1964). Tocharisches Elementarbuch, Band II, Texte und Glossar, Unter Mitwirkung von Wolfgang Krause, Heidelberg: Carl Winter Universitätsverlag.

ToDAyEVA, B. H. (1961). Dunsyanskiy Yazyk, Moskva: İzdatel'stvo Vostoçnoy Literatur1.

TodayeVA, B. H. (1964). Baoan'skiy Yazık, Moskva: Nauka.

TODAYEVA, B. H. (1973). Mongorskiy Yazık, Moskva: Nauka. 


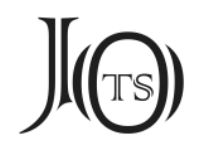

TodAYEva, B. H. (1986). Dagurskiy Yazık, Moskva: Nauka.

Todayeva, B. H. (2001). Slovar' Yazıka Oyratov Sin'tszyana, Elista: Kalmitskoye Knijnoye İzdatel'stvo.

TOPARLI, R. \& M. ARGUNŞAH (2008). Mu'înü'l-Mürîd (İnceleme-Metin-Çeviri-DizinTıpkıbasım), Ankara: Türk Dil Kurumu Yayınları.

ToparLI, R. (1992). İrşâdü'l-Mülūk ve’s-Selâtîn, Ankara: Türk Dil Kurumu Yayınları.

TOPARLI, R. et al. (1999). El-Kavânînü'l-Külliyye Li Zabti'l-Lügati't-Türkiyye, Ankara: Türk Dil Kurumu Yayınları.

Toparli, R. et al. (2000). Kitâb-1 Mecmû-1 Tercümân-1 Türkî ve Acemî ve Mugalî, Ankara: Türk Dil Kurumu Yayınları.

TseVel, Ya. (1966). Mongol Helniy Tovç Taylbar Tol', Ulaanbaatar.

TsinTsius, V. İ. (1975-1977). Sravnitelnıy Slovar' Tunguso-Man'jurskih Yazıkov, Materialı k Etimologiçeskomu Slovaryu, I-II, Leningrad: Nauk.

TumAşEVA, D. (1992). Slovar’ Dialektov Sibirskih Tatar, Kazan: Kazan Universitet1 Neşriyet1.

TumurTogoo, D. (2006). Mongolian Monuments in Uighur-Mongolian Script (XIIIXVI Centuries), Introduction, Transcription and Bibliography, with the collaboration of G. CECEGDARI, Taipei, Taiwan: Institute of Linguistics, Academia Sinica.

Tumurtogoo, D. (2010). Mongolian Monuments in 'Phags-Pa Script, Introduction, Transliteration, Transcription and Bibliography, with the collaboration of G. CECEGDARI, Taipei, Taiwan: Institute of Linguistics, Academia Sinica.

Türkiye'de Halk Ağzından Derleme Sözlüğü I-XII (1993). 2. Baskı, Ankara: Türk Dil Kurumu Yayınları.

UÇAR, E. (2014). “Contributions to Uighur Lexicography II: Remarks on Čog”, Acta Orientalia Academiae Scientiarum Hungaricae, 67/2: 151-162.

URAKSIN, Z. G. (1996). Başkirsko-Russkiy Slovar', Moskova: Digora.

ÜNAL, O. (2013). “Ant Kelimesinin Kökeni Üzerine”, Yemin Kitab1, Ed. E. GÜRsoYNASKALI, Kitabevi, İstanbul: 225-233.

ÜNAL, O. (2015). “İhe Ashete Yazıtı: Yeni Bir Okuma ve Anlamlandırma Denemesi”, Bilig, 73: 271-294. 


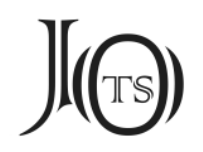

ÜNAL, O. (2016). Klasik Moğolca Söz Varlığında Türkçe Kökenli Kelimeler ve Türkçe-Moğolca Ses Denklikleri, Marmara Üniversitesi, İstanbul. [Yayımlanmamış Doktora Tezi]

ÜNLÜ, S. (2012). Karahanlı Türkçesi Sözlüğü, Konya: Eğitim Yayınevi.

VASILYEViç, G. M. (1958). Evenkiysko-Russkiy Slovar', Moskva: Gosudarstvennoye İzdatel'stvo İnostrannıh i Natsional'nıh Slovarey.

VASMER, M. (1986-1987). Russisches Etymologisches Wörterbuch/Etimologiçeskiy Slovar' Russkogo Yazıka I-IV, Moskva: Progress.

VentuRI, F. (2008). “An Old Tibetan Document On The Uighurs: A New Translation and Interpretation", Journal of Asian History, 42/1: 1-35.

VerbítskiY, P. V. (1884). Slovar’ Altayskago i Aladagskago Nareçiy Tyurkskago Yazıka, Kazan'.

VladimirTsov, B. Ya. (1917). “Anonimniy Gruzinskiy İstorik XIV Věka o Mongol'skom Yazıke”, Izvěstiya Rossiyskoy Akademii Nauk, 11/17: 1487-1501.

Vovin, A. (2003). "Once Again on Khitan Words in Chinese-Khitan Mixed Verses", Acta Orientalia Academiae Scientiarum Hungaricae, 56/2-4: 237-244.

Vovin, A. (2007). "Once Again on the Tabgač Language”, Mongolian Studies, 29: 191-206.

Vovin, A. (2013). “Old Turkic Loanwords in the Khitan Language”, Yalım Kaya Bitigi, Osman Fikri SeRTKAYA Armağanı, Ed. H. ŞíRin UsER \& B. GÜL, Türk Kültürünü Araştırma Enstitüsü Yayınları, Ankara: 621-625.

WeHR, Hans (1985). Arabisches Wörterbuch für die Schriftsprache der Gegenwart, Arabisch-Deutsch, 5. Auflage, Wiesbaden: Harrassowitz.

WEIERS, M. (1972). "Ein arabisch-mongolischer Wörterspiegel aus der Biblioteca Corsini in Rom", Zentralasiatische Studien, 6: 7-61.

WERNER, H. (2002). Vergleichendes Wörterbuch der Jenissej-Sprachen I-III, Wiesbaden: Harrassowitz.

WERNER, H. (2010). “Zum historisch-kulturellen Hintergrund der jenissejisch-türkischen Wortparallelen", Studies on the Turkic World, A Festschrift for Professor St. Stachowski on the Occasion of His 80th Birthday, Ed. E. MAŃCZAK-WOHLFELD \& B. PODOLAK, Jagiellonian University Press, Kraków: 169-189. 


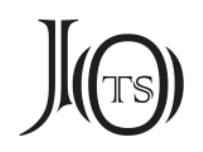

WichmanN, Y. (1987). Wotjakischer Wortschatz, Bearbeitet von T. E. UoTiLA \& M. KORHONEN, Hrsg. M. KORHONEN, Helsinki: Suomalais-Ugrilainen Seura.

WiLKENS, J. (2016). Buddhistische Erzählungen aus dem alten Zentralasien: Edition der altuigurischen Daśakarmapathāvadānamālā I-III, Turnhout: Brepols.

WiNDEKENS, A. J. van (1941). Lexique Étymologique des Dialectes Tokhariens, Louvain: Bureaux du Muséon.

WitTfogel, K. A. \& FÊNG CHIA-SHÊNG (1949). History of Chinese society, Liao, 9071125, With the assistance of J. De FRANCIS, et al. Philadelphia: The American Philosophical Society.

WU, Y. \& A. RónA-Tas (2019). "Khitan Studies I. The Glyphs of the Khitan Small Script 3. The Consonants, 3.1 Labial stops", Acta Orientalia Academiae Scientiarum Hungariae, 72/1: 47-79.

WU, Y. \& J. JANHUnEN (2010). New Materials on the Khitan Small Script, A Critical Edition of Xiao Dilu and Yelü Xiangwen, Folkestone: Global Oriental.

XIII. Yüzyıldan Beri Türkiye Türkçesiyle Yazılmış Kitaplardan Toplanan Tanıklarıyla Tarama Sözlüğü I-VIII (1996). 2. Baskı, Ankara: Türk Dil Kurumu Yayınları.

YILDIRIM, F. et al. (2013). Yenisey-Kırgızistan Yazıtları ve Irk Bitig, Ankara: BilgeSu.

YudAHIN, K. K. (1985). Kirgizsko-Russkiy Slovar’ I-II, Frunze: Glavnaya Redaktsiya Kirgizskoy Sovetskoy Entsiklopedii.

YunUSoĞLU, M. K. (2012). Uygurca-Çince İdikut Sözlüğü, İstanbul: Türk Dil Kurumu Yayınları.

YÜCE, N. (1993). Mukaddimetü'l-Edeb, Hvāarizm Türkçesi ile Tercümeli Şuşter Nüshası, Giriş-Dil Özellikleri-Metin-İndeks, Ankara: Türk Dil Kurumu Yayınları.

ZAJĄCZKOWSKI, A. (1954). Vocabulaire Arabe-Kiptchak de l'époque de l'État Mamelouk, Bulgiat al-Muštaq Fī Luġat at-Turk wa-l-Qifžāq, II-ème partie, Le verbe, Warszawa: Państwowe Wydawnictwo Naukowe.

ZAJĄCZKOWSKI, A. (1958). Vocabulaire Arabe-Kiptchak de l'époque de l'État Mamelouk, Bulgat al-Muštāq Fī Lugat at-Turk wa-l-Qifžāq, I-ère partie, Le nom, Warszawa: Państwowe Wydawnictwo Naukowe.

ZAJĄCZKOWSKI, A. (1961). Najstarsza wersja turecka Husräv u Šīrīn Quṭba III, Warszawa: Polska Akademia Nauk, Komitet Orientalistyczny. 


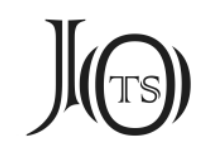

ZajączKowsKi, A. (1965a). "Chapitres choisis du Vocabulaire arabe-kiptchak «adDurra al-mudī’a fï-l-lugat at-turkìya» (I)”, Rocznik Orientalistyczny, 29/1: 39-98.

ZajączKowsKi, A. (1965b). "Chapitres choisis du Vocabulaire arabe-kiptchak «adDurra al-mudị’a fî-l-lugiat at-turkīya» (II)”, Rocznik Orientalistyczny, 29/2: 67-116.

ZAJĄCZKowsKi, A. (1968). "Materiał kolokwialny arabsko-kipczacki w Słowniku «adDurra al-mudị’a fî-l-lugat at-turkìya”, Rocznik Orientalistyczny, 31/1: 71-115.

ZajączKowski, A. (1969). "Chapitres choisis du Vocabulaire arabe-kiptchak «adDurra $^{t}$ al-mudị’a fi-l-lugat at-turkīya» (III)”, Rocznik Orientalistyczny, 32/2: 19-61.

ZIEME, P. (1997). “'Silk' and 'Wad' in Old Turkish Terminology”, Türk Dilleri Araştırmaları, 7: 149-155.

ZIEME, P. (1998). “Der Wettkampf Śāriputras mit den Häretikern nach einer alttürkischen Version”, Bahşı Ögdisi, Klaus Röhrborn Armağanı, Eds. J. P. LAUT \& M. ÖLmEZ, Freiburg-İstanbul: 429-447.

ZIEME, P. (2007). "Notes on Uighur Medicine, Especially on the Uighur Siddhasāra Tradition”, Asian Medicine, 3: 308-322.

ZIEME, P. (2008). "A Note on the Word 'Shaman' in Old Turkic", Shaman, 16/1-2: $85-90$.

ZIEME, P. (2011). "Klaus Röhrborn: Uigurisches Wörterbuch. Sprachmaterial der vorislamischen türkischen Texte aus Zentralasien - Neubearbeitung - I. Verben, Band 1: ab- - äzüglä-. Stuttgart, Franz Steiner Verlag, 2010.”, Acta Orientalia Academiae Scientiarum Hungariae, 64/1: 107-111. (Rezension) 